\title{
1 Constraining the Solomon Sea as a Source of Al and Mn to the Equatorial 2 Undercurrent
}

3 Authors: Susanna Michael ${ }^{\mathrm{a}, \mathrm{b},{ }^{*}, J}$ Joseph Resing ${ }^{\mathrm{b}, \mathrm{c}}$, Francois Lacan ${ }^{\mathrm{d}}$, Nathaniel Buck ${ }^{\mathrm{b}, \mathrm{c}}$, Catherine

$4 \quad$ Pradoux $^{\mathrm{d}}$, Catherine Jeandel ${ }^{\mathrm{d}}$

5 Affiliations:

6 a School of Oceanography, University of Washington, Seattle, WA 98195 USA

7 (smicha@uw.edu)

8 b Joint Institute for the Study of the Atmosphere and Ocean, University of Washington, 3737

9 Brooklyn Ave NE, Seattle, WA 98105 USA

$10{ }^{\mathrm{c}}$ NOAA Pacific Marine Environmental Laboratory, 7600 Sand Point Way NE, Seattle, WA

1198115 USA

12 (joseph.resing@noaa.gov; nathan.buck@noaa.gov)

13 d LEGOS, Université de Toulouse, CNRS, CNES, IRD, UPS (Toulouse), France

14 (francois.lacan@legos.obs-mip.fr; catherine.pradoux@legos.obs-mip.fr;

15 Catherine.Jeandel@legos.obs-mip.fr)

16 Corresponding author: smicha@uw.edu

17 


\section{Highlights}

$19 \mathrm{Al}$ and $\mathrm{Mn}$ are not significantly enriched during transit through the Solomon Sea.

20 Fluxes of $\mathrm{Al}$ and $\mathrm{Mn}$ into and out of the Solomon Sea are almost equal.

$21 \mathrm{Al}$ and $\mathrm{Mn}$ are elevated near continental shelves and margins in the Solomon Sea.

22 Local enrichments must be balanced by boundary exchange and scavenging processes.

23 Water exiting the Solomon Sea accounts for ca. half the flux of Al and Mn in the EUC. 


\section{Abstract}

25 Total dissolvable and dissolved aluminum (TDAl, DAl) and manganese (TDMn, DMn)

26 concentrations were measured at 12 stations in and around the Solomon Sea in 2012 as part of

27 the GEOTRACES GP-12 cruise. These data were used to determine the potential for the

28 Solomon Sea to act as a source of Al and Mn to the Equatorial Undercurrent (EUC). From a net

29 budget perspective, waters entering the Solomon Sea at the time of the cruise were already

30 enriched in $\mathrm{Al}$ and $\mathrm{Mn}$, and as that water transited through the Solomon Sea, further net

31 enrichments were small compared to overall concentrations of these metals. Despite this overall

32 balance, on a local scale, we observed enrichment of Al and Mn at stations located near

33 coastlines, most likely caused by sediment scouring by strong currents. Calculated fluxes of DA1,

34 and TDAl out of the Solomon Sea relative to the EUC are large enough to account for about

35 three quarters of their respective budgets within the EUC, while the DMn and TDMn fluxes

36 exiting the Solomon Sea can only account for about half of their respective budgets in the EUC.

37 These fluxes are subject to high temporal variability and to uncertainty of the relative

38 contributions of Northern and Southern Hemisphere water mass to the EUC.

\section{Keywords:}

40 Aluminum, Manganese, Solomon Sea, Equatorial Undercurrent, GEOTRACES 


\section{Introduction}

44 The Equatorial Undercurrent (EUC) flows at $200 \mathrm{~m}$ depth along the equator at a rate of 20-30

$45 \mathrm{~Sv}$, transporting water, nutrients, and trace elements (e.g., aluminum (Al), and manganese (Mn), 46 and iron $(\mathrm{Fe})$ ) from the Western Pacific to the Eastern Pacific in less than a year (Tsuchiya et al., 47 1989). There, it shoals in the photic zone of the High Nutrient, Low Chlorophyll (HNLC) region 48 of the eastern equatorial Pacific — where $\sim 20 \%$ of the world's new primary productivity takes

49 place (Coale et al., 1996). Understanding sources of trace elements to the EUC is thus important 50 to better understanding the factors that contribute to primary productivity in the eastern 51 equatorial Pacific and its contribution to the global carbon cycle.

52 Concentrations of $\mathrm{Al}, \mathrm{Mn}$, (and Fe) are elevated in the EUC, relative to open ocean values

53 (Coale et al., 1996; Gordon et al., 1997; Kaupp et al., 2011; Slemons et al., 2010, 2012) with

54 concentrations increasing westward. In the western equatorial Pacific, the major water sources to 55 the EUC are two low-latitude western boundary currents, the New Guinea Coastal Undercurrent 56 (NGCU) coming from the south and the Mindanao Current from the north, with the NGCU being 57 the more important of the two (e.g., Tsuchiya et al., 1989; Grenier et al., 2011, 2013). The 58 NGCU originates in the Solomon Sea (Fig. 1) where it comes in contact with the coastlines of 59 volcanic islands with abundant natural and anthropogenic runoff. As a result, the Solomon Sea is 60 considered to be an important source of trace metals, especially Al and Fe, to the NGCU and

61 thus the EUC. This conclusion is supported by both modeling studies and geochemical

62 measurements within the current (Lacan and Jeandel, 2001, 2005; Mackey et al., 2002a,b;

63 Slemons et al., 2009; Kaupp et al., 2011; Qin et al., 2015; Pham et al., 2019). Here we report on

64 dissolved and total dissolvable Al (DAl; TDAl) and Mn (DMn; TDMn) collected from seven 65 stations within the Solomon Sea and five stations just outside of it during the 2012 PANDORA 66 cruise (GEOTRACES GP-12). While several trace metal profiles have been collected within the

67 Solomon Sea and in the neighboring Bismarck and Coral Seas (Mackey et al., 2002a,b; Obata et 68 al., 2008), those studies were not part of a broader interdisciplinary study. The PANDORA 4 
69 cruise discussed here included a major physical oceanographic component that examined the 70 major currents flowing through the Solomon Sea (Ganachaud et al., 2017). The combination of

71 these chemical and physical oceanographic data enables examination of the trace metal budget of

72 the Solomon Sea, and in turn, its importance to the trace metal budget of the EUC. The data

73 presented here suggest that the waters entering the Solomon Sea were enriched in trace metals

74 prior to entering the basin and that their transit through the basin resulted in only a minor net 75 increase of $\mathrm{Mn}$ and $\mathrm{Al}$ to these waters.

\subsection{Geographic Setting: The Solomon Sea}

77 The Solomon Sea is a semi-enclosed basin bounded by the islands of Papua New Guinea (PNG)

78 to the west, New Ireland and New Britain to the north, and the Solomon Islands to the east, and

79 is open to the southeast (Fig. 1). An important oceanographic characteristic of this region is the

80 flow of the New Guinea Coastal Current/ Undercurrent system (NGCC/NGCU) through the

81 basin. This large current system transports water into the Solomon Sea at depths of $0-1400 \mathrm{~m}$

82 with the strongest transport $(40-80 \mathrm{~cm} / \mathrm{s})$ being within the thermocline waters that feed the EUC,

83 at $200 \mathrm{~m}$ (Lindstrom et al., 1987; Tsuchiya et al., 1989; Cravatte et al., 2011; Germineaud et

84 al., 2016; Alberty et al., 2019). The large transport and associated current speeds result in

85 relatively short residence time for waters in the Solomon Sea (e.g., $\sim 4$ months for thermocline

86 waters). The waters that make up the NGCU originate as the Southern Equatorial Current (SEC),

87 which flows west between $\sim 5^{\circ} \mathrm{N}$ and $20^{\circ} \mathrm{S}$. As the SEC encounters islands in the Coral Sea, it

88 branches into various currents, including the North Vanuatu Jet (NVJ) and the New Caledonia

89 Jet (NCJ, Kessler and Cravatte, 2013; Germineaud et al., 2016). The NCJ further bifurcates

90 around $18^{\circ} \mathrm{S}$ into the North Queensland Current (NQC), which flows north through the northern

91 Coral Sea and the Gulf of Papua, and around the southern coast of PNG before joining the NVJ

92 to form the NGCU (Fig. 1; Sokolov and Rintoul, 2000). In the surface ocean $(0-\sim 150 \mathrm{~m})$, in

93 addition to the NGCU and NVJ, waters from the SEC flow into the Solomon Sea through gaps

94 between the Solomon Islands (Hristova and Kessler, 2012) and through the Solomon Strait 
95 (Germineaud et al., 2016; Alberty et al., 2019). Most of the surface water exits through the

96 Vitiaz Strait, with some flowing through the St. George's Channel and/or the Solomon Strait

97 (e.g., Alberty et al., 2019). The direction of flow through the Solomon Strait varies seasonally,

98 and on a net annual basis flows into the Solomon Sea (Alberty et al., 2019). The thermocline

99 waters of the NGCU flow at a depth of $200 \mathrm{~m}$ along the eastern PNG coast and bifurcate south

100 of New Britain where northwestward flow exits through the Vitiaz Strait (Tsuchiya et al., 1989);

101 the remainder flows eastward as the New Britain Coastal Undercurrent (NBCU) (Melet et al.,

102 2010). The NBCU bifurcates around New Ireland, with the western limb flowing out of Saint

103 George's Channel as the Saint George's Undercurrent (SGU), while the eastern limb exits out

104 the Solomon Strait as the New Ireland Coastal Undercurrent (NICU; Butt and Lindstrom, 1994).

105 The NICU then combines with the EUC (Fig. 1; Germineaud et al., 2016). The deeper sub-

106 thermocline $\left(450-1400 \mathrm{~m}, 26.9-\sim 27.5 \sigma_{\theta}\right)$ circulation in the Solomon Sea is also dominated by the

107 NGCU, however at much reduced levels of transport. Here, as the NGCU approaches the

108 Woodlark Archipelago it is pushed eastward over this depth range; below $1000 \mathrm{~m}$ it passes

109 through, over and around the submarine extension of the Woodlark Archipelago. This deep water

110 exits through the Vitiaz Strait ( 65\%) and Solomon Strait ( 30\%; Alberty et al., 2019), but with

111 some seasonal variability.

112 The western equatorial Pacific is temporally variable on both seasonal (monsoonal) and 113 interannual ( ENSO) scales. This variability leads to fluctuations in transport through the

114 Solomon Sea and the EUC, and is accompanied by changes in river input and surface circulation

115 (Cresswell, 2000; Melet et al., 2013; Delcroix et al., 2014). Seasonal differences in transport and

116 circulation in the Solomon Sea have been studied during the PANDORA (austral winter 2012)

117 and MOORSPICE (austral summer 2014) cruises. Both cruises occurred during a neutral El Niño

118 phase, and demonstrated that the overall flow into and out of the Solomon Sea was enhanced

119 during austral winter (PANDORA) (Germineaud et al., 2016). While overall transport through

120 the Solomon Sea varies seasonally, modeling studies have shown that transport through the

121 Vitiaz Strait exhibits less temporal variability, presumably because transport through the strait is 
122 mainly controlled by bathymetry (narrow, $1200 \mathrm{~m}$ deep channel) which restricts water flow,

123 while seasonality changes are a result of changes in flow of the NVJ and NQC upstream (Melet

124 et al., 2010). These changes are observed further downstream, in strong temporal variability in

125 the current flow through Saint George's Channel and the Solomon Strait. Historical observations,

126 however, do show variation in the transport through the Vitiaz Strait, with intensification during

127 positive El Nino phase (Lindstrom et al., 1987; Butt and Lindstrom, 1994; Murray et al., 1995).

128 Modeling studies have also observed intensification of the NGCU during El Nino events, which

129 creates eddies, causing increased contact with the PNG shelf (Ryan et al., 2006). While models

130 predict intensification of the NGCU, during the El Nino event of 1991/1992, Murray et al. (1995)

131 observed a weakening of the EUC, where the maximum velocity during neutral El Nino was

132 observed at $90 \mathrm{~cm} / \mathrm{s}$, and then dropped to $20 \mathrm{~cm} / \mathrm{s}$ during peak El Nino. The EUC also varies

133 seasonally, and is stronger in austral winter and weaker in austral summer (Melet et al., 2010).

135 The waters that flow through the Solomon Sea are subject to many potential chemical inputs

136 from the margins, rivers, runoff, mine tailings, and volcanic and hydrothermal activities; it is

137 thus thought that the NGCU should undergo significant chemical enrichments as it passes

138 through the Solomon Sea (Lacan and Jeandel, 2001, 2005). Islands in this region are young and

139 easily eroded, leading to large lithogenic inputs via rivers (e.g., Milliman et al., 1999; Sholkovitz

140 et al., 1999). Two very large rivers empty into the ocean along the pathway of the major currents

141 flowing through the region: the Sepik River empties into the Bismarck Sea, thus contributing to

142 the NGCU as it exits the Solomon Sea, and the Fly River empties into the northern Coral Sea

143 where it alters the chemistry of the North Queensland Current (Fig. 1). The Sepik River and Fly

144 River estuaries are two very different systems: The Sepik river system is located over a steep and

145 narrow shelf, such that river sediments are discharged directly into the ocean (Milliman et al.,

146 1999, Sholkovitz et al., 1999; Kineke et al., 2000). Sedimentation occurs on the shelf through the

147 settling of sinking particles from the surface plume, as well as via hyperpycnal flows, which 
transport sediment to intermediate depths along isopycnals (Kineke et al., 2000). The Fly River

149 is a shallow estuary where sediment deposition and resuspension impacts the chemical makeup

150 of the surface water. The Fly River has a high sediment load $\left(85 \times 10^{9} \mathrm{~kg} / \mathrm{year}\right)$ relative to its

151 discharge (220 km³ /year) (Salomons and Eagle, 1990). These sediments are dominated by

152 resuspension due to intense tidal activity, and bioturbated muds in this region have been shown

153 to have elevated Al, Mn, and Fe fluxes (Harris et al., 1993; Alongi et al., 1996).

154 The Fly river, in addition to having a large sediment load due to its strong relief, high rainfall,

155 and easily erodible rock, (e.g., Harris et al., 1993) is impacted at its head waters by increased

156 contamination from the Ok Tedi mine. This ore deposit, and others in the area, are a result of

157 elevated tectonic and volcanic activity in the region. Over the life of the Ok Tedi mine it is

158 estimated that it was responsible for the input of 66 million tons per year of mine tailings,

159 including 24 million tons per year of mill fines (e.g., Hettler et al., 1997). Tailings from mines

160 throughout the region are delivered to the ocean through run off, smaller rivers, and erosion, and

161 a portion of this waste reaches the coastal ocean, where it might be entrained into the NQC.

162 A seafloor spreading-center in the Woodlark Basin in the eastern Solomon Sea hosts

163 hydrothermal vent systems at $>2500 \mathrm{~m}$ (e.g., Laurila et al., 2012) and undersea-volcanos in the

164 region are hydrothermally (McConachy et al., 2002; Laurila et al., 2012) and volcanically active

165 (McConachy et al., 2002); the eruption of Kavachi volcano in the surface ocean is notable (Baker

166 et al., 2002; Phillips et al., 2016). In the shallow ocean both diffuse and focused venting have

167 been observed at Tutum Bay on the northeastern side of the Solomon Sea, enriching the surface

168 waters in Fe and $\mathrm{Mn}$, though these concentrations only persist near the vent sites (Pichler et al.,

169 1999). In coastal regions, runoff from Rabaul volcano (4¹4'25"S, 152 $11^{\prime} 45^{\prime \prime} \mathrm{E}$, east of New

170 Britain) was measured to be high in Fe (Labatut et al., 2014), and ash from Rabaul's eruptions

171 are deposited onto the ocean surface with precipitation being slightly acidic from the volcanic

$172 \mathrm{SO}_{2}$ (Ganachaud et al., 2017). The elevated tectonic and magmatic activity in this region

173 suggests that other, undiscovered hydrothermal vent sites likely exist, and this region has been 
174 extensively explored for deep-sea mining of hydrothermally-sourced minerals (e.g., Jankowski, 175 2011).

\subsection{Sampling locations}

177 The PANDORA cruise (GEOTRACES GP-12) took place during austral winter 2012 (28 June-6

178 August) aboard the R/V l'Atalante and was led by the Laboratoire d'Etudes en Geophysique et

179 Oceanographie Spatiales (LEGOS, Chief Scientist G. Eldin). A more detailed description of

180 hydrographic data and geochemical sampling, as well as preliminary findings about this cruise, 181 can be found in Ganachaud et al. (2017). A total of 170 casts were collected at 83 stations in and 182 around the Solomon Sea. The 12 stations that are examined in this study (Fig. 1a) were sampled 183 using a trace-metal clean rosette according to GEOTRACES protocols. Five of these stations 184 were located outside of the Solomon Sea: three to the south of the entrance (stations 4, 10, and 185 82), one to the northeast near the Solomon Strait (station 43), and one northeast of the Solomon 186 Archipelago (station 13). Within the Solomon Sea, one station was located on the west side of 187 the Solomon Islands, off San Cristobal (station 21). Two stations were located within the flow 188 path of the NGCU near Trobriand Island (stations 39 and 71). In the northern Solomon Sea, 189 stations are located in the Vitiaz Strait (station 77), near the Solomon Strait (station 42), and 190 along the flow path of thermocline waters as they exit via Saint George's Channel (station 60). 191 One station is located at the southern entrance of the Solomon Sea, off the coast of Rossel Island, 192 PNG (station 34) and was only sampled to $350 \mathrm{~m}$.

\section{Methods}

194 Water sampled for Al and Mn was collected using an epoxy-coated titanium CTD Rosette with 195 twelve 12-L Go-Flo bottles and described in more detail in Ganachaud et al. (2017) . Go-Flo 196 bottles spent minimal time on-deck, and after filling were transported to a clean-air environment 197 for sub-sample removal and storage between casts. Total acid-soluble metal samples, which 9 
includes the dissolved fraction plus the acid soluble portion of particles present in unfiltered samples (abbreviated as TD - total dissolvable, based on the terminology of Mackey et al. 2002a and Slemons et al. 2010) were collected directly from Go-Flo bottles into acid-cleaned $100 \mathrm{~mL}$ LDPE bottles (with LDPE caps). Dissolved metal (D) samples were collected from the Go-Flo bottles using slight overpressure of filtered $\mathrm{N}_{2}$ for filtration through $0.2 \mu \mathrm{m}$ Sartobran-300 capsule filters into acid-cleaned $100 \mathrm{~mL}$ LDPE bottles (with LDPE caps). All samples were acidified to $0.024 \mathrm{~N}$ using Optima $\mathrm{HCl}$ one month prior to $\mathrm{Al}$ analysis, and six months prior to Mn analysis.

Al was analyzed by flow injection analysis (FIA) using direct injection and fluorescent detection of the Al-lumogallion complex, following Resing and Measures (1994). This method had an average detection limit of $0.85 \mathrm{nM}$, which is $34 \%$ of the lowest concentration measured, and $7 \%$ of the average concentration of all samples. GEOTRACES GD (consensus $\pm 1 \mathrm{SD}=17.7 \pm 0.2$ $\mathrm{nM})$ reference standard was run daily, with an average value of $19.49 \pm 0.88 \mathrm{nM}(1 \mathrm{SD}, \mathrm{n}=17)$. We acknowledge that this value is higher than the reported consensus value, but we are not able to identify any blanks in our system based on the methodology that was used here. We note that the reference material is fairly old (GEOTRACES GD was collected 11 years prior to these analyses), and has been stored with HDPE caps, which are known to cause contamination for Al (Brown and Bruland, 2008). Other analysts have found consistently elevated Al values for the low nM level GEOTRACES standards (e.g. Resing et al., 2015; Singh et al., 2020). Daily precision for standards was on average 3.4\% relative standard deviation (RSD) at $1 \mathrm{nM}$ and $2.2 \%$ RSD at $20 \mathrm{nM}$.

Mn was analyzed by FIA using in-line preconcentration of Mn onto an 8-hydroxyquinoline column and spectroscopic detection of leuchomalachite green, based on the method of Resing and Mottl (1992), with the addition of $4 \mathrm{~g}$ of nitrilo tri-acetic acid per liter to the ammonium acetate reaction buffer. This method had a detection limit of $0.027 \mathrm{nM}$, which is $14 \%$ of the lowest sample measured and 3\% of the average concentration of all samples measured. 
224 GEOTRACES GD (consensus $\pm 1 \mathrm{SD}=1.50 \pm 0.11 \mathrm{nM}$ ) standards were run at least once a day

225 and measured to be $1.80 \pm 0.19(1 \mathrm{SD}, \mathrm{n}=17)$. Daily precision for standards was on average

$2263.0 \% \mathrm{RSD}$ at $0.1 \mathrm{nM}$ and $2.0 \% \mathrm{RSD}$ at $1.0 \mathrm{nM}$. An internal consistency standard was run at least

227 twice daily and found to be $0.32 \mathrm{nM} \pm 0.02 \mathrm{nM}(1 \mathrm{SD}, \mathrm{n}=94)$.

\subsection{Calculation of a trace metal budget in the Solomon Sea}

229 To examine the net impact on water passing through the Solomon Sea, we construct a budget to

230 evaluate the fluxes into and out of the Solomon Sea at three density intervals, based on transport

231 estimates calculated for the PANDORA cruise by Germineaud et al. (2016): Surface layer (surf -

$\left.23224 \sigma_{\theta}\right)$, Thermocline layer or NGCU $\left(24-26.9 \sigma_{\theta}\right)$, and Deep layer $\left(>26.9 \sigma_{\theta}\right.$; our maximum

233 sampled $\sigma_{\theta}$ is $\left.27.54 / 1300 \mathrm{~m}\right)$. For the thermocline layer $\left(24 \sigma_{\theta}-26.9 \sigma_{\theta}\right)$, we can also compare

234 these fluxes to the flux of the trace metals at the Equatorial Undercurrent to evaluate the

235 contribution of the Solomon Sea trace metal pool to that of the EUC (section 4.2).

236 The depth-weighted average concentration over each density interval is calculated using a

237 trapezoidal integration over the depth range corresponding to potential density for each station

238 and is reported in Table 1. The corresponding depths for each density interval can be found in

239 Table S1 and the full dataset can be found in Table S2. Errors reported in the text and in the

240 tables represent one standard deviation calculated using the analytical error on each

241 measurement.

242 This budget considers that there is a background flux of Al and Mn entering the Solomon Sea

243 over each of the three potential density ranges, referred to here as the Solomon Sea Inflow. The

244 outflow budget considers outputs through the Vitiaz Strait (station 77), St. George's Channel

245 (station 60) and the Solomon Strait (station 42), which we refer to collectively as the Solomon

246 Sea Outflow. Germineaud et al. (2016) reported outflow values for the Vitiaz Strait and the sum 
247 of the outflow for the water leaving via the Solomon Strait and St. George's Channel. Because

248 they do not report individual outflows for these two straits, we assume their outflows to be equal.

249 While Alberty et al. (2019) estimate transport through each channel, it is on an annual basis and

250 not over shorter time intervals. This is important because the flows are seasonally variable with

251 water flowing both into and out of the Solomon Strait based on season. During PANDORA,

252 surface water was flowing out of the Solomon Sea via Solomon Strait, rather than into it, as it

253 does on a net annual basis (Alberty et al., 2019). For these reasons, we find that the estimates

254 provided by Germineaud et al. (2016) are the best to use for this budget.

255 Chemical influx and efflux are calculated by considering transport and the concentrations of each 256 DAl, DMn, TDAl, and TDMn at appropriate stations as follows:

257 Flux $($ moles $/ \mathrm{s})=$ volume transport $\left(\mathrm{m}^{3} / \mathrm{s}\right) \times[$ element $]\left(\right.$ moles $\left./ \mathrm{m}^{3}\right)$

258 For the efflux, transport out of the Solomon Sea is considered for each of the exit straits

259 combined with the depth-weighted average concentration at stations closest to them.

260 The specific assumptions and processes used to determine average concentration for each flux 261 are described below.

263 We assume the $\mathrm{Al}$ and $\mathrm{Mn}$ concentrations at stations 10 and 82 to be representative of those 264 flowing into the Solomon Sea. Station 10 is located where water flows across the Vanuatu 265 Archipelago via the North Vanuatu Jet, while station 82 is located in the middle of the Coral Sea, 266 farther away from potential shelf inputs, and likely is dominated by water flowing via the NQC.

267 Station 34, which is the station likely to be most representative of the NGCU inflow, was not 12 
268 sampled through the potential density range of the EUC due to bad weather, and also shows

269 elevated Al relative to other profiles within the Solomon Sea, suggesting shelf input, and we

270 have therefore chosen not to consider it as a background profile. While a full profile of trace

271 metal samples was not collected for station 34, a standard CTD-rosette package collected a full

272 depth CTD profile, which shows that temperature, salinity, oxygen, and potential density profiles

273 at this station appear to be intermediate between stations 10 and 82. Station 82 generally has

274 lower concentrations of $\mathrm{Mn}$ and $\mathrm{Al}$ (by $\sim 0.2 \mathrm{nM} \mathrm{Mn}$ and up to $5 \mathrm{nM} \mathrm{Al}$ ) than Station 10. To

275 calculate influx, the average $\mathrm{Al}$ and Mn concentrations over each density interval for station 82

276 and 10 were calculated and multiplied by transport rate. Error was determined using the

277 combined analytical error (1SD) of the measurements used to calculate the average.

279 The depth-weighted average concentrations of DAl, TDAl, DMn, and TDMn over each density 280 interval for each strait/station were multiplied by water transport rate (Eq. 1). The chemical 281 distributions at station 77 (Vitiaz Strait), station 60 (St. George's Channel), and station 42 282 (Solomon Strait) are assumed to be representative of the water leaving the Solomon Sea. Station 28360 is not located within St. George's Channel; however we assume that it is representative of 284 water leaving the Solomon Sea via this channel for two reasons. First, the temperature-salinity 285 profile of other stations sampled using the standard CTD rosette in Saint George's Channel are 286 similar to Station 60 (Germineaud et al., 2016). Second, ADCP data at station 60 show that 287 currents flow toward both Saint George's Channel and the Solomon Strait, meaning that at least 288 some portion of the water that flows across station 60 must ultimately be directed out of the 289 Solomon Sea (Germineaud et al., 2016). 
291 DAl, TDAl, DMn, and TDMn in and around the Solomon Sea from the 2012 PANDORA cruise

292 are shown versus potential density in Figures 2-5, and versus depth (supplemental Fig. S2-S5).

293 Here we define the surface layer as being from the surface $\left(\sim 21 \sigma_{\theta}\right)$ to $24 \sigma_{\theta}(0-\sim 150 \mathrm{~m})$, the

294 thermocline layer from $\sim 150-\sim 450 \mathrm{~m}\left(24-26.9 \sigma_{\theta}\right)$, and deep waters at depths $>\sim 450 \mathrm{~m}-1300 \mathrm{~m}$

$295\left(>26.9 \sigma_{\theta}\right)$. Each plot includes a profile of the average of stations 10 and 82 , which are

296 considered to be representative of water entering the Solomon Sea at its southern entrance.

297 However, we note that these profiles are not representative of all surface water entering the

298 Solomon Sea, as there is additional inflow through the Solomon Islands or through the Solomon

299 Strait (e.g., Hristova and Kessler, 2012; Alberty et al., 2019).

Table 1a. Depth-weighted average DAl and TDAl concentrations. Values are calculated by integrating concentration data over the depth interval corresponding to the potential density range of each station. Reported error represents one standard deviation calculated from the analytical error of each measurement.

\begin{tabular}{|c|c|c|c|c|c|c|c|}
\hline & & $\begin{array}{l}\text { Surf: } \\
\text { Surf }\end{array}$ & $\begin{array}{l}\text { layer } \\
24 \sigma_{\theta}\end{array}$ & $\begin{array}{r}\text { Thermoclin } \\
24-\end{array}$ & $\begin{array}{l}\text { ayer /NGCU } \\
.9 \sigma_{\theta}\end{array}$ & $\begin{array}{r}\text { Dee } \\
<2\end{array}$ & $\begin{array}{l}\text { layer } \\
\sigma_{\theta}\end{array}$ \\
\hline & Station & $\mathrm{DAl}(\mathrm{nM})$ & TDAl (nM) & DAl (nM) & TDAl (nM) & $\mathrm{DAl}(\mathrm{nM})$ & TDAl (nM) \\
\hline & 82 & $12.7 \pm 0.6$ & $12.7 \pm 0.6$ & $6.2 \pm 0.8$ & $7.8 \pm 0.8$ & $6.8 \pm 0.8$ & $7.3 \pm 0.8$ \\
\hline Inflow & 10 & $10.4 \pm 0.7$ & $10.1 \pm 0.8$ & $5.8 \pm 0.8$ & $5.1 \pm 0.8$ & $8.0 \pm 0.9$ & $7.5 \pm 0.9$ \\
\hline & Average & $11.4 \pm 1.3$ & $11.2 \pm 1.5$ & $6.0 \pm 0.8$ & $6.5 \pm 1.5$ & $7.5 \pm 0.7$ & $7.4 \pm 0.7$ \\
\hline & 34 & $12.5 \pm 0.6$ & $12.5 \pm 0.6$ & $10.5 \pm 0.6$ & $11.5 \pm 0.5$ & & \\
\hline NUCU & 39 & $13.3 \pm 0.5$ & $13.2 \pm 0.5$ & $6.5 \pm 0.8$ & $6.4 \pm 0.8$ & $8.3 \pm 0.7$ & $7.9 \pm 0.7$ \\
\hline & 71 & $12.5 \pm 0.8$ & $12.6 \pm 0.8$ & $6.0 \pm 1.3$ & $8.0 \pm 1.3$ & $6.0 \pm 1.4$ & $9.6 \pm 1.4$ \\
\hline & 77 & $15.5 \pm 0.7$ & $19.1 \pm 0.8$ & $9.0 \pm 0.7$ & $10.8 \pm 0.5$ & $8.1 \pm 0.8$ & $11.5 \pm 0.8$ \\
\hline $\begin{array}{l}\text { Outtlow/ } \\
\text { Straits }\end{array}$ & 42 & $11.0 \pm 0.7$ & $13.0 \pm 0.7$ & $8.9 \pm 0.7$ & $9.5 \pm 0.7$ & $9.3 \pm 0.7$ & $12.9 \pm 0.8$ \\
\hline & 60 & $12.3 \pm 0.7$ & $12.3 \pm 0.7$ & $6.6 \pm 0.7$ & $7.5 \pm 0.7$ & $6.1 \pm 0.7$ & $9.3 \pm 0.7$ \\
\hline & 43 & $6.3 \pm 0.5$ & $5.7 \pm 0.7$ & $6.0 \pm 1.0$ & $4.7 \pm 1.1$ & $5.9 \pm 1.0$ & $6.0 \pm 0.7$ \\
\hline Outside of & 13 & $9.6 \pm 1.0$ & $9.2 \pm 0.9$ & $5.6 \pm 1.2$ & $5.6 \pm 1.2$ & $8.6 \pm 1.1$ & $7.6 \pm 1.1$ \\
\hline $\begin{array}{l}\text { Solomon } \\
\text { Sea }\end{array}$ & 21 & $14.4 \pm 0.7$ & $23.5 \pm 0.8$ & $9.4 \pm 0.8$ & $15.0 \pm 1.1$ & $10.2 \pm 0.7$ & $15.3 \pm 1.1$ \\
\hline & 4 & $11.9 \pm 0.5$ & $11.5 \pm 0.5$ & $10.2 \pm 0.8$ & $10.1 \pm 0.8$ & $7.7 \pm 0.8$ & $8.8 \pm 0.9$ \\
\hline
\end{tabular}




\begin{tabular}{|c|c|c|c|c|c|c|c|}
\hline \multicolumn{8}{|c|}{$\begin{array}{l}\text { Table 1b. Depth-weighted average DMn and TDMn concentrations. Values are calculated by integrating } \\
\text { concentration data over the depth interval corresponding to the potential density range of each station. Reported } \\
\text { error represents one standard deviation calculated from the analytical error of each measurement. }\end{array}$} \\
\hline & \multirow[b]{2}{*}{ Station } & \multicolumn{2}{|c|}{$\begin{array}{l}\text { Surface layer } \\
\text { Surf }-24 \sigma_{\theta}\end{array}$} & \multicolumn{2}{|c|}{$\begin{array}{c}\text { Thermocline layer/NGCU } \\
24-26.9 \sigma_{\theta}\end{array}$} & \multicolumn{2}{|c|}{$\begin{array}{c}\text { Deep layer } \\
<26.9 \sigma_{\theta}\end{array}$} \\
\hline & & $\mathrm{DMn}(\mathrm{nM})$ & $\begin{array}{c}\text { TDMn } \\
(\mathrm{nM})\end{array}$ & $\mathrm{DMn}(\mathrm{nM})$ & $\begin{array}{c}\text { TDMn } \\
\text { (nM) }\end{array}$ & $\mathrm{DMn}(\mathrm{nM})$ & $\begin{array}{l}\text { TDMn } \\
(\mathrm{nM})\end{array}$ \\
\hline \multirow{3}{*}{ Inflow } & 82 & $1.52 \pm 0.11$ & $1.61 \pm 0.11$ & $0.27 \pm 0.02$ & $0.41 \pm 0.03$ & $0.23 \pm 0.02$ & $0.41 \pm 0.03$ \\
\hline & 10 & $1.21 \pm 0.11$ & $1.30 \pm 0.09$ & $0.27 \pm 0.02$ & $0.39 \pm 0.02$ & $0.37 \pm 0.02$ & $0.56 \pm 0.05$ \\
\hline & Average & $1.32 \pm 0.22$ & $1.43 \pm 0.19$ & $0.27 \pm 0.02$ & $0.40 \pm 0.02$ & $0.30 \pm 0.07$ & $0.48 \pm 0.07$ \\
\hline \multirow{3}{*}{$\begin{array}{l}\text { NGCU } \\
\text { Flow path }\end{array}$} & 34 & $0.59 \pm 0.12$ & $0.84 \pm 0.06$ & $0.30 \pm 0.04$ & $0.48 \pm 0.04$ & & \\
\hline & 39 & $1.32 \pm 0.09$ & $1.51 \pm 0.10$ & $0.25 \pm 0.05$ & $0.43 \pm 0.05$ & $0.27 \pm 0.04$ & $0.53 \pm 0.05$ \\
\hline & 71 & $1.05 \pm 0.06$ & $1.15 \pm 0.06$ & $0.24 \pm 0.03$ & $0.40 \pm 0.04$ & $0.34 \pm 0.04$ & $0.63 \pm 0.06$ \\
\hline \multirow{3}{*}{$\begin{array}{l}\text { Outflow/ } \\
\text { Straits }\end{array}$} & 77 & $1.22 \pm 0.10$ & $1.45 \pm 0.12$ & $0.26 \pm 0.01$ & $0.49 \pm 0.02$ & $0.51 \pm 0.04$ & $0.88 \pm 0.07$ \\
\hline & 42 & $0.77 \pm 0.06$ & $1.07 \pm 0.09$ & $0.27 \pm 0.05$ & $0.49 \pm 0.05$ & $0.46 \pm 0.06$ & $0.81 \pm 0.06$ \\
\hline & 60 & $1.26 \pm 0.10$ & $1.35 \pm 0.11$ & $0.28 \pm 0.02$ & $0.44 \pm 0.03$ & $0.43 \pm 0.03$ & $0.74 \pm 0.06$ \\
\hline \multirow{4}{*}{$\begin{array}{l}\text { Outside of } \\
\text { Solomon } \\
\text { Sea }\end{array}$} & 43 & $0.72 \pm 0.05$ & $0.79 \pm 0.05$ & $0.32 \pm 0.14$ & $0.42 \pm 0.04$ & $0.33 \pm 0.03$ & $0.50 \pm 0.05$ \\
\hline & 13 & $0.70 \pm 0.05$ & $0.80 \pm 0.06$ & $0.29 \pm 0.10$ & $0.40 \pm 0.09$ & $0.39 \pm 0.08$ & $0.60 \pm 0.05$ \\
\hline & 21 & $0.93 \pm 0.07$ & $1.38 \pm 0.11$ & $0.31 \pm 0.09$ & $0.56 \pm 0.04$ & $0.38 \pm 0.08$ & $0.68 \pm 0.05$ \\
\hline & 4 & $1.54 \pm 0.09$ & $1.58 \pm 0.09$ & $0.38 \pm 0.02$ & $0.54 \pm 0.05$ & $0.36 \pm 0.02$ & $0.63 \pm 0.06$ \\
\hline
\end{tabular}

303 In the surface layer, average DAl and TDAl inflowing water are $11.4 \pm 1.4 \mathrm{nM}$ and $11.2 \pm 1.3$

$304 \mathrm{nM}$, respectively. Within the Solomon Sea (stations 34, 39, 71) and in St. George's Channel

305 (station 60), average DAl and TDAl in the surface layer are $\sim 1-2 \mathrm{nM}$ greater than in the

306 inflowing water. The Solomon Strait (station 42$)$ shows a decrease in DAl ( 0.5 nM), but an

307 enrichment of $\sim 1 \mathrm{nM}$ in TDA1. By contrast the Vitiaz Strait (station 77), shows a much greater

308 enrichment in both DAl and TDAl ( 4 nM and $\sim 8 \mathrm{nM}$, respectively). Outside of the Solomon

309 Sea to the north and northeast (stations 13 and 43; Figs. 2,3 j,k) DAl and TDAl are $\sim 2-5$ nM

310 lower than the waters entering the Solomon Sea. Station 21, which is just outside of the eastern

311 opening of the Solomon Sea and south of the Solomon Islands, is fed by waters from north of the

312 Solomon Islands (e.g., from station 13) that flows through gaps in the islands, resulting in

313 average concentrations at station 21 being enriched by $5 \mathrm{nM}$ for DAl and $13 \mathrm{nM}$ for TDAl

314 relative to their concentrations at station 13. 
315 In the thermocline layer which, within the Solomon Sea, is largely made up of the NGCU $(\sim 150$ $316450 \mathrm{~m} ; 24-26.9 \sigma_{\theta}$ ), DAl and TDAl generally decrease from surface concentrations to lower 317 values, often reaching mid-depth minima at different depths for different stations (Fig. 2 and Fig. 318 S2). Over this density range, the inflowing waters have depth-weighted average DAl and TDAl 319 concentrations of $6.0 \pm 0.8 \mathrm{nM}$, and $6.5 \pm 1.5 \mathrm{nM}$, respectively. Along the flow path of the 320 NGCU (stations 39 and 71), concentrations remain roughly constant relative to inflow, with 321 slight enrichments of DAl $(\sim 0.5 \mathrm{nM})$ at station 39 and TDAl $(\sim 1.6 \mathrm{nM})$ at station 71 . In the exit 322 straits (stations 42, 60, and 77) DAl and TDAl are enriched relative to the inflow by $\sim 0.65 \mathrm{nM}-$ $3234 \mathrm{nM}$. To the north and northeast of the Solomon Sea (station 13 and 43) DAl is similar to the 324 inflowing water, while TDAl is less at station $13(\sim 1 \mathrm{nM})$ and station $43(\sim 2 \mathrm{nM}$; however, it 325 should be noted that DAl at station 43 exceeds TDAl, suggesting that these samples may be 326 slightly contaminated). Stations 4 and 21, which are close to local bathymetry (e.g., sills, straits) 327 are enriched in DAl at both stations by $\sim 4 \mathrm{nM}$, and in TDAl by $\sim 4 \mathrm{nM}$ and $\sim 8 \mathrm{nM}$ at station 4 328 and 21, respectively.

329 In the deep layer $\left(>450 \mathrm{~m} ;>26.9 \sigma_{\theta}\right)$ the depth-weighted average inflowing DAl is $7.5 \pm 0.7 \mathrm{nM}$, 330 and TDAl is $7.4 \pm 0.7 \mathrm{nM}$. Within the basin (stations 39 and 71), in the Vitiaz Strait (station 77), 331 as well as outside the Solomon Sea (station 13), depth-weighted average DAl concentrations are 332 within the observed variability of the inflowing water. There is slight enrichment in DAl ( 2-3 $333 \mathrm{nM}$ ) in the Solomon Strait (station 42) and near the Solomon Islands (station 21). There are 334 small (2-3 nM) enrichments of TDAl within the basin at station 71 and in St. George's channel at 335 station 60, and larger enrichments relative to the inflow (4-5 nM) in Vitiaz (station 77) and 336 Solomon (station 42) Straits, as well $\sim 8 \mathrm{nM}$ enrichment at station 21 on the eastern edge of the 337 basin, again reflecting the proximity to local bathymetry. Northeast of the Solomon Sea (station 338 43), both DAl and TDAl are depleted by $\sim 1 \mathrm{nM}$, relative to the waters flowing into the Solomon 339 Sea. 
340 Mn has a scavenged distribution at all stations, with the highest concentrations at the surface and

341 generally decreasing with depth. From the surface to $24 \sigma_{\theta}$, the depth-weighted average

342 concentration of inflowing waters for DMn is $1.32 \pm 0.22 \mathrm{nM}$, while TDMn is $1.43 \pm 0.19 \mathrm{nM}$.

343 Within the Solomon Sea, DMn and TDMn at most stations do not vary from these inflow values

344 (stations $39,60,77$ ), or are depleted relative to the inflowing waters by $\sim 0.3-0.7 \mathrm{nM}$ along the

345 flow path of the NGCU (stations 34, 42). Station 21 is also depleted in DMn by $\sim 0.4 \mathrm{nM}$ relative

346 to inflowing waters. Outside the Solomon Sea (stations 13, 43), DMn and TDMn are depleted by

$347 \sim 0.6 \mathrm{nM}$ relative to inflowing water, while south of the Solomon Sea at station 4, DMn and

348 TDMn concentrations are $\sim 0.2 \mathrm{nM}$ higher than the waters flowing into the Solomon Sea.

349 Over 24-26.9 $\sigma_{\theta}$, the depth-weighted average DMn of inflowing water is $0.27 \pm 0.02 \mathrm{nM}$ and

350 TDMn is $0.40 \pm 0.02 \mathrm{nM}$. In this density interval, most stations have DMn and TDMn

351 concentrations that are within the variability of the inflow. There are a few stations where there

352 is enrichment $(\sim 0.1 \mathrm{nM})$ of TDMn - along the flow path of the NGCU at station 34, in the Vitiaz

353 (station 77) and Solomon (station 42) Straits. TDMn is enriched $\sim 0.2 \mathrm{nM}$ near the Solomon

354 Islands (station 21). South of the Solomon Sea (station 4) DMn and TDMn are higher than those

355 waters entering the Solomon Sea by $\sim 0.1 \mathrm{nM}$ and $\sim 0.2 \mathrm{nM}$ respectively.

356 In the deeper ocean $\left(>450 \mathrm{~m} ;>26.9 \sigma_{\theta}\right)$, on average, DMn and TDMn generally increase with 357 depth at all stations. Below $26.9 \sigma_{\theta}$, the inflowing waters have a depth-weighted average DMn 358 concentration of $0.30 \pm 0.07 \mathrm{nM}$ and TDMn concentration of $0.48 \pm 0.07 \mathrm{nM}$. In the straits, 359 (stations 77, 60, and 42), enrichments in DMn and TDMn relative to the inflow are on the order 360 of 0.1-0.2 $\mathrm{nM}$ and 0.3-0.4 nM, respectively. Within the basin (stations 34, 39, 71) the average 361 concentrations of DMn are generally similar to those in the inflow, while smaller enrichments $362(\sim 0.1 \mathrm{nM})$ of TDMn are found at stations $4,10,13,71$, and of $0.2 \mathrm{nM}$ at station 21. 


\section{Discussion}

\subsection{Al and Mn enrichments within the Solomon Sea}

\subsubsection{Surface Layer ( $\left.\operatorname{surf}-24 \sigma_{\theta}\right)$}

366 Over this potential density interval, average Al and Mn concentrations are lowest in the surface

367 ocean at the two stations (13 and 43) located in the westward flowing South Equatorial Current

368 (SEC) north and east of the Solomon Islands just outside of the Solomon Sea, relative to

369 concentrations elsewhere in the Solomon Sea basin. This must reflect their westward transport

370 from the open ocean. This is consistent with the Al values observed at the eastern entrance of the

371 Solomon Sea (station 10; Table 1a, Table S2). Within the Solomon Sea and the straits, average

372 concentrations over this density interval tends to be higher.

373 The elevated surface concentrations (Table 1) that are observed in Mn and Al within the

374 Solomon Sea could be derived from riverine, aeolian, or coastal/margin sources. Based on

375 salinity, our data reveal no large inputs of fresh water to the Solomon Sea during this cruise and

376 consequently no correlation between salinity and trace metals is observed. This means either that

377 at the time of the cruise, trace metal inputs to the Solomon Sea via rivers were small or that trace

378 metal inputs were large relative to freshwater input, which is more consistent with observations

379 of high sediment loads, relative to fluvial discharge in this region (e.g., Milliman et al., 1999).

380 Dust input to the Solomon Sea can be predicted using the MADCOW model (Measures and 381 Brown, 1996) based on regional dust fluxes and empirical dust solubilities. Using a dust flux of

$3821.0 \mathrm{~g} \mathrm{~m}^{-2} \mathrm{y}^{-1}$ to the Solomon Sea (Shank and Johansen, 2008), an empirical dust solubility of $3836.0 \%$ (Buck et. al., 2006), a residence time of surface water in the Solomon Sea of 0.6-2 months 384 (estimated based on an average velocity of $20-60 \mathrm{~cm} \mathrm{~s}^{-1}$ over the $\sim 1000 \mathrm{~km}$ distance between the 385 inflow and outflow, and consistent with literature estimates (Melet et al., 2011, Hristova and 
386 Kessler, 2012; Alberty et al., 2019)) and a mixed layer depth $<100 \mathrm{~m}$ (based the definition of de 387 Boyer Montégut et al., 2004), it can be estimated that DAl added from dust deposition accounts 388 for only $0.30 \mathrm{nM}$ to $1.14 \mathrm{nM}$ of the DAl added to the surface waters as they transit through the 389 Solomon Sea which is only $\sim 5.4 \% \pm 2.5 \%$ (1SD) of DAl present there. Thus, dust is a relatively 390 small source of DAl to the waters in this region. A similar estimation for DMn can be made 391 using a fractional solubility of $\mathrm{Mn}$ in dust of $45.1 \%$ from Buck et al. (2013), and a crustal 392 abundance of Mn of 954 ppm from Taylor, (1964) to be consistent with the reference used by 393 Measures and Brown (1996). We estimate that DMn added from dust deposition as the waters 394 transit through the Solomon Sea to be only $0.01 \mathrm{nM}$ to $0.05 \mathrm{nM}$ or $\sim 1.9 \% \pm 0.9 \%$ (1SD) of DMn 395 present in the surface Solomon Sea.

396 Elevated Al and Mn concentrations in the surface ocean within the straits and Solomon Sea, 397 relative to inflowing waters or stations outside the Solomon Sea, suggest that these elements 398 become enriched when waters interact with local bathymetry as they enter the basin. The SEC 399 transports surface waters into the Solomon Sea passing through both the Solomon Strait and 400 other gaps in the Solomon archipelago ultimately exiting through the Vitiaz strait (Cravatte et al., 401 2011; Hristova and Kessler, 2012). TDAl of the surface samples in both the Solomon Strait 402 (station $42-18.7 \pm 0.4 \mathrm{nM}$ ) and Vitiaz Strait (station $77-38.7 \pm 0.4 \mathrm{nM}$ ) are enriched compared to 403 DAl $(13.5 \pm 0.3 \mathrm{nM}, 28.7 \pm 0.4 \mathrm{nM}$ respectively) suggesting the input of sediments or rapid removal 404 of DAl by scavenging. A similar but muted effect is seen for Mn at these stations. The high Mn $405(2.5 \mathrm{nM})$ and $\mathrm{Al}(>20 \mathrm{nM})$ in the surface waters that exit through the Vitiaz Strait (station 77 ) 406 must result from scouring and entrainment of local sediments into the water column due to rapid 407 geostrophic current velocities (20-60 cm/s; e.g. Hristova and Kessler 2012) coupled with the 408 narrow strait. A maximum in Rare Earth Elements (REE), including dissolved Cerium (Ce), was 409 also observed in the surface waters at station 77 during the PANDORA cruise (Pham et al., 410 2019). At the eastern end of the Solomon archipelago, where waters flow from the SEC (station 411 13) through the islands to station 21, Mn and $\mathrm{Al}$ concentrations are also greater than those in the 412 SEC (see results) reflecting input from the islands and the scouring of coastal sediments. This is 19 
413 also largely consistent with enrichments in REEs observed during PANDORA (Pham et al.,

414 2019). The surface water flowing through the Solomon Sea has a residence time of $\sim 53-103$

415 days (Melet et al., 2011), so input and removal processes for Mn and Al must be both strong and

416 rapid to produce the changes in concentrations observed here.

417 Using transport estimates reported in Germineaud et al. (2016) and the average concentrations of

418 metals at stations in/near the straits, we can estimate the fluxes entering the Solomon Sea from

419 the southern entrance and exiting via the three straits. However, transport estimates

420 (Germineaud et al., 2016) are unbalanced with a transport entering the Solomon Sea via the

421 southern entrance of $3.3 \pm 0.4 \mathrm{~Sv}$, and exiting the Solomon Sea of $6.9 \pm 0.6 \mathrm{~Sv}(4.5 \pm 0.4 \mathrm{~Sv}$

422 through the Vitiaz Strait and a combined 2.4 $\pm 0.3 \mathrm{~Sv}$ through St. George's Channel, and the

423 Solomon Strait). The missing flow likely enters through the gaps in the Solomon Islands. As a

424 result, in the surface layer, our budget is unbalanced, and the larger exit fluxes reflect the

425 differences in flow. Table 2 reports the flux in through the southern entrance and out through the

426 straits. While we cannot calculate a balanced flux value for the inflow, the depth-weighted

427 average concentrations at the exit straits all suggest that water leaving the Solomon Sea is within

428 the variability of, or enriched in, Al and Mn relative to the inflowing surface layer (Table 1).

429 Trace metal fluxes based on transport in the surface layer are reported in Table 2. This budget

430 does not consider diapycnal/vertical mixing between layers, because vertical mixing does not

431 appear to be reflected in the chemical profiles that we see in Al and $\mathrm{Mn}$ in the upper NGCU.

432 While diapycnal mixing in the Solomon Sea is important (Melet et al., 2011), based on the

433 erosion of the salinity maximum in the thermocline between the entrance and the exit of the

434 Solomon Sea and the salinity of the surface layer, we calculate that no more than $33 \%$ of water is

435 mixed between our density intervals. Additionally, several water masses converge upon entrance

436 into the Solomon Sea (e.g., Kessler et al., 2019) and there is evidence of vertical mixing due to

437 internal tides in the region (e.g., Melet et al., 2011), making diapycnal mixing in the surface layer

438 hard to resolve. 
Table 2: Transport and trace metal flux estimates for the surface (surf-24) in the Solomon Sea. Transport estimates from Germineaud et al. (2016). Solomon Strait and St. George's Channel transport are estimated based on total transit through the two outflow straits. Errors represent the combined error from the transport estimate and the analytical error (1 SD) of the average concentration.

\begin{tabular}{lccccc}
\hline Station & $\begin{array}{c}\text { Transport } \\
(\mathrm{Sv})\end{array}$ & $\begin{array}{c}\mathrm{DAl} \\
(\mathrm{mol} / \mathrm{s})\end{array}$ & $\begin{array}{c}\text { TDAl } \\
(\mathrm{mol} / \mathrm{s})\end{array}$ & $\begin{array}{c}\text { DMn } \\
(\mathrm{mol} / \mathrm{s})\end{array}$ & $\begin{array}{c}\text { TDMn } \\
(\mathrm{mol} / \mathrm{s})\end{array}$ \\
\hline $\begin{array}{l}\text { Inflow } \\
\text { Vitiaz Strait }\end{array}$ & $3.3 \pm 0.4$ & $38 \pm 6$ & $37 \pm 7$ & $4.4 \pm 0.9$ & $4.71 \pm 0.8$ \\
$\begin{array}{l}\text { (station 77) } \\
\text { Solomon Strait }\end{array}$ & $1.2 \pm 0.3$ & $13 \pm 3$ & $15.6 \pm 4.0$ & $0.9 \pm 0.2$ & $1.3 \pm 0.3$ \\
$\begin{array}{l}\text { (station 42) } \\
\begin{array}{l}\text { St. George's Channel } \\
\text { (station 60) }\end{array}\end{array}$ & $1.2 \pm 0.3$ & $15 \pm 4$ & $14.7 \pm 3.8$ & $1.5 \pm 0.4$ & $1.6 \pm 0.4$ \\
$\begin{array}{l}\text { Total Outflow } \\
\text { Stat }\end{array}$ & $6.9 \pm 0.3$ & $98 \pm 11$ & $116 \pm 12$ & $7.9 \pm 1.1$ & $9.4 \pm 1.3$
\end{tabular}

443 The water between $\sim 150-450 \mathrm{~m}$ and 24-26.9 $\sigma_{\theta}$ is dominated by the core of NGCU, which 444 originates from the south and east of the Solomon Sea (see section 1.1). At this depth/density 445 range, dissolved and total dissolvable $\mathrm{Al}$ and $\mathrm{Mn}$ are lower than in the surface ocean (see Table 1 446 and results), however there are enrichments in DA1, TDAl, and TDMn (but not DMn) relative to 447 the water flowing into the Solomon Sea (Sta. 10 and 82). The pattern of enrichments is similar, 448 in part, to those in the surface layer with enrichments in DA1, TDA1, and TDMn in the Solomon 449 (station 42) and Vitiaz (station 77) straits. At station 21 where water flows roughly from station 45013 to 21 through the gaps in the Solomon Islands (Hristova and Kessler, 2012) and near a 451 shallow sill, enrichments in DAl, TDAl, DMn, and TDMn are observed (Figures 2-5, k and 1). 
452 Sampling during PANDORA included measurements of Rare Earth Elements, and our data is 453 consistent with increases in dissolved Lanthanum (La), Neodymium (Nd), Europium (Eu), and 454 Ytterbium (Yb) between stations 13 and 21, reported by Pham et al. (2019). Dissolved Ce and 455 the Ce anomaly are not modified between stations (Pham et al., 2019), which suggests that the 456 water mass is the same between the two stations, but that particle inputs are recent and 457 modifications do not cause changes in dissolved Ce, because it is insoluble. The best explanation 458 for these observations is sediment resuspension which is supported by larger enrichments $(\sim 9$ $459 \mathrm{nM}$ TDAl, $0.2 \mathrm{nM}$ TDMn) in total dissolvable metals versus dissolved metals ( 4 nM DAl, 0 $460 \mathrm{nM} \mathrm{DMn).} \mathrm{Coincident} \mathrm{enrichment} \mathrm{of} \mathrm{Mn} \mathrm{and} \mathrm{Al} \mathrm{also} \mathrm{occurs} \mathrm{in} \mathrm{the} \mathrm{Vitiaz} \mathrm{Strait} \mathrm{(station} \mathrm{77),}$ 461 similarly suggesting sediment resuspension, rather than reductive release from shelf sediments or 462 hydrothermal input at these stations, as these other two processes would impact Mn distributions 463 to a greater extent than Al distributions. This is also consistent with Ce anomaly data, which 464 shows decreasing solubility, rather than remineralization in the Vitiaz Strait (Pham et al., 2019). 465 Physical resuspension/non-reductive dissolution is implicated for the enrichment of Fe in the 466 Vitiaz Strait and the NICU based on Fe isotope measurements (Labatut et al., 2014). These Fe 467 enrichments reflect particulate iron transported from the continent across shelves and slopes, 468 followed by release of DFe from suspended particles (Labatut et al., 2014). This has also been 469 observed for $\mathrm{Al}$ and $\mathrm{Mn}$ in other regions. Al remobilized from benthic nepheloid layers is an 470 important source for Al in the deep waters of the North Pacific (Moran and Moore, 1991). 471 Lateral transport of Mn remobilized from shelves has been observed off the coast of California 472 (Martin et al., 1987) who show that major sub-surface maxima and minima in the Mn 473 distributions are controlled primarily by sedimentary release combined with water mass 474 movement and physical mixing, rather than through scavenging and remineralization processes.

475 The NGCU is expected to flow from station 34 to 39 and then to 71 after which it bifurcates, 476 going WNW to the Vitiaz strait (station 77) and NE to station 60 and then on to the Solomon 477 strait (station 42) (Fig. 1). Two of the stations along the predicted flow path of the NGCU (34 478 and 71) show enrichments in DAl, TDAl, and TDMn that exceed the variability of the average 
inflow profile, while station 39 shows no enrichments in either $\mathrm{Al}$ or Mn (see Table 1 and results). At station 71, the coherence between DAl and TDAl provides confidence in sample quality and thus the lack of a mid-depth enrichment at station 39 indicates that this station is 482 either not in the NGCU, or that local trace metal input and removal are highly dynamic and 483 variable. Based on transport and current speeds, the NGCU/NBCU is estimated to take 2-4 484 months to transit through the Solomon Sea, which is also consistent with model estimates of 485 residence times (Melet et al., 2011). This is much shorter than reported residence times of $\mathrm{Al}$ in 486 the open ocean. Because this region has large coastal influence, it is possible that input and 487 removal of $\mathrm{Al}$ are rapid, and riverine inputs and coastal sediments must release and scavenge $\mathrm{Al}$ 488 on shorter timescales than the residence time of NGCU waters in the Solomon Sea. If station 34 489 is not in the flow path of the NGCU, then the enrichments seen at station 39 are local. However, 490 if station 39 is not in the flow path of the NGCU, then the enrichments at station 71 might be 491 sourced from the upstream waters coming from station 34. In either case, the small increases in 492 TDAl without enrichments in DAl and Mn at station 60 may be sourced from station 71.

493 In the thermocline layer, observations show that water transport into and out of the Solomon Sea 494 was roughly equal at the time of the PANDORA cruise with transport into the Solomon Sea at its 495 southern entrance $\approx 23.6 \pm 0.8 \mathrm{~Sv}$, and transport out of the Solomon Sea through the exit straits $496 \approx 22.8 \pm 1.0 \mathrm{~Sv}$ (Germineaud et al., 2016). This allows us to construct a steady state budget with 497 regard to transport over this density interval. Despite strong seasonal and interannual variability 498 in flow through the Solomon Sea, (e.g., Germineaud et al., 2016; Alberty et al., 2019), estimates 499 of the transport of the EUC (e.g., Grenier et al., 2011; Lindstrom et al., 1987; Tsuchiya et al., 500 1989) are similar to the Solomon Sea transport over this density interval (22-23 Sv) observed by 501 Germineaud et al. (2016) during PANDORA. In our steady state model, chemical influx is thus 502 calculated by multiplying the depth-weighted average inflow profile for the Solomon Sea by $50322.8 \pm 1.0 \mathrm{~Sv}$. We also consider that DA1, TDAl, DMn, and TDMn distributions in the Vitiaz 504 Strait (station 77), St. George's Channel (station 60), and Solomon Strait (station 42) are 
505 representative of the water leaving the Solomon Sea via the NGCU, SGU, and NICU,

506 respectively.

507 The inflow, outflow, and EUC trace metal fluxes are reported in Table 3.

Table 3. Transport and trace metal flux estimates for the thermocline layer $\left(24-26.9 \sigma_{\theta}\right)$ in the Solomon Sea. Transport estimates are from Germineaud et al. (2016). Solomon Strait and St. George's Channel transport are estimated based on total transit through the two outflow straits. Errors represent the combined uncertainty from the transport estimate and the analytical error (1 SD) of the average concentration.

\begin{tabular}{|c|c|c|c|c|c|}
\hline & $\begin{array}{l}\text { Transport } \\
\text { (Sv) }\end{array}$ & $\begin{array}{c}\text { Dal } \\
\text { mols/s }\end{array}$ & $\begin{array}{l}\text { TDAl } \\
\text { mols/s }\end{array}$ & $\begin{array}{c}\mathrm{DMn} \\
\mathrm{mols} / \mathrm{s}\end{array}$ & $\begin{array}{l}\text { TDMn } \\
\text { mols } / \mathrm{s}\end{array}$ \\
\hline Inflow* $\left(\mathrm{mol} \mathrm{s}^{-1}\right)$ & $22.8 \pm 1.0$ & $136 \pm 19$ & $147 \pm 35$ & $6.1 \pm 0.5$ & $9.1 \pm 0.6$ \\
\hline Vitiaz Strait & $10.3 \pm 0.3$ & $93 \pm 8$ & $111 \pm 5$ & $2.7 \pm 0.1$ & $5.0 \pm 0.3$ \\
\hline $\begin{array}{l}\text { (station 77) } \\
\text { Solomon Strait } \\
\text { (station 42) }\end{array}$ & $6.25 \pm 0.4$ & $56 \pm 6$ & $59 \pm 6$ & $1.7 \pm 0.3$ & $3.1 \pm 0.4$ \\
\hline $\begin{array}{l}\text { St. George's } \\
\text { Channel (station 60) }\end{array}$ & $6.25 \pm 0.5$ & $42 \pm 5$ & $47 \pm 4$ & $1.7 \pm 0.2$ & $2.7 \pm 0.3$ \\
\hline Outflow $\left(\mathrm{mol} \mathrm{s}^{-1}\right)$ & $22.8 \pm 1.0$ & $190 \pm 19$ & $217 \pm 16$ & $6.1 \pm 0.6$ & $10.8 \pm 1.0$ \\
\hline
\end{tabular}

508

509 These data show that at the time of the PANDORA cruise, fluxes of DA1, TDAl, and TDMn out

510 of the Solomon Sea in the thermocline waters were only slightly higher (8-90 mol/s DAl, 7-130

$511 \mathrm{~mol} / \mathrm{s} \mathrm{TDAl}, 0.3-2.4 \mathrm{~mol} / \mathrm{s} \mathrm{TDMn}$ ) than fluxes into the Solomon Sea, and that DMn fluxes

512 remained constant through the basin. 
514 In the deeper ocean $\left(450 \mathrm{~m}-1300 \mathrm{~m} ; 26.9 \sigma_{\theta}-\sim 27.5 \sigma_{\theta}\right) \mathrm{Al}$ and Mn generally show enrichment

515 within the straits or near local bathymetry, which is similar to what was observed in the

516 thermocline layer, with some exceptions. The enrichments in TDAl and TDMn relative to

517 background concentrations that are observed in the Vitiaz and Solomon Straits (stations 77 and

518 42) reflect the proximity of these stations to local bathymetry, combined with flow through these

519 straits by the NGCU (station 77) and NICU (station 42). Similarly at station 21, increases in

520 DAl, TDAl, and TDMn relative to concentrations at station 13 reflect enrichments due to to

521 scouring as the SEC flows through the Solomon Islands.

522 Other factors, such as accumulation of sinking particles may be responsible for the enrichments

523 in $\mathrm{Mn}$ and $\mathrm{Al}$ at stations 39, 71, and 60, which lie deep within the Solomon Sea and are isolated

524 from local features. The Woodlark Rise, extending $250 \mathrm{~km}$ NE from the Woodlark Island

525 Archipelago to within $\sim 60 \mathrm{~km}$ from the Solomon Archipelago, is a ridge line of bathymetric

526 highs that reach $\leq 1000 \mathrm{~m}$ with gaps between highs reaching $\sim 1500 \mathrm{~m}$. This feature creates a semi-

527 enclosed basin below $\sim 1000 \mathrm{~m}$ that encompasses stations 71 and 60 in the NE Solomon Sea.

528 Below 400m, the NGCU (Alberty et al., 2019) transits from the Coral Sea and flows around the

529 Louisiade Archipelago and then around, through, and/or over the Woodlark Rise; below $1000 \mathrm{~m}$

530 it likely passes through the channel between the Woodlark Rise and the Solomon Islands (Fig.

531 1b). At stations 42 and 60, enrichments in TDAl and TDMn, the HCl-labile portion of the

532 particulate fraction, likely represent sinking particles accumulating along the flow path of the

533 NGCU/NBCU and within the semi-enclosed basin due to longer residence time for waters there.

534 The residence time of water in the basin between $\sim 450$ and $\sim 1400 \mathrm{~m}$ is estimated to be $<1$ year

535 based on models (Melet et al., 2011) or transport estimates, however transport (and current

536 speed) significantly decreases with depth below 450m (Alberty et al., 2019; Gasparin et al.,

537 2012) resulting in increased residence times with depth. 
538 The relative increases in TDAl and TDMn also arise from the scavenging of dissolved phases

539 sourced along the flow path or from particles resuspended as water flows over the Woodlark rise

540 and other bathymetry. Through the Vitiaz Strait (station 77), there is likely sediment

541 resuspension from the bottom and walls of the channel $\left(\sim 1100 \mathrm{~m} / 27.4 \sigma_{\theta}\right)$ as water passes

542 through. The larger enrichments in the exit straits may also be due to accumulation of sinking

543 particles, or other local, shorter-lived phenomena (e.g., increased river runoff), though we do not

544 have enough information to say this definitively. It is possible that at these deeper depths,

545 especially through the Solomon Strait (station 42), decreased current speeds lessen the likelihood

546 of scouring and sediment resuspension, supporting a role for sinking particles from shallow

547 sources. Additional measurements in this region would help better constrain this hypothesis.

548 The straits in the Solomon Sea also exhibit increases in DMn with depth, which, in the deep

549 layer, generally indicates recent inputs from sedimentary and/or hydrothermal sources but can

550 also be associated with oxygen deficient zones. Prior to reaching the Woodlark Rise, within the

551 Woodlark basin, hydrothermal activity is present at $>2500 \mathrm{~m}$ (Laurila et al., 2012) with

552 shallower hydrothermal activity inferred at Kana Keoki seamount at 650 m near the Solomon

553 Archipelago (InterRidge Database: https://vents-data.interridge.org/). These are unlikely to be

554 the source of the Mn enrichments between 700 and $1350 \mathrm{~m}$, however. Given the highly tectonic

555 and magmatic character of the region, hydrothermal hot springs likely exist throughout the basin.

556 Diffusion from or resuspension of sediments are also possible source mechanisms for DMn

557 whose input coincides with transport through and along the Woodlark Rise. Dissolved oxygen

558 remains relatively elevated throughout the basin at these depths, suggesting that particle

559 remineralization does not play a large role in maintaining DMn levels. This is supported by

560 dissolved Ce concentrations (Pham et al., 2019), which decrease as water flows through the

561 basin, and Ce anomalies in the deeper ocean that do not indicate any shifts towards either

562 remineralization or increased solubility due to changes in redox chemistry. The increase in DMn

563 concentrations between stations 71 and 60 versus those in the straits suggest that sediments may

564 be the predominant sources of DMn in the regional deep layer. The absence of an enrichment in 
565 DMn, DAl, and TDAl at station 39 (and small TDMn enrichment) suggests that there is little to 566 no Mn input as the NGCU transits through and around bathymetry prior to reaching station 39 at 567 these depths. While it is possible that the NGCU is bathymetrically steered away from station 56839 , it seems more likely that $\mathrm{Mn}$ and/or Al are added after passing this station. The presence of

569 DMn at this station suggests that the TDMn is sourced at depth from the oxidation and

570 scavenging of DMn. Station 21 also shows enrichments in TDMn, TDAl, and DAl relative to

571 stations outside of the Solomon Sea suggesting the accumulation of dissolved metals and

572 sediments as water flows through the Solomon Archipelago. While various small enrichments

573 are observed at stations outside of the Solomon Sea, it is not possible to evaluate background

574 values for these stations. However, we do note that the SEC flows past many shallow seamounts

575 en route to the Solomon Sea.

576 Estimated fluxes of trace metals in the deep layer are determined based on transport estimates for 577 the PANDORA cruise calculated by Germineaud et al. (2016) and are reported in Table 4.

578 Because there is less mixing deeper in the ocean, transport estimates are more consistent between

579 the inflow $(9.3 \pm 1.4 \mathrm{~Sv})$ and outflow $(8.4 \pm 2.6 \mathrm{~Sv})$ than they are in the surface layer, but there are

580 still large uncertainties on transport estimates deeper in the water column, as well as a slight

581 imbalance between inflowing and outflowing water transport. Fluxes reported here for total

582 outflow show that trace metal modifications are minimal relative to inflowing water, despite

583 regions of local enrichment observed in profile data.

Table 4: Transport and trace metal flux estimates for the deep layer $\left(>26.9 \sigma_{\theta}\right)$ in the Solomon Sea. Transport estimates from Germineaud et al. (2016). Solomon Strait and St. George's Channel transport are estimated based on total transit through the two outflow straits. The combined error from the transport estimate and the analytical error (1 SD) of the average concentration. 


\begin{tabular}{lccccc}
\hline Station & $\begin{array}{c}\text { Transport } \\
(\mathrm{Sv})\end{array}$ & $\begin{array}{c}\mathrm{DAl} \\
(\mathrm{mol} / \mathrm{s})\end{array}$ & $\begin{array}{c}\text { TDAl } \\
(\mathrm{mol} / \mathrm{s})\end{array}$ & $\begin{array}{c}\mathrm{DMn} \\
(\mathrm{mol} / \mathrm{s})\end{array}$ & $\begin{array}{c}\text { TDMn } \\
(\mathrm{mol} / \mathrm{s})\end{array}$ \\
\hline $\begin{array}{l}\text { Inflow } \\
\begin{array}{l}\text { Vitiaz Strait } \\
\text { (station 77) }\end{array}\end{array}$ & $9.3 \pm 1.4$ & $69.6 \pm 12.1$ & $68.6 \pm 12.0$ & $2.76 \pm 0.78$ & $4.51 \pm 0.96$ \\
$\begin{array}{l}\text { Solomon Strait } \\
\text { (station 42) }\end{array}$ & $4.6 \pm 0.2$ & $37.3 \pm 4.0$ & $53.0 \pm 4.2$ & $2.33 \pm 0.20$ & $4.05 \pm 0.37$ \\
$\begin{array}{l}\text { St. George's Channel } \\
\text { (station 60) }\end{array}$ & $1.9 \pm 1.2$ & $17.7 \pm 11.6$ & $24.5 \pm 15.5$ & $0.87 \pm 0.56$ & $1.54 \pm 0.98$ \\
Total Outflow & $8.4 \pm 2.6$ & $66.61 \pm 22.7$ & $96.3 \pm 31.7$ & $4.01 \pm 1.27$ & $6.99 \pm 2.24$
\end{tabular}

585

586

\subsection{Constraining the Solomon Sea Flux to the EUC}

588 The EUC is largely composed of water originating from the NGCU/thermocline waters (24-26.9

$589 \sigma_{\theta}$ ), and so we can compare the flux of trace metals out of the Solomon Sea (Table 3 ) in this

590 layer to the flux of trace metals in the EUC over the same density interval by using average DAl,

591 TDAl, DMn, and TDMn concentrations from the EUC collected at $0^{\circ}, 156^{\circ} \mathrm{E}$ by Slemons et al.

592 (2010; Station 22). At this longitude, water exiting the Solomon Sea would have been entrained

593 in the EUC. These measurements were collected six years before the PANDORA cruise, but

594 during the same season, and in a similar ENSO phase. The implicit assumption in the

595 comparison of flux out of the Solomon Sea and the flux into the EUC is that everything leaving

596 the Solomon Sea at that depth range enters the EUC, as shown in Fig. 6. This is clearly not the

597 case, but this assumption establishes an upper bound for trace metals contributed from the

598 Solomon Sea to the EUC. For flux estimates several additional assumptions are made: the

599 Solomon Sea is in steady state and not temporally variable; stations in the straits are

600 representative of water leaving the Solomon Sea; and that the two profiles used for inflow waters 28 
601 are, on average, representative water entering the Solomon Sea. The trace metal fluxes of the

602 Solomon Sea Inflow, Outflow, and flux at the EUC are shown in Table 5.

Table 5. Average metal fluxes into and out of the Solomon Sea at $24-26.9 \sigma_{\theta}$ compared to metal fluxes in the EUC $156^{\circ} \mathrm{E}$. This assumes that transport in and out of the Solomon Sea is $22.8 \mathrm{~Sv} \pm 1.0 \mathrm{~Sv}$. Errors are calculated using uncertainty reported on transport estimates (1SD) by Germineaud et al. (2016) and analytical error of the concentration data (1SD)

\begin{tabular}{lllll}
\hline & DAl & TDAl & DMn & TDMn \\
\hline Inflow $\left(\mathrm{mol} \mathrm{s}^{-1}\right)$ & $136 \pm 19$ & $147 \pm 35$ & $6.1 \pm 0.5$ & $9.1 \pm 0.6$ \\
Outflow $\left(\mathrm{mol} \mathrm{s}^{-1}\right)$ & $190 \pm 19$ & $217 \pm 16$ & $6.1 \pm 0.6$ & $10.8 \pm 1.0$ \\
In EUC $\left(\mathrm{mol} \mathrm{s}^{-1}\right)$ & $160 \pm 9$ & $177 \pm 10$ & $7.8 \pm 0.4$ & $17 \pm 0.9$ \\
\hline
\end{tabular}

603

\subsubsection{Sources of water to the EUC}

605 It is important to note that the EUC does not receive its water solely from the Solomon Sea, and

606 the breakdown of how much water comes from the Solomon Sea versus from other Southern and

607 Northern Hemisphere sources is still unclear. Hydrographic parameters measured during the

608 Western Equatorial Pacific Ocean Study (WEPOCS, 1985/1986) (e.g., Lindstrom et al., 1987;

609 Tsuchiya et al., 1989) show the EUC was fed predominantly by water from the Southern

610 Hemisphere with $\sim 2 / 3$ from southern low latitude western boundary currents, including the

611 NGCU (Tsuchiya et al., 1989) and $\sim 1 / 4$ of the water originating in the Northern Hemisphere

612 (Lindstrom et al., 1987; Tsuchiya et al., 1989). However, this study also observed a seasonally

613 variable NGCU, including one season in which it flowed at the same rate as the EUC. Since then,

614 other studies have investigated the relative importance of water from northern and southern

615 sources and have come to differing conclusions about the proportion of water from the north and

616 south. Grenier et al. (2011) estimate about $58 \%$ of the water in the EUC at $156^{\circ} \mathrm{W}$ passed

617 through the Solomon Sea, and about 33\% comes from the Mindanao Current in the north, with 
618 the remainder coming from other sources south of the EUC. A modeling study by Izumo et al.

619 (2002) indicates roughly equal contributions from the Northern and Southern Hemispheres,

620 while other studies suggest the dominance of a southern source (Liu and Huang, 1998). Most

621 recently, biogeochemical tracer data indicate that the nutrients in the EUC are primarily derived

622 from Southern Hemisphere water: based on isotopic tracers $\left({ }^{15} \mathrm{~N}\right.$ and ${ }^{18} \mathrm{O}$ measured in nitrate) and

623 oxygen measurements combined with the nutrient data (silicic acid and nitrate), the fraction of

624 water in the EUC derived from the Mindanao Current (in the Northern Hemisphere) is estimated

625 to be much smaller than that from the Southern Hemisphere (Lehmann et al., 2018).

626 The relative contributions of trace metals from the Solomon Sea to the EUC trace metal pool can 627 then be estimated for the different estimates of northern versus southern water contribution to the 628 EUC (Table 6). Averaging these estimates, our data suggest that about $70 \%$ of the DAl, $80 \%$ of 629 the TDAl, $50 \%$ of DMn, and $40 \%$ of the TDMn in the EUC must come from waters exiting the 630 Solomon Sea. It is also important to note that there is seasonal variability in these estimates, and 631 that as the EUC flows east, it entrains additional water, and the relative importance of the waters 632 originally feeding the EUC diminishes during its eastward transit (Qin et al., 2015). Our results 633 indicate that the Solomon Sea can supply a majority of the required Al to the EUC. However, 634 relative to $\mathrm{Al}$, there is proportionally less $\mathrm{Mn}$ in the EUC coming from the Solomon Sea, 635 suggesting other sources to the EUC must be more enriched in Mn and have higher Mn/Al ratio.

636 Because there are other sources of water to the EUC, there are other potential sources of trace 637 metals to the EUC that are not accounted for with these Solomon Sea data. Waters exiting the 638 Solomon Sea through the Vitiaz Strait pass along the PNG coast/shelf and through the Bismark 639 Sea. However Mn data collected at stations just beyond the Vitiaz Strait along the PNG coast by 640 Slemons et al. (2010) are remarkably consistent with Mn concentrations reported here. By 641 comparison $\mathrm{Al}$ concentrations along the coast vary greatly, especially in the surface, but are 642 generally lower by $\sim 2-5 \mathrm{nM}$ (and in the surface up to $35 \mathrm{nM}$ ) compared to the data for the 643 Solomon Sea reported here. These findings indicate that the PNG coastline does not provide the 30 
644 missing Mn and may be a sink for Al. This is consistent with the findings of Mackey et al.

645 (2002a) who show that while concentrations of Fe and Mn are high off the coast of PNG

646 especially near the outflow of the Sepik River, this riverine source of Mn and Fe to the Bismarck

647 Sea is insufficient to produce the concentrations of these elements observed in the EUC. Just

648 beyond the Solomon Strait, enrichments observed for Rare Earth Elements indicate hydrothermal

649 and/or lithogenic inputs to the waters along the flow path of the NICU (Behrens et al., 2020)

650 between the Solomon Sea and EUC, however there are no Al and Mn data in this region and

651 thus, while we might anticipate inputs of Al and Mn to the NICU, conclusions about their inputs

652 to the NICU are not possible. As noted above, the EUC is derived from waters originating both

653 from the south and north of the equator and the balance of $\mathrm{Al}$ and $\mathrm{Mn}$ required to balance the

654 trace metal budget of the EUC may have their source there.

Table 6. Contribution of the Solomon Sea contribution to EUC trace metal pool based on variations in source waters. The flux of each trace metal out of the Solomon Sea is multiplied by the percentage of water contributed by the Solomon Sea to the EUC at $156^{\circ} \mathrm{E}$ based on different studies.

$\begin{array}{ccll}\text { Reference } & \begin{array}{c}\% \text { of EUC } \\ \text { derived from }\end{array} & \begin{array}{l}\text { Method of } \\ \text { Estimate }\end{array} & \begin{array}{l}\% \text { trace metals contributed to EUC } \\ \text { based on magnitude of source }\end{array}\end{array}$

Southern

\begin{tabular}{lclllll} 
& Hemisphere & & DAl & TDAl & DMn & TDMn \\
\hline & $100 \%$ & Upper Bound & 119 & 123 & 79 & 64 \\
\hline $\begin{array}{l}\text { Grenier et al., } \\
2011^{1}\end{array}$ & $59 \%$ & Model & 70 & 72 & 47 & 38 \\
\hline $\begin{array}{l}\text { Tsuchiya et al., } \\
1989\end{array}$ & $67 \%$ & WEPOCS & 80 & 82 & 53 & 43 \\
\hline $\begin{array}{l}\text { Izumo et al., 2002 } \\
\text { Lehman et al., }\end{array}$ & $52 \%$ & Model & 62 & 64 & 41 & 33 \\
\hline $\begin{array}{l}2018^{2} \\
\text { Qin et al., 2015 }\end{array}$ & $670 \%$ & O2, Si, N isotopes & 83 & 86 & 55 & 45 \\
\hline Average & $63 \%$ & Model & 75 & 77 & 50 & 40 \\
\hline
\end{tabular}

\footnotetext{
${ }^{1}$ Fluxes are contribution from Solomon Sea, specifically, ${ }^{2}$ Looks at upper and lower EUC, $340 \%$ Solomon Strait, $23 \%$ Vitiaz Strait at $165^{\circ} \mathrm{E}$
} 


\section{Conclusions}

657 Our data show that water exiting the Solomon Sea is important in supplying aluminum, and to a 658 lesser degree, manganese, to the Equatorial Undercurrent. However, from a net budget

659 perspective, the amount of $\mathrm{Al}$ and $\mathrm{Mn}$ enrichment that occurs within the basin is small, relative

660 to the inflow concentrations, indicating that most of the $\mathrm{Al}$ and $\mathrm{Mn}$ was acquired prior to 661 reaching the Solomon Sea or that inputs are approximately balanced by scavenging within the

662 basin. This is also true for deeper water in the Solomon Sea. The trace metal pool in the surface 663 layer does appear to be enriched relative to inflowing waters, but because of large seasonal 664 variability and disparities in water transport between entrance and exit, more studies are needed 665 to conclude this definitively.

666 Our work is consistent with previous studies and supports the idea that boundary exchange 667 through sediment resuspension, non-reductive release of dissolved species from suspended 668 particles, and scavenging onto these suspended particles are the dominant processes providing 669 additional metals to the Solomon Sea (e.g., Lacan and Jeandel, 2005; Grenier et al., 2013; 670 Labatut et al., 2014; Jeandel, 2016). These highly localized input processes indicate that a higher

671 resolution study is required to better understand these boundary processes, and in particular, their 672 potential to impact larger-scale cycling.

673 The importance of the Solomon Sea as a source of trace nutrients to the EUC is heavily

674 influenced by the proportion of water in the EUC that is derived from the Southern Hemisphere. 675 Improving our estimates of the EUC water mass breakdown from important regions of input in 676 the Northern Hemisphere (e.g., North Equatorial Current, Mindanao Current) will be valuable in 677 better constraining these fluxes. Higher sampling resolution (spatial and temporal) within the 678 region, including within the EUC, at potential source regions south of the Solomon Sea 679 (including near Vanuatu, and in the Coral Sea), and from the SEC will be important in 680 constraining the impact of the waters passing through the Solomon Sea on the chemistry of the 32 
681 EUC. This increased resolution would allow for a more thorough understanding of trace metal 682 and nutrient dynamics in the western Pacific and their impact on the HNLC eastern equatorial 683 Pacific.

\section{Acknowledgements}

685 M. Grand, M. Labatut and F. Quéroué are thanked for their hard work with trace element 686 sampling. Thanks to the crew of the R/V l'Atalante and Chief Scientist G. Eldin, for technical 687 assistance, and expertise during the PANDORA Cruise. W. Kessler provided helpful discussion 688 about the circulation of the Solomon Sea. Most geochemical graphics were created using ODV 689 (Schlitzer, R., Ocean Data View, http://odv.awi.de, 2015).

$690 \quad$ Funding

691 This publication is partially funded by the Joint Institute for the Study of the Atmosphere and 692 Ocean (JISAO) under NOAA Cooperative Agreement NA15OAR4320063, Contribution No. 693 2018-0188, and PMEL Contribution No. 4904. JAR, NB, SM were funded by US NSF award 694 OCE-1237011 and OCE-0649505. The PANDORA cruise was co-funded by NSF grant 695 OCE1029487, and by ANR project ANR- 09-BLAN-0233-01 and INSU/LEFE project Solwara 696 (IDAO and CYBER).

697 
699 Alberty, M., Sprintall, J., MacKinnon, J., Germineaud, C., Cravatte, S., Ganachaud, A., 2019.

700 Moored Observations of Transport in the Solomon Sea. J. Geophys. Res. Ocean. 124, 8166-

701 8192. https://doi.org/10.1029/2019JC015143

702 Alongi, D.M., Boyle, S.G., Tirendi, F., Payn, C., 1996. Composition and behaviour of trace

703 metals in post-oxic sediments of the Gulf of Papua, Papua New Guinea. Estuar. Coast. Shelf Sci.

704 42, 197-211. https://doi.org/10.1006/ecss.1996.0015

705 Baker, E.T., Massoth, G.J., de Ronde, C.E.J., Lupton, J.E., Mclnnes, B.I.A., 2002. Observations

706 and sampling of an ongoing subsurface eruption of Kavachi volcano, Solomon Islands, May

707 2000. Geology 30, 975-978. https://doi.org/10.1130/0091-

708 7613(2002)030<0975:OASOAO $>2.0 . \mathrm{CO} ; 2$

709 Behrens, M.K., Pahnke, K., Delpech, A., Cravatte, S., Marin, F., Jeandel, C., 2020. Trace

710 element sources and fluxes in the zonal current system of the western tropical Pacific Ocean:

711 Evidence from combined rare earth element, $\mathrm{Nd}$ isotope distributions and physical observations.

712 Ocean Sciences Meeting, San Diego, CA.

713 Brown, M.T., Bruland, K.W., 2008. An improved flow-injection analysis method for the

714 determination of dissolved aluminum in seawater. Limnol. Oceanogr. Methods 6, 87-95.

715 https://doi.org/10.4319/lom.2008.6.87

716 Buck, C.S., Landing, W.M., Resing, J.A., 2013. Pacific Ocean aerosols: Deposition and

717 solubility of iron, aluminum, and other trace elements. Mar. Chem. 157, 117-130.

718 https://doi.org/10.1016/j.marchem.2013.09.005 
719 Buck, C.S., Landing, W.M., Resing, J.A., Lebon, G.T., 2006. Aerosol iron and aluminum

720 solubility in the northwest Pacific Ocean: Results from the 2002 IOC cruise. Geochem. Geophys.

721 Geosyst. 7, 1-21. https://doi.org/10.1029/2005GC000977

722 Butt, J., Lindstrom, E.J., 1994. Currents off the east coast of New Ireland, Papua New Guinea, 723 and their relevance to regional undercurrents in the western equatorial Pacific Ocean. J.

724 Geophys. Res. 99, 12503-12514. https://doi.org/10.1029/94JC00399

725 Coale, K.H., Fitzwater, S.E., Gordon, R.M., Johnson, K.S., Barber, R.T., 1996. Control of 726 community growth and export production by upwelled iron in the equatorial Pacific Ocean.

727 Nature 379, 621-624. https://doi.org/10.1038/379621a0

728 Cravatte, S., Ganachaud, A., Duong, Q.P., Kessler, W.S., Eldin, G., Dutrieux, P., 2011. Observed 729 circulation in the Solomon Sea from SADCP data. Prog. Oceanogr. 88, 116-130.

730 https://doi.org/10.1016/j.pocean.2010.12.015

731 Cresswell, G.R., 2000. Coastal currents of northern Papua New Guinea, and the Sepik River 732 outflow. Mar. Freshw. Res. 51, 553-564. https://doi.org/10.1071/MF99135

733 de Boyer Montégut, C., Madec, G., Fischer, A.S., Lazar, A., Iudicone, D., 2004. Mixed layer 734 depth over the global ocean: An examination of profile data and a profile-based climatology. J. 735 Geophys. Res. 109, C12003. https://doi.org/10.1029/2004JC002378

736 Delcroix, T., Radenac, M.-H., Cravatte, S., Alory, G., Gourdeau, L., Leger, F., Singh, A., 737 Varillon, D., 2014. Sea surface temperature and salinity seasonal changes in the western 738 Solomon and Bismarck Seas. J. Geophys. Res. Oceans 119, 2642-2657.

739 https://doi.org/10.1002/2013JC009733 
740 Ganachaud, A., Cravatte, S., Sprintall, J., Germineaud, C., Alberty, M.S., Jeandel, C., Eldin, G.,

741 Metzl, N., Bonnet, S., Benavides, M., Heimburger, L.-E., Lefèvre, J., Michael, S., Resing, J.A.,

742 Quéroué, F., Sarthou, G., Rodier, M., Berthelot, H., Baurand, F., Grelet, J., Hasegawa, T.,

743 Kessler, W., Kilepak, M., Lacan, F., Privat, E., Send, U., Van Beek, P., Souhaut, M., Sonke, J.E.,

744 2017. The Solomon Sea: its circulation, chemistry, geochemistry and biology explored during

745 two oceanographic cruises. Elem. Sci. Anth. 5, 33. https://doi.org/10.1525/elementa.221

746 Gasparin, F., Ganachaud, A., Maes, C., Marin, F., Eldin, G., 2012. Oceanic transports through

747 the Solomon Sea: The bend of the New Guinea Coastal Undercurrent. Geophys. Res. Lett. 39, 1-

748 6. https://doi.org/10.1029/2012GL052575

749 Germineaud, C., Ganachaud, A., Sprintall, J., Cravatte, S., Eldin, G., Alberty, M.S., Privat, E.,

750 2016. Pathways and water mass properties of the thermocline and intermediate waters in the

751 Solomon Sea. J. Phys. Oceanogr. 46, 3031-3049. https://doi.org/10.1175/JPO-D-16-0107.1

752 Gordon, R.M., Coale, K.H., Johnson, K.K.S., 1997. Iron distributions in the equatorial Pacific:

753 Implications for new production. Limnol. Oceanogr. 42, 419-431.

754 https://doi.org/10.4319/1o.1997.42.3.0419

755 Grenier, M., Cravatte, S., Blanke, B., Menkes, C., Koch-Larrouy, A., Durand, F., Melet, A., 756 Jeandel, C., 2011. From the western boundary currents to the Pacific Equatorial Undercurrent:

757 Modeled pathways and water mass evolutions. J. Geophys. Res. Oceans 116, C12044.

758 https://doi.org/10.1029/2011JC007477

759 Grenier, M., Jeandel, C., Lacan, F., 2013. From the subtropics to the central equatorial Pacific

760 Ocean: Neodymium isotopic composition and rare earth element concentration variations. J.

761 Geophys. Res. Oceans 118, 592-618. https://doi.org/10.1029/2012JC8239 
762 Harris, P.T., Baker, E.K., Cole, A.R., Short, S.A., 1993. A preliminary study of sedimentation in

763 the tidally dominated Fly River Delta, Gulf of Papua. Cont. Shelf Res. 13, 441-472.

764 https://doi.org/10.1016/0278-4343(93)90060-B

765 Hettler, J., Irion, G., Lehmann, B., 1997. Environmental impact of mining waste disposal on a 766 tropical lowland river system: A case study on the Ok Tedi Mine, Papua New Guinea. Miner. 767 Depos. 32, 280-291. https://doi.org/10.1007/s001260050093

768 Hristova, H.G., Kessler, W.S., 2012. Surface circulation in the Solomon Sea derived from 769 Lagrangian drifter observations. J. Phys. Oceanogr. 42, 448-458. https://doi.org/10.1175/JPO-D$770 \quad 11-099.1$

771 Izumo, T., Picaut, J., Blanke, B., 2002. Tropical pathways, equatorial undercurrent variability 772 and the 1998 La Niña. Geophys. Res. Lett. 29, 2080. https://doi.org/10.1029/2002GL015073

773 Jankowski, P., 2011. Independent Technical Assessment of Sea Floor Massive Sulphide

774 Exploration Tenements in Papua New Guinea, Fiji and Tonga. SRk Consult.Jeandel, C., 2016.

775 Overview of the mechanisms that could explain the 'Boundary Exchange' at the land-ocean

776 contact. Philos. Trans. R. Soc. A 374, 20150287. https://doi.org/10.1098/rsta.2015.0287

777 Jeandel, C., 2016. Overview of the mechanisms that could explain the 'Boundary Exchange' at 778 the land-ocean contact. Philos. Trans. R. Soc. A Math. Phys. Eng. Sci. 374, 20150287.

779 https://doi.org/10.1098/rsta.2015.0287

780 Kaupp, L.J., Measures, C.I., Selph, K.E., Mackenzie, F.T., 2011. The distribution of dissolved Fe 781 and $\mathrm{Al}$ in the upper waters of the eastern equatorial Pacific. Deep-Sea Res. Part II Top. Stud.

782 Oceanogr. 58, 296-310. https://doi.org/10.1016/j.dsr2.2010.08.009 
783 Kessler, W.S., Cravatte, S., 2013. Mean circulation of the Coral Sea. J. Geophys. Res. Ocean. 784 118, 6385-6410. https://doi.org/10.1002/2013JC009117

785 Kessler, W.S., H.G. Hristova and R.E. Davis, 2019. Equatorward western boundary transport 786 from the South Pacific: Glider observations, dynamics, and consequences. Prog. Oceanogr., 175 787 (2019) 208-225. https://doi.org/10.1016/j.pocean.2019.04.005

788 Kineke, G.C., Woolfe, K.J., Kuehl, S.A., Milliman, J.D., Dellapenna, T.M., Purdon, R.G., 2000. 789 Sediment export from the Sepik River, Papua New Guinea: Evidence for a divergent sediment 790 plume. Cont. Shelf Res. 20, 2239-2266. https://doi.org/10.1016/S0278-4343(00)00069-8

791 Labatut, M., Lacan, F., Pradoux, C., Chmeleff, J., Radic, A., Murray, J.W., Poitrasson, F., 792 Johansen, A.M., Thil, F., 2014. Iron sources and dissolved-particulate interactions in the 793 seawater of the western equatorial Pacific, iron isotope perspectives. Global Biogeochem. Cycles 794 28, 1044-1065. https://doi.org/10.1002/2014GB004928

795 Lacan, F., Jeandel, C., 2001. Tracing Papua New Guinea imprint on the central Equatorial 796 Pacific Ocean using neodymium isotopic compositions and Rare Earth Element patterns. Earth 797 Planet. Sci. Lett. 186, 497-512. https://doi.org/10.1016/S0012-821X(01)00263-1

798 Lacan, F., Jeandel, C., 2005. Neodymium isotopes as a new tool for quantifying exchange fluxes 799 at the continent-ocean interface. Earth Planet. Sci. Lett. 232, 245-257.

800 https://doi.org/10.1016/j.eps1.2005.01.004

801 Laurila, T.E., Petersen, S., Devey, C.W., Baker, E.T., Augustin, N., Hannington, M.D., 2012.

802 Tectonic and magmatic controls on hydrothermal activity in the Woodlark Basin. Geochemistry, 803 Geophys. Geosystems 13, 1-13. https://doi.org/10.1029/2012GC004247 
804 Lehmann, N., Granger, J., Kienast, M., Brown, K.S., Rafter, P.A., Martínez-Méndez, G.,

805 Mohtadi, M., 2018. Isotopic evidence for the evolution of subsurface nitrate in the western

806 equatorial Pacific. J. Geophys. Res. Oceans 123, 1684-1707.

807 https://doi.org/10.1002/2017JC013527

808 Lindstrom, E.J., Lukas, R., Fine, R.A., Firing, E., Godfrey, S., Meyers, G., Tsuchiya, M., 1987.

809 The western equatorial Pacific Ocean circulation study. Nature 330, 533-537.

810 https://doi.org/10.1038/330533a0

811 Liu, Z., Huang, B., 1998. Why is there a tritium maximum in the central equatorial Pacific

812 thermocline? J. Phys. Oceanogr. 28, 1527-1533. https://doi.org/ 10.1175/1520-

$8130485(1998) 028<1527:$ WITATM $>2.0 . C O ; 2$

814 Mackey, D.J., O’Sullivan, J., Watson, R.J., 2002a. Iron in the western Pacific: a riverine or

815 hydrothermal source for iron in the Equatorial Undercurrent? Deep-Sea Res. Part I-Oceanogr.

816 Res. Pap. 49, 877-893. https://doi.org/10.1016/S0967-0637(01)00075-9

817 Mackey, D.J., O’Sullivan, J.E., Watson, R.J., Dal Pont, G., 2002b. Trace metals in the Western

818 Pacific: temporal and spatial variability in the concentrations of $\mathrm{Cd}, \mathrm{Cu}, \mathrm{Mn}$ and Ni. Deep-Sea

819 Res. Part I-Oceanogr. Res. Pap. 49, 2241-2259. https://doi.org/10.1016/S0967-0637(02)00124-3

820 Martin, J.H., Knauer, G.A., Karl, D.M., Broenkow, W.W., 1987. VERTEX: carbon cycling in

821 the northeast Pacific. Deep-Sea Res. Part A, Oceanogr. Res. Pap. 34, 267-285.

822 https://doi.org/10.1016/0198-0149(87)90086-0

823 McConachy, T., Binns, R., Arculus, R.J., 2002. Submarine hydrothermal activity and volcanic 824 petrogenesis associated with the birth of island arcs in the Solomon Islands (SOLA VENTS - 
825 2002). Cruise Report of RV Franklin, Commonwealth Scientific and Industrial Research 826 Organisation, Australia.

827 Measures, C.I., Brown, E.T., 1996. Estimating dust input to the Atlantic Ocean using surface 828 water aluminium concentrations, in: Guerzoni, S., Chester, R. (Eds.), The Impact of Desert Dust 829 across the Mediterranean. Springer, Dordrecht, pp. 301-311. https://doi.org/10.1007/978-94-017830 3354-0_30

831 Melet, A., Gourdeau, L., Kessler, W.S., Verron, J., Molines, J.-M., 2010. Thermocline 832 circulation in the Solomon Sea: A modeling study. J. Phys. Oceanogr. 40, 1302-1319. 833 https://doi.org/10.1175/2009JPO4264.1

834 Melet, A., Gourdeau, L., Verron, J., Djath, B., 2013. Solomon Sea circulation and water mass 835 modifications: Response at ENSO timescales. Ocean Dyn. 63, 1-19.

836 https://doi.org/10.1007/s10236-012-0582-0

837 Melet, A., Verron, J., Gourdeau, L., Koch-Larrouy, A., 2011. Equatorward Pathways of Solomon 838 Sea Water Masses and Their Modifications. J. Phys. Oceanogr. 810-826.

839 https://doi.org/10.1175/2010JPO4559.1

840 Milliman, J.D., Farnsworth, K.L., Albertin, C.S., 1999. Flux and fate of fluvial sediments leaving 841 large islands in the East Indies. J. Sea Res. 41, 97-107. https://doi.org/10.1016/S1385842 1101(98)00040-9

843 Moran, S.B., Moore, R.M., 1991. The potential source of dissolved aluminum from resuspended 844 sediments to the North Atlantic Deep Water. Geochim. Cosmochim. Acta 55, 2745-2751. 845 https://doi.org/10.1016/0016-7037(91)90441-7 
846 Murray, J.W., Johnson, E., Garside, C., 1995. A U.S. JGOFS process study in the equatorial

847 Pacific (EqPac): Introduction. Deep. Res. Part II 42, 275-293. https://doi.org/10.1016/0967-

848 0645(95)00044-Q

849 Obata, H., Shitashima, K., Isshiki, K., Nakayama, E., 2008. Iron, manganese and aluminum in

850 upper waters of the western South Pacific Ocean and its adjacent seas. J. Oceanogr. 64, $233-245$.

851 https://doi.org/10.1007/s10872-008-0018-0

852 Pham, V.Q., Grenier, M., Cravatte, S., Michael, S., Jacquet, S., Belhadj, M., Nachez, Y., 853 Germineaud, C., Jeandel, C., 2019. Dissolved rare earth elements distribution in the Solomon 854 Sea. Chem. Geol. 524, 11-36. https://doi.org/10.1016/j.chemgeo.2019.05.012

855 Phillips, B., Dunbabin, M., Henning, B., Howell, C., Deciccio, A., Flinders, A., Kelley, K.A., 856 Scott, J.J., Albert, S., Carey, S., Tsadok, R., 2016. Exploring the "Sharkcano": Biogeochemical 857 observations of the Kavachi submarine volcano (Solomon Islands). Oceanography 24, 160-169. 858 https://doi.org/10.5670/oceanog.2016.85

859 Pichler, T., Veizer, J., Hall, G.E.M., 1999. The chemical composition of shallow-water 860 hydrothermal fluids in Tutum Bay, Ambitle Island, Papua New Guinea and their effect on 861 ambient seawater. Mar. Chem. 64, 229-252. https://doi.org/10.1016/S0304-4203(98)00076-0

862 Qin, X., Sen Gupta, A., Van Sebille, E., 2015. Variability in the origins and pathways of Pacific 863 Equatorial Undercurrent water. J. Geophys. Res. Oceans 120, 3113-3128.

864 https://doi.org/10.1002/2014JC010549 
865 Resing, J.A., Measures, C.I., 1994. Fluorometric determination of Al in seawater by flow 866 injection analysis with in-line preconcentration. Anal. Chem. 66, 4105-4111.

867 https://doi.org/10.1021/ac00094a039

868 Resing, J.A., Mottl, M., 1992. Determination of manganese in seawater using flow injection 869 analysis with on-line preconcentration and spectrophotometric detection. Anal. Chem. 64, 2682870 2687. https://doi.org/10.1021/ac00046a006

871 Resing, J.A., Sedwick, P.N., German, C.R., Jenkins, W.J., Moffett, J.W., Sohst, B.M., Tagliabue, 872 A., 2015. Basin-scale transport of hydrothermal dissolved metals across the South Pacific Ocean. 873 Nature 523, 200-203. https://doi.org/10.1038/nature14577

874 Ryan, J.P., Ueki, I., Chao, Y., Zhang, H., Polito, P.S., Chavez, F.P., 2006. Western Pacific 875 modulation of large phytoplankton blooms in the central and eastern equatorial Pacific. J. 876 Geophys. Res. Biogeosciences 111, 1-14. https://doi.org/10.1029/2005JG000084

877 Salomons, W., Eagle, A.M., 1990. Hydrology, sedimentology and the fate and distribution of 878 copper in mine-related discharges in the fly river system, Papua New Guinea. Sci. Total Environ. 879 97-98, 315-334. https://doi.org/10.1016/0048-9697(90)90248-S

880 Shank, L.M., Johansen, A.M., 2008. Atmospheric trace metal and labile iron deposition fluxes to 881 the equatorial Pacific during EUCFe2006, Ocean Sciences Meeting, Orlando, Fla, USA.

882 Sholkovitz, E.R., Elderfield, H., Szymczak, R., Casey, K., 1999. Island weathering: River 883 sources of rare earth elements to the Western Pacific Ocean. Mar. Chem. 68, 39-57.

884 https://doi.org/10.1016/S0304-4203(99)00064-X 
885 Singh, N.D., Chinni, V., Singh, S.K., 2020. Dissolved aluminium cycling in the northern, 886 equatorial and subtropical gyre region of the Indian Ocean. Geochim. Cosmochim. Acta 268, 887 160-185. https://doi.org/10.1016/j.gca.2019.09.028

888 Slemons, L.O., Gorgues, T., Aumont, O., Menkes, C., Murray, J.W., 2009. Biogeochemical 889 impact of a model western iron source in the Pacific Equatorial Undercurrent. Deep-Sea Res. 890 Part I Oceanogr. Res. Pap. 56, 2115-2128. https://doi.org/10.1016/j.dsr.2009.08.005

891 Slemons, L.O., Murray, J.W., Resing, J.A., Paul, B., Dutrieux, P., 2010. Western Pacific coastal 892 sources of iron, manganese, and aluminum to the Equatorial Undercurrent. Global Biogeochem. 893 Cycles 24, GB3024. https://doi.org/10.1029/2009GB003693

894 Slemons, L.O., Paul, B., Resing, J.A., Murray, J.W., 2012. Particulate iron, aluminum, and 895 manganese in the Pacific equatorial undercurrent and low latitude western boundary current 896 sources. Mar. Chem. 142-144, 54-67. https://doi.org/10.1016/j.marchem.2012.08.003

897 Sokolov, S., Rintoul, S., 2000. Circulation and water masses of the southwest Pacific: WOCE 898 Section P11, Papua New Guinea to Tasmania. J. Mar. Res. 58, 223-268.

899 https://doi.org/10.1357/002224000321511151

900 Taylor, S.R., 1964. Abundance of chemical elements in the continental crust: a new table.

901 Geochim. Cosmochim. Acta 28, 1273-1285. https://doi.org/10.1016/0016-7037(64)90129-2

902 Tsuchiya, M., Lukas, R., Fine, R.A., Firing, E., Lindstrom, E.J., 1989. Source waters of the 903 Pacific Equatorial Undercurrent. Prog. Oceanogr. 23, 101-147. https://doi.org/10.1016/0079$904 \quad 6611(89) 90012-8$ 
906 Fig. 1. a) Sub-surface currents [dark blue; after Germineaud et al. (2016)], rivers (blue text), 907 straits (purple text) and potential point sources (yellow) to the Solomon Sea. These currents are:

908 Equatorial Undercurrent (EUC); South Equatorial Current (SEC); New Guinea Coastal

909 Undercurrent (NGCU); New Ireland Coastal Undercurrent (NICU); Saint George's Undercurrent

910 (SGU); North Queensland Current (NQC); New Caledonia Jet (NCJ); North Vanuatu Jet (NVJ);

911 East Australian Current (EAC)

912 Red dots and numbers represent stations sampled for Al and Mn. Orange dot shows the 913 location of station 22 from Slemons et al. (2010). b) Bathymetry of the Woodlark 914 Basin and Trobriand Islands.

915 Fig. 2. Dissolved Al (DAl) profiles versus potential density from the PANDORA cruise. Light 916 blue circles show measured DAl concentrations. Orange line represents average inflow DAl 917 profile, while grey shading represents the bounds of the average profile. Green box represents the 918 density interval over which budget of the thermocline waters is calculated. (a-c) waters that are

919 located south of the Solomon Sea; $(\mathbf{d}-\mathbf{f})$ profiles found along the NGCU; $(\mathbf{g}-\mathbf{i})$ profiles that are at 920 the exit straits of the Solomon Sea; $(\mathbf{j}-\mathbf{l})$ located outside the Solomon Sea.

921 Fig. 3. Total Dissolvable Al (TDAl) profiles versus potential density from the PANDORA 922 cruise. Dark blue circles show measured TDAl concentrations. Orange line represents average 923 inflow TDAl profile, while grey shading represents the range of inflow concentrations. Green 924 box represents the density interval over which budget of the thermocline waters is calculated. (a925 c) waters that are located south of the Solomon Sea; (d-f) profiles found along the NGCU; (g-i) 926 profiles that are at the exit straits of the Solomon Sea; $(\mathbf{j}-\mathbf{l})$ located outside the Solomon Sea. 
927 Fig. 4. Dissolved Mn (DMn) profiles versus potential density from the PANDORA cruise. Pink 928 diamonds show measured DMn concentrations. Orange line represents average inflow DMn 929 profile, while grey shading represents the range of inflow concentrations. Green box represents 930 the density interval over which budget of the thermocline waters is calculated. (a-c) waters that 931 are located south of the Solomon Sea; $(\mathbf{d}-\mathbf{f})$ profiles found along the NGCU; (g-i) profiles that 932 are at the exit straits of the Solomon Sea; $(\mathbf{j}-\mathbf{l})$ located outside the Solomon Sea.

933 Fig. 5 Total Dissolvable Mn (TDMn) profiles versus potential density from the PANDORA 934 cruise. Red diamonds show measured TDMn concentrations. Orange line represents average 935 inflow TDMn profile, while grey shading represents the range of inflow concentrations. Green 936 box represents the density interval over which the mass balance is calculated. (a-c) waters that 937 are located south of the Solomon Sea; $(\mathbf{d}-\mathbf{f})$ profiles found along the NGCU; $(\mathbf{g}-\mathbf{- i})$ profiles that 938 are at the exit straits of the Solomon Sea; $(\mathbf{j}-\mathbf{l})$ located outside the Solomon Sea.

939 Fig. 6. Budget for thermocline waters (24-26.9 $\left.\sigma_{\theta}\right)$, showing the flux of DAl, TDA1, DMn, 940 TDMn at the inflow, the outflow via currents (NGCU, NICU, and SGU), and the flux out of the

941 EUC at $156^{\circ} \mathrm{E}$, as well as the average concentration of the Solomon Sea, calculated from stations 942 most representative of the Solomon Sea. Red dots represent stations used to calculate 943 concentrations at each exit strait over the potential density range of the EUC

945 Supplemental Fig. 1. Implied labile particle concentrations of aluminum (PAl) and manganese 946 (PMn). Where values are not reported, the dissolved (D) concentration exceeded the total 947 dissolvable (TD) concentration, but within the standard deviation of the measurement. $\mathrm{P}=\mathrm{TD}$ 948 D. 
949 Supplemental Fig. 2. Dissolved Al (DAl) profiles versus potential density from the PANDORA

950 cruise. Light blue circles show measured DAl concentrations. Orange line represents average

951 inflow DAl profile, while grey shading represents the range of inflow concentrations. Green box

952 represents the density interval over which budget of the thermocline waters is calculated. (a-c)

953 waters that are located south of the Solomon Sea; $(\mathbf{d}-\mathbf{f})$ profiles found along the NGCU; (g-i)

954 profiles that are at the exit straits of the Solomon Sea; $(\mathbf{j}-\mathbf{l})$ located outside the Solomon Sea.

955 Supplemental Fig. 3. Total Dissolvable Al (TDAl) profiles versus potential density from the

956 PANDORA cruise. Dark blue circles show measured TDAl concentrations. Orange line

957 represents average inflow TDAl profile, while grey shading represents the range of inflow

958 concentrations. Green box represents the density interval over which budget of the thermocline

959 waters is calculated. (a-c) waters that are located south of the Solomon Sea; (d-f) profiles found

960 along the NGCU; (g-i) profiles that are at the exit straits of the Solomon Sea; (j-l) located

961 outside the Solomon Sea.

962 Supplemental Fig. 4. Dissolved Mn (DMn) profiles versus potential density from the

963 PANDORA cruise. Pink diamonds show measured DMn concentrations. Orange line represents

964 average inflow DMn profile, while grey shading represents the range of inflow concentrations.

965 Green box represents the density interval over which budget of the thermocline waters is

966 calculated. $(\mathbf{a}-\mathbf{c})$ waters that are located south of the Solomon Sea; $(\mathbf{d}-\mathbf{f})$ profiles found along the

967 NGCU; (g-i) profiles that are at the exit straits of the Solomon Sea; $(\mathbf{j}-\mathbf{l})$ located outside the

968 Solomon Sea.

969 Supplemental Fig. 5. Total Dissolvable Mn (TDMn) profiles versus depth from the PANDORA

970 cruise. Red diamonds show measured TDMn concentrations. Orange line represents average

971 inflowing TDMn profile, while grey shading represents the range of inflow concentrations.

972 Green box represents the density interval over which budget of the thermocline waters is 
973 calculated. $(\mathbf{a}-\mathbf{c})$ waters that are located south of the Solomon Sea; $(\mathbf{d}-\mathbf{f})$ profiles found along the

974 NGCU; $(\mathbf{g}-\mathbf{i})$ profiles that are at the exit straits of the Solomon Sea; $(\mathbf{j}-\mathbf{l})$ located outside the 975 Solomon Sea. 


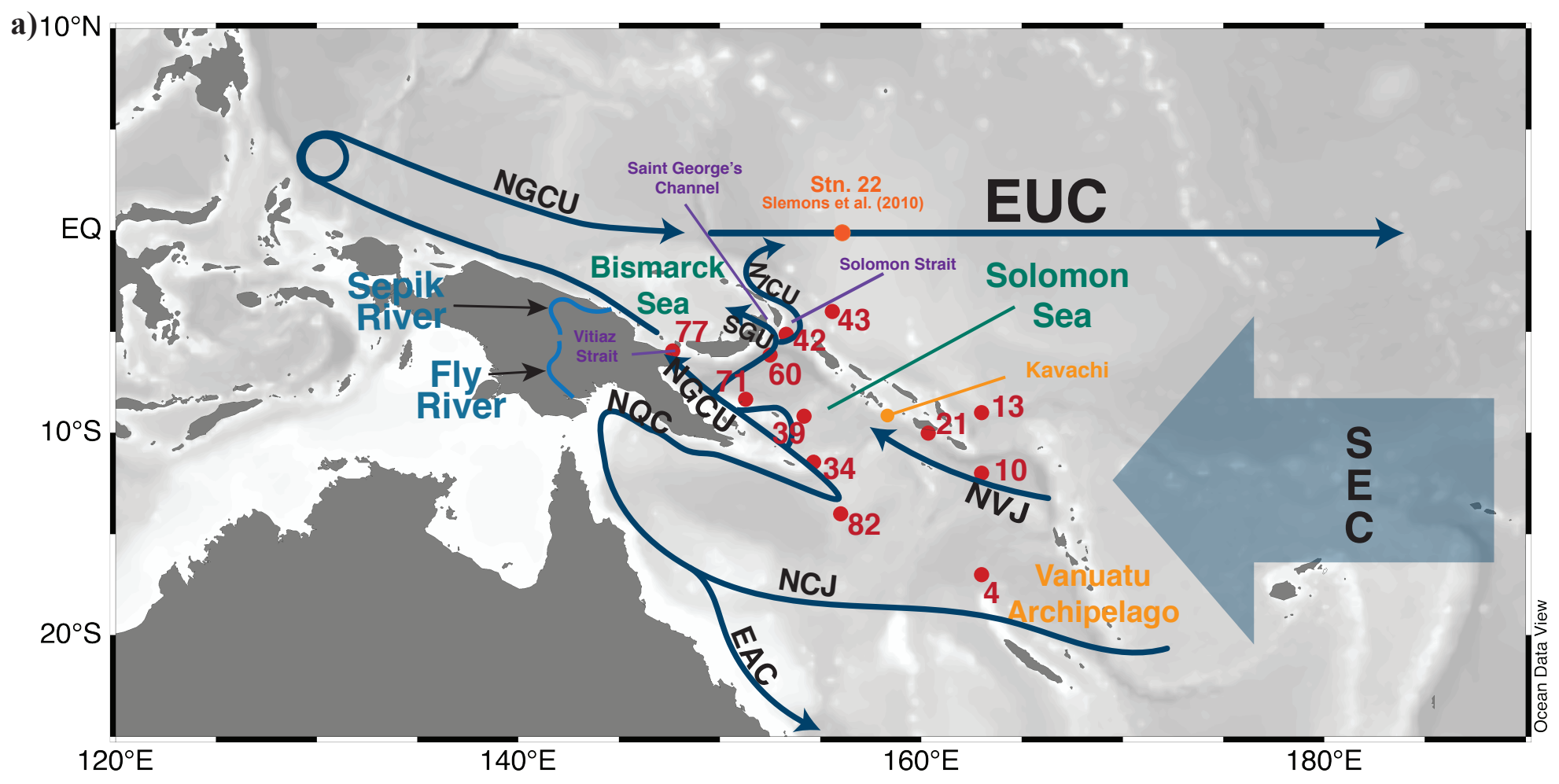

b)

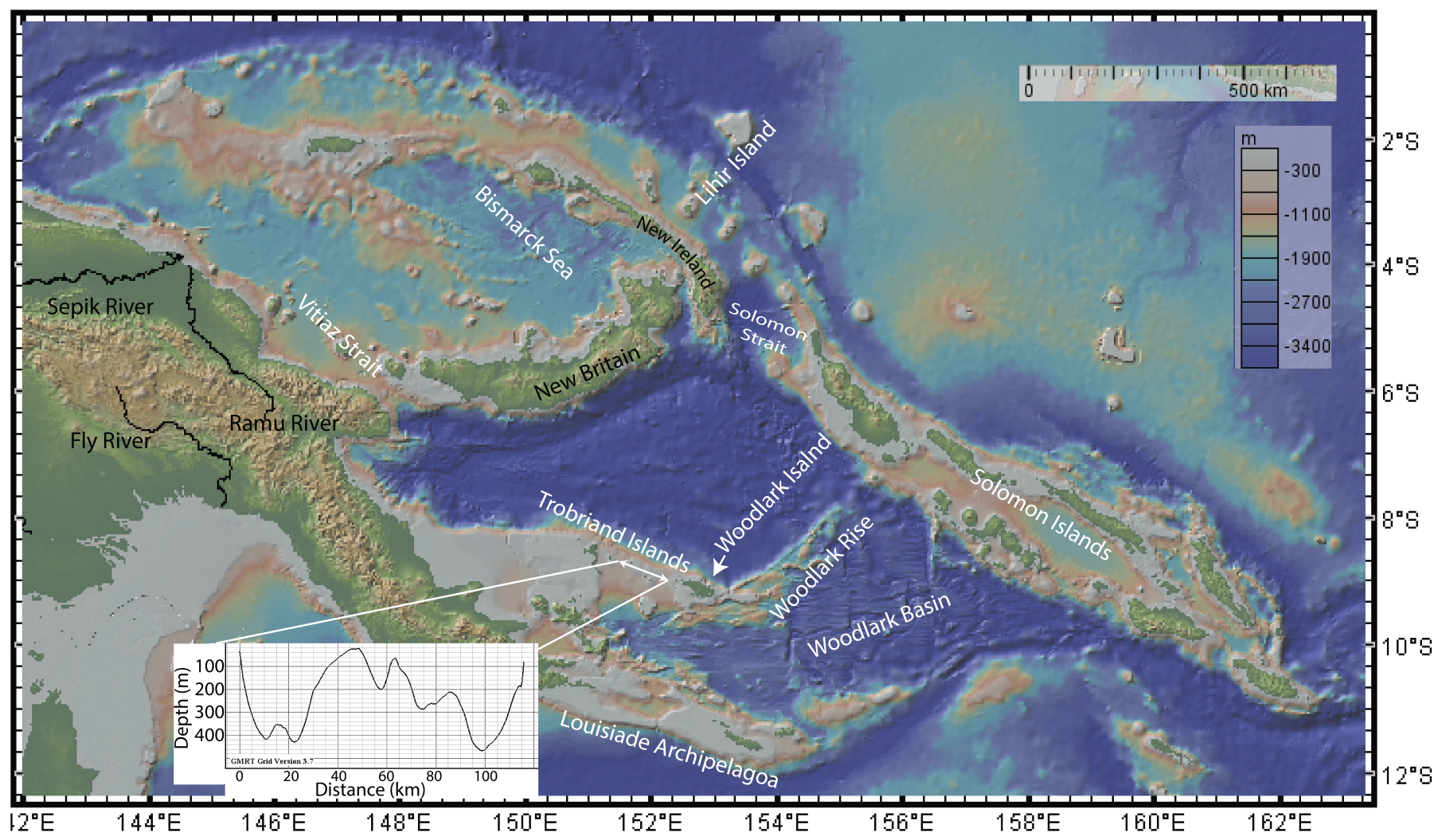

Fig. 1. a) Currents [dark blue; after Germineaud et al. (2016)], rivers (blue text), straits (purple text), and potential point sources (yellow text) to the Solomon Sea. These currents are: Equatorial Undercurrent (EUC); South Equatorial Current (SEC); New Guinea Coastal Undercurrent (NGCU); New Ireland Coastal Undercurrent (NICU); Saint George's Undercurrent (SGU); North Queensland Current (NQC); New Caledonia Jet (NCJ); North Vanuatu Jet (NVJ); East Australian Current (EAC) Red dots and numbers represent stations sampled for $\mathrm{Al}$ and $\mathrm{Mn}$.

b) Bathymetry of the Woodlark Basin and Trobriand Islands 

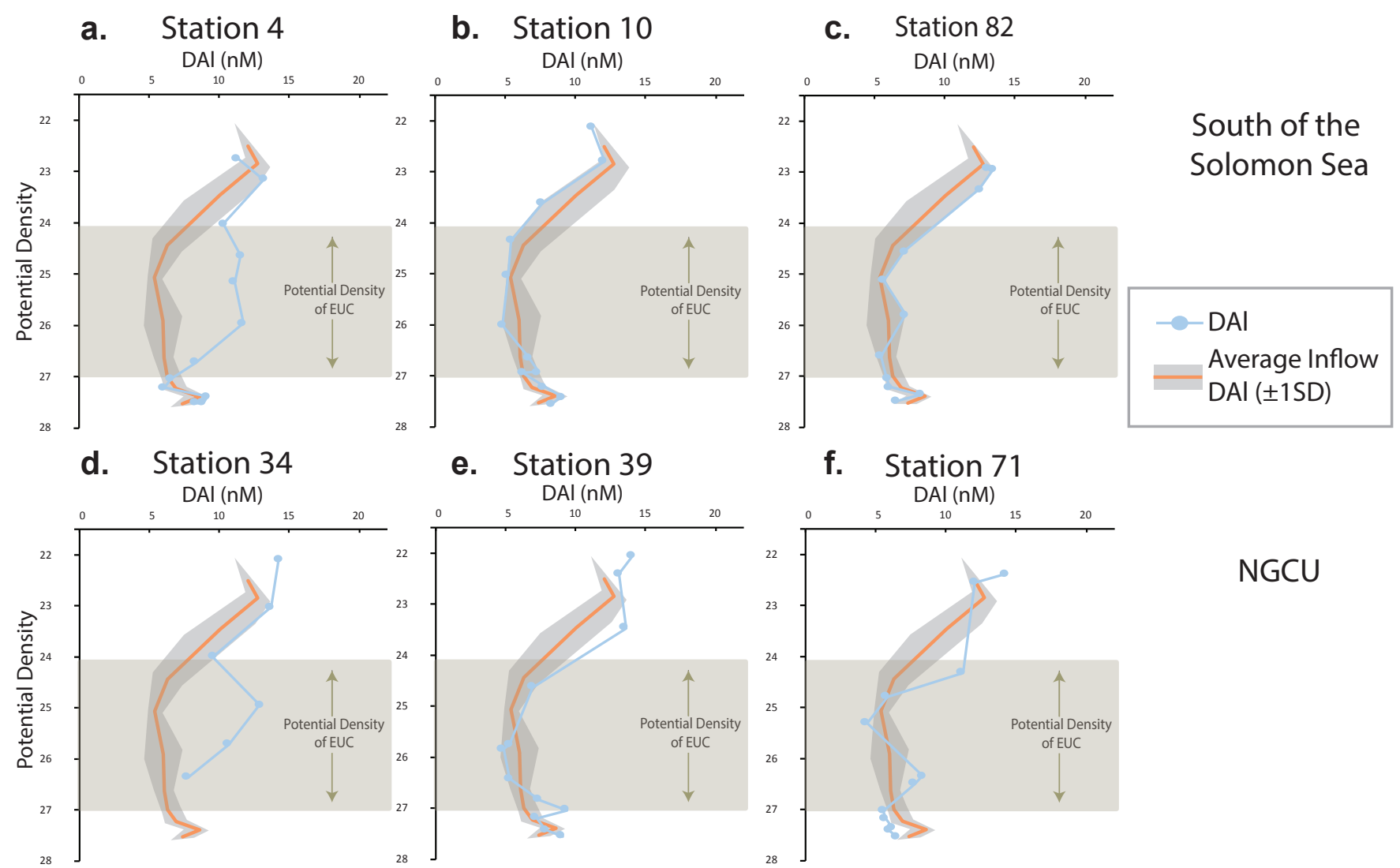

f. Station 71

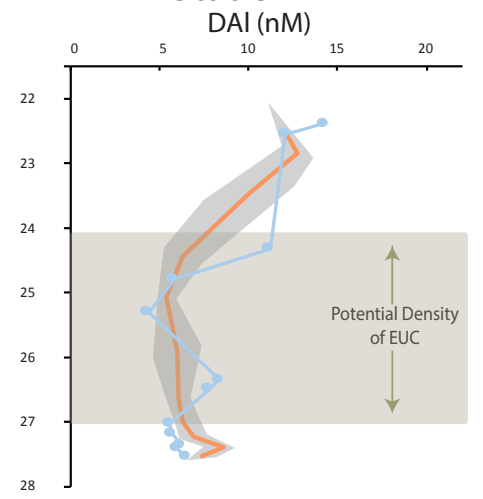

NGCU

g. Station 77
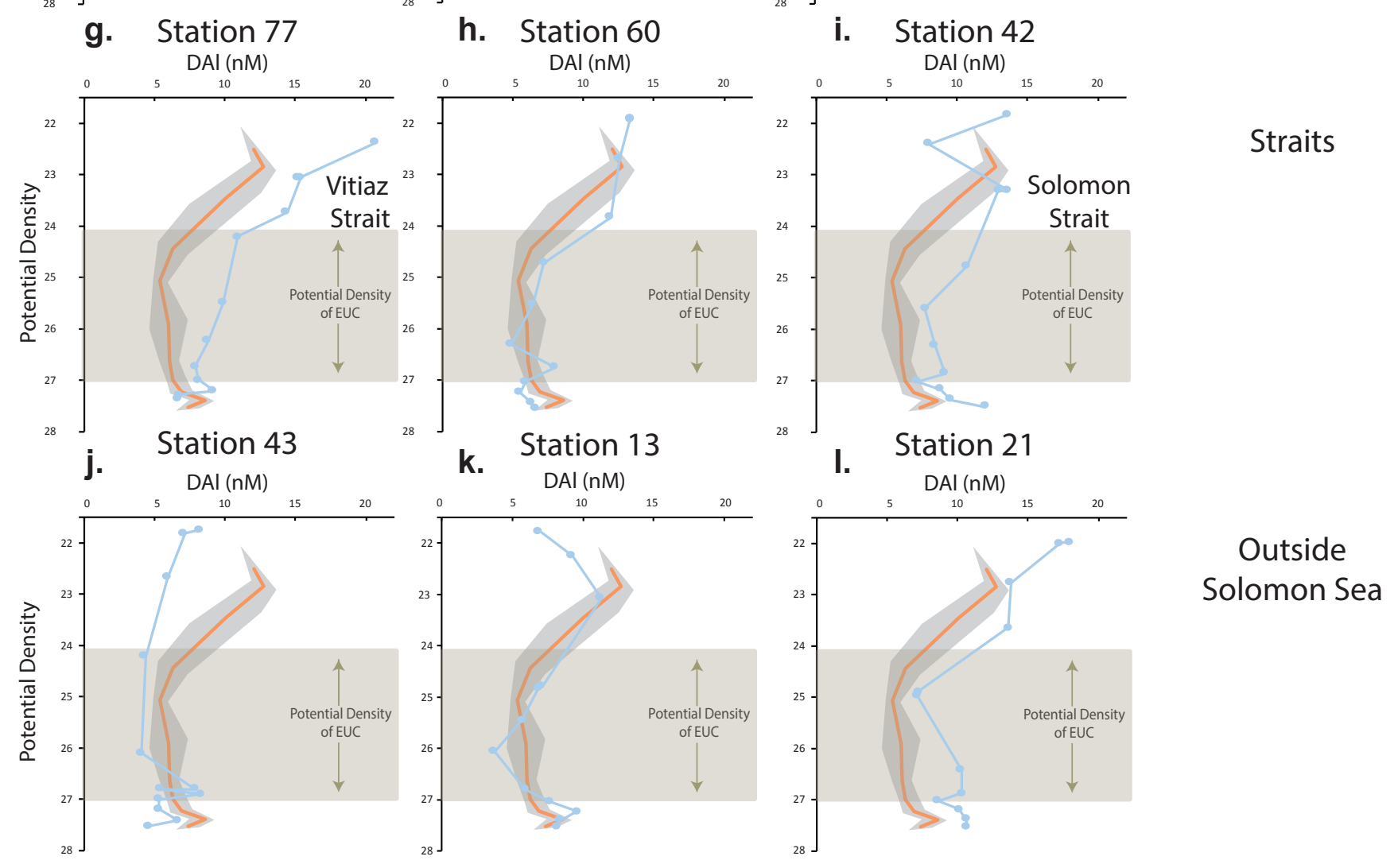

\section{Outside Solomon Sea}

Fig. 2. Dissolved Al (DAl) profiles versus potential density from the Pandora cruise. Light blue circles show measured DAl concentrations. Orange line represents average inflow DAl profile, while grey shading represents the range of inflow concentrations. Green box represents the density interval over which budget of the thermocline waters is calculated. $(\mathbf{a}-\mathbf{c})$ waters that are located south of the Solomon Sea; (d-f) profiles found along the NGCU; (g-i) profiles that are at the exit straits of the Solomon Sea; $(\mathbf{j}-\mathbf{l})$ located outside the Solomon Sea. 

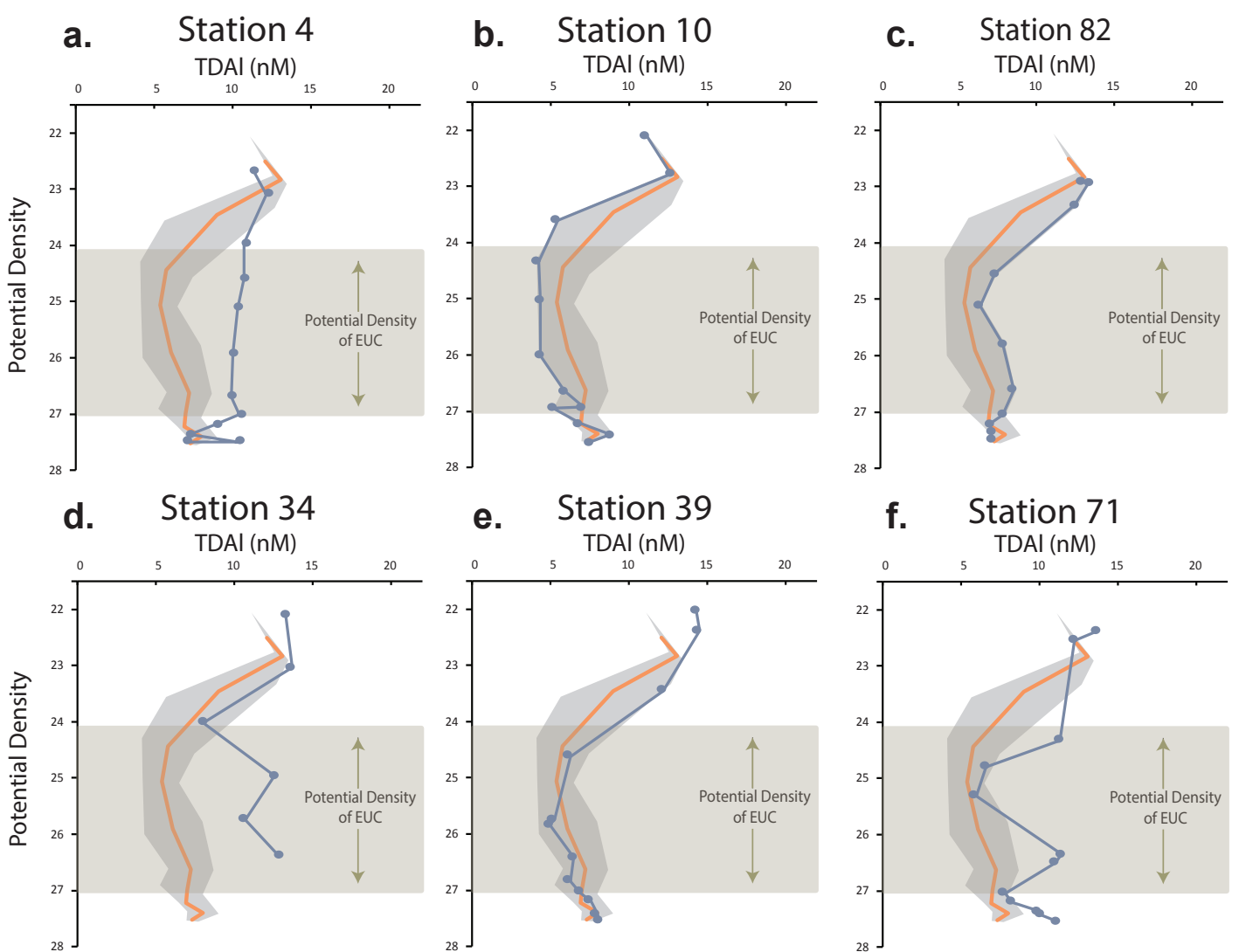

South of the
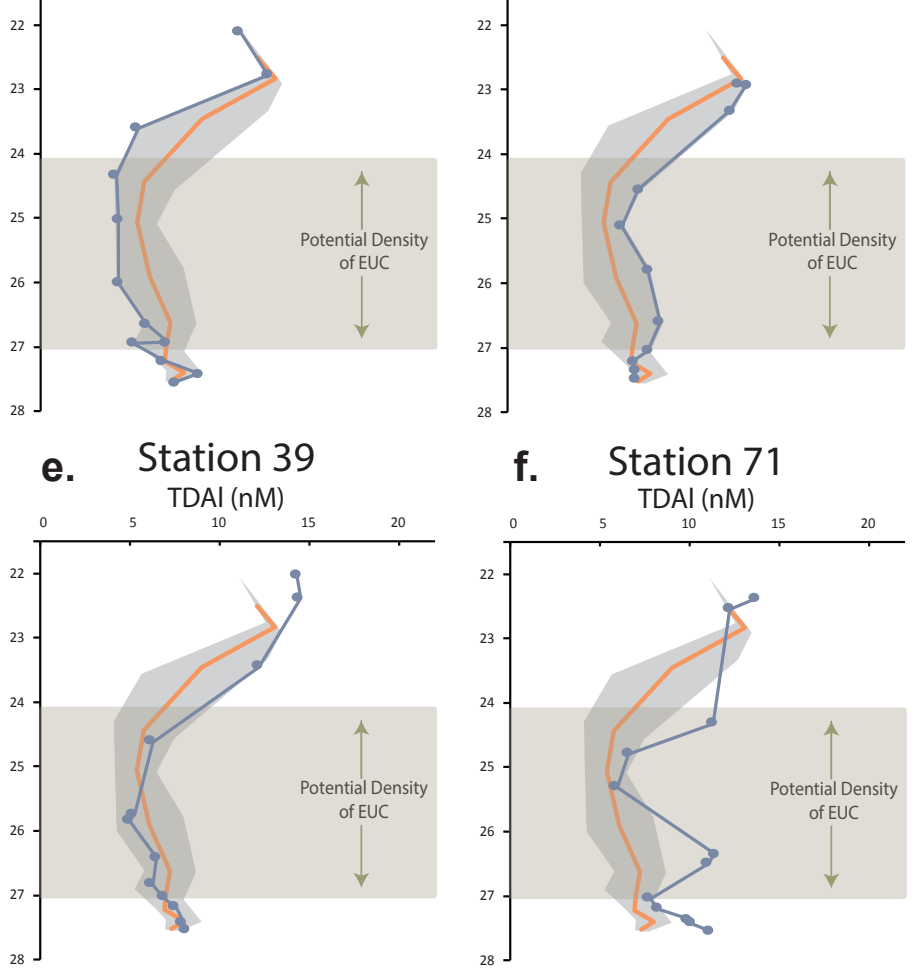

Solomon Sea
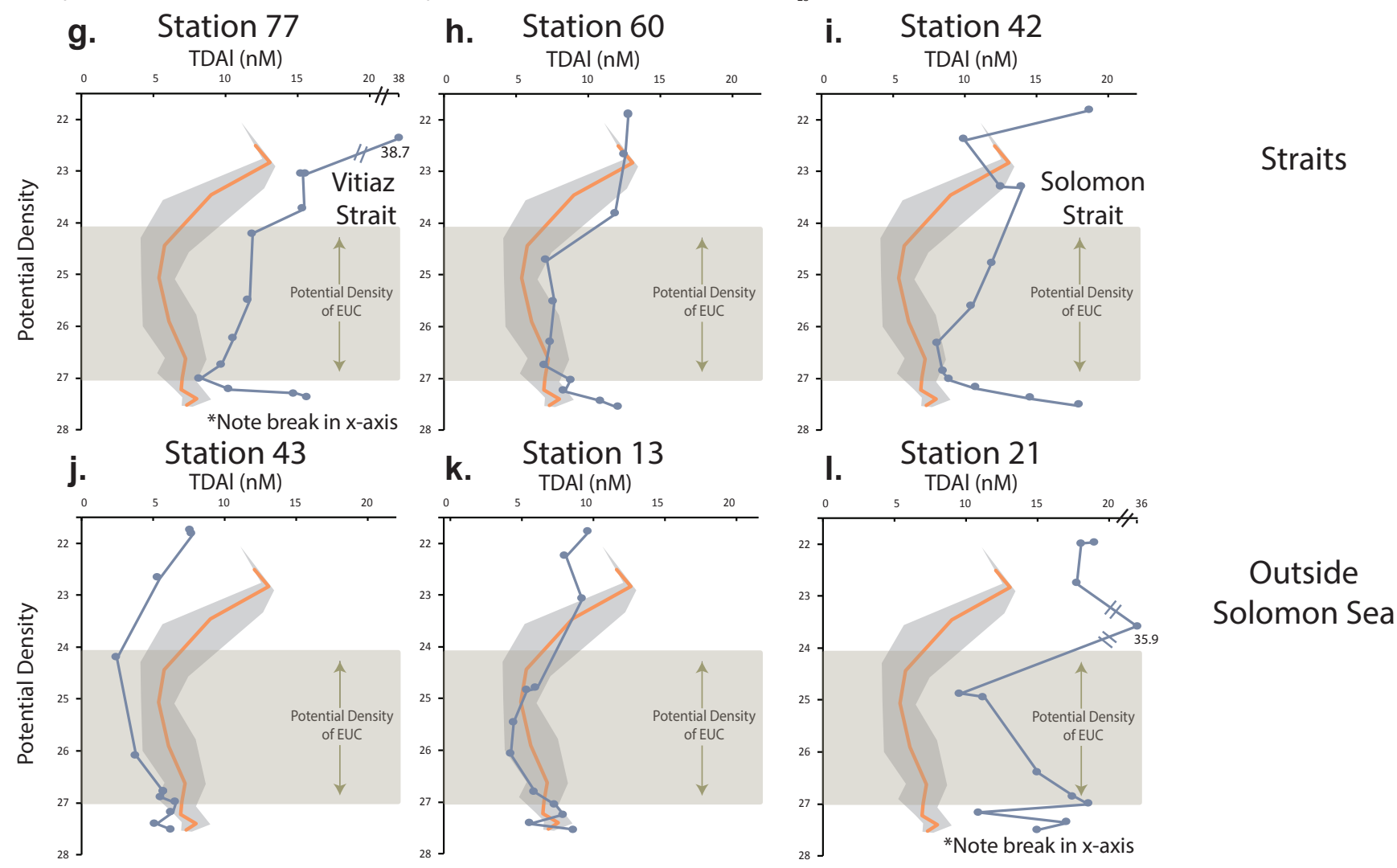

Fig. 3. Total Dissolvable Al (TDAl) profiles versus potential density from the PANDORA cruise. Dark blue circles show measured TDAl concentrations. Orange line represents average inflow TDAl profile, while grey shading represents the range of inflow concentrations. Green box represents the density interval over which budget of the thermocline waters is calculated. $(\mathbf{a}-\mathbf{c})$ waters that are located south of the Solomon Sea; $(\mathbf{d}-\mathbf{f})$ profiles found along the NGCU; $(\mathbf{g}-\mathbf{i})$ profiles that are at the exit straits of the Solomon Sea; (j-l) located outside the Solomon Sea. 

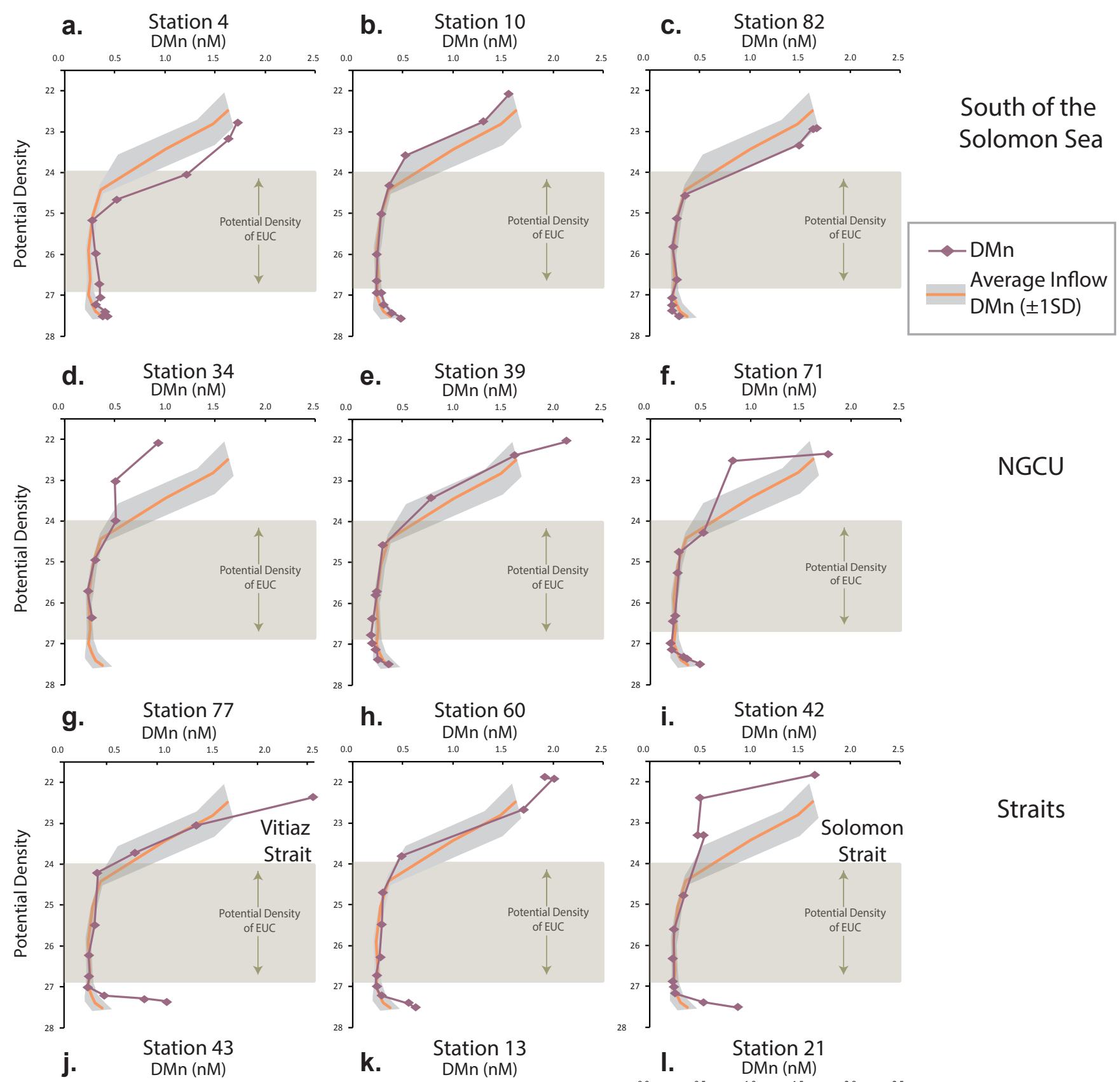

NGCU
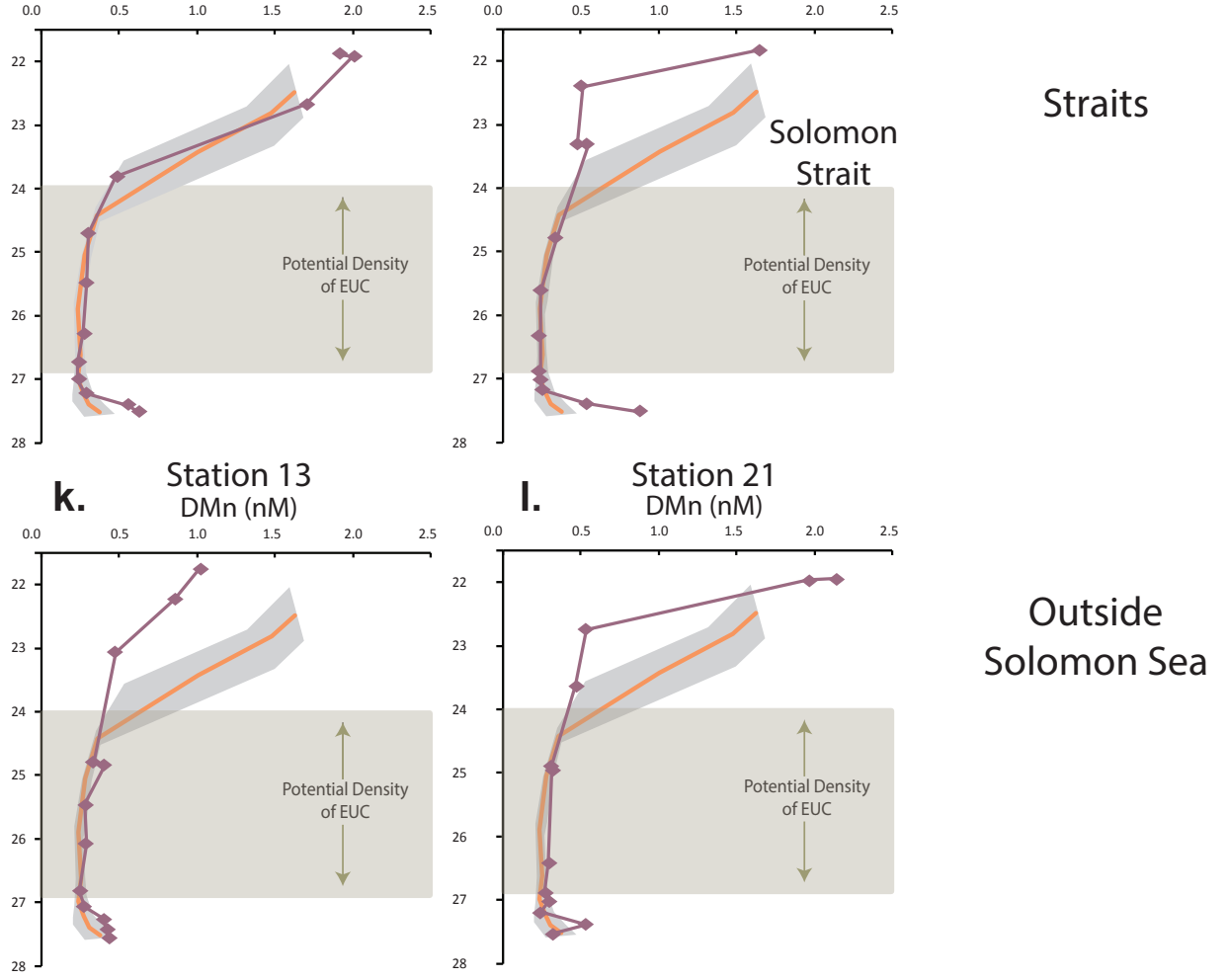

Straits

\section{Outside Solomon Sea}
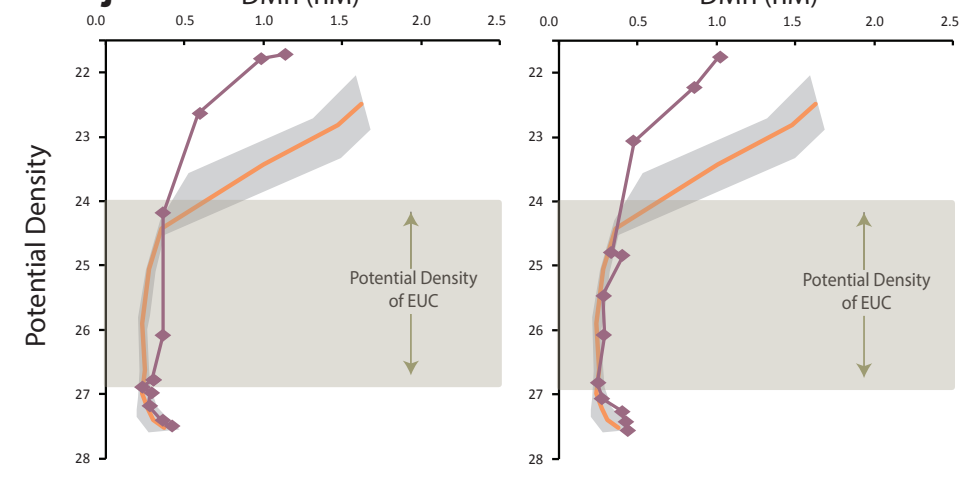

Fig. 4. Dissolved Mn (DMn) profiles versus potential density from the PANDORA cruise. Pink diamonds show measured DMn concentrations. Orange line represents average inflow DMn profile, while grey shading represents the range of inflow concentrations. Green box represents the density interval over which budget of the thermocline waters is calculated. $(\mathbf{a}-\mathbf{c})$ waters that are located south of the Solomon Sea; $(\mathbf{d}-\mathbf{f})$ profiles found along the NGCU; $(\mathbf{g}-\mathbf{i})$ profiles that are at the exit straits of the Solomon Sea; $(\mathbf{j}-\mathbf{l})$ located outside the Solomon Sea. 

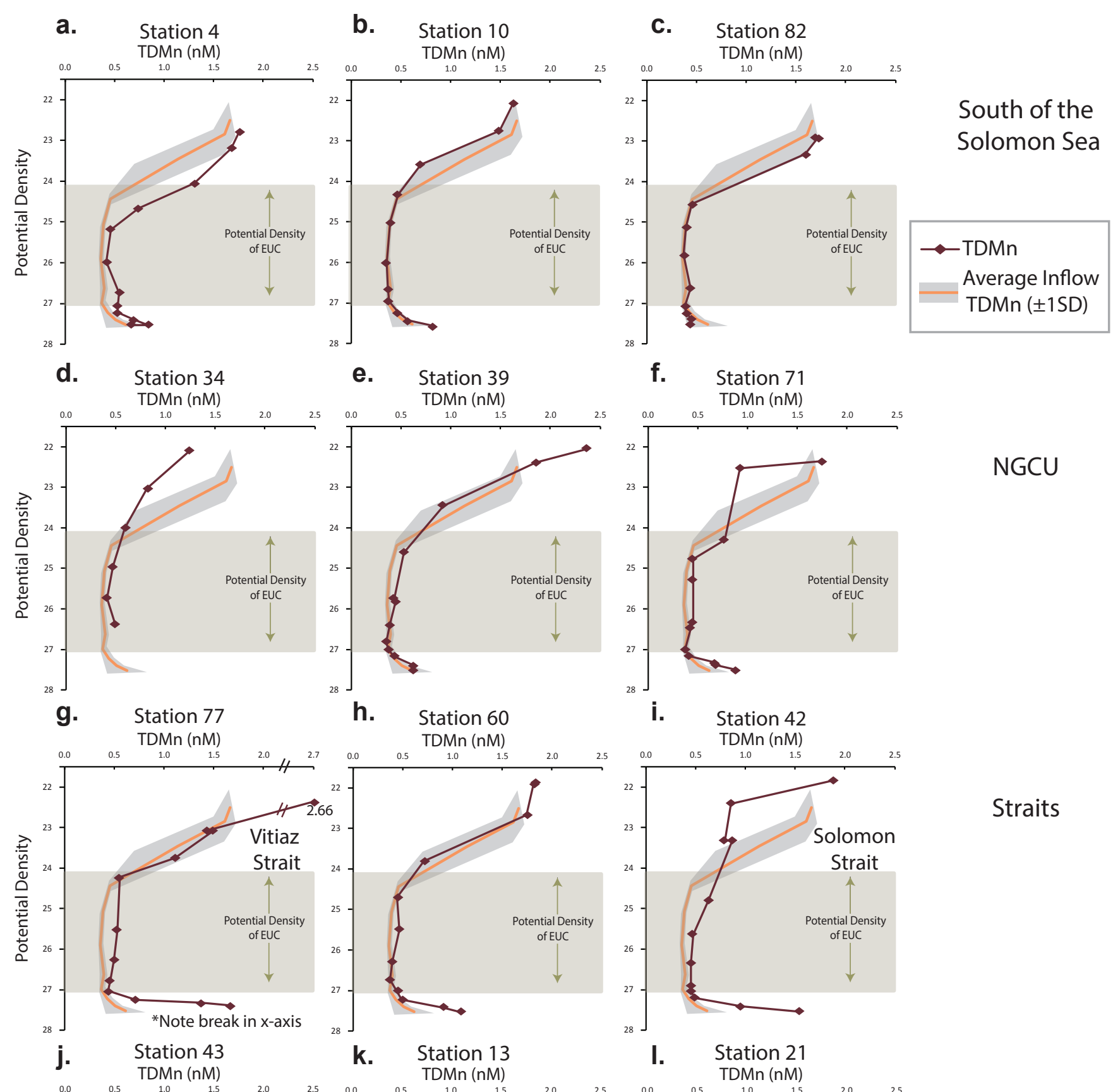

NGCU
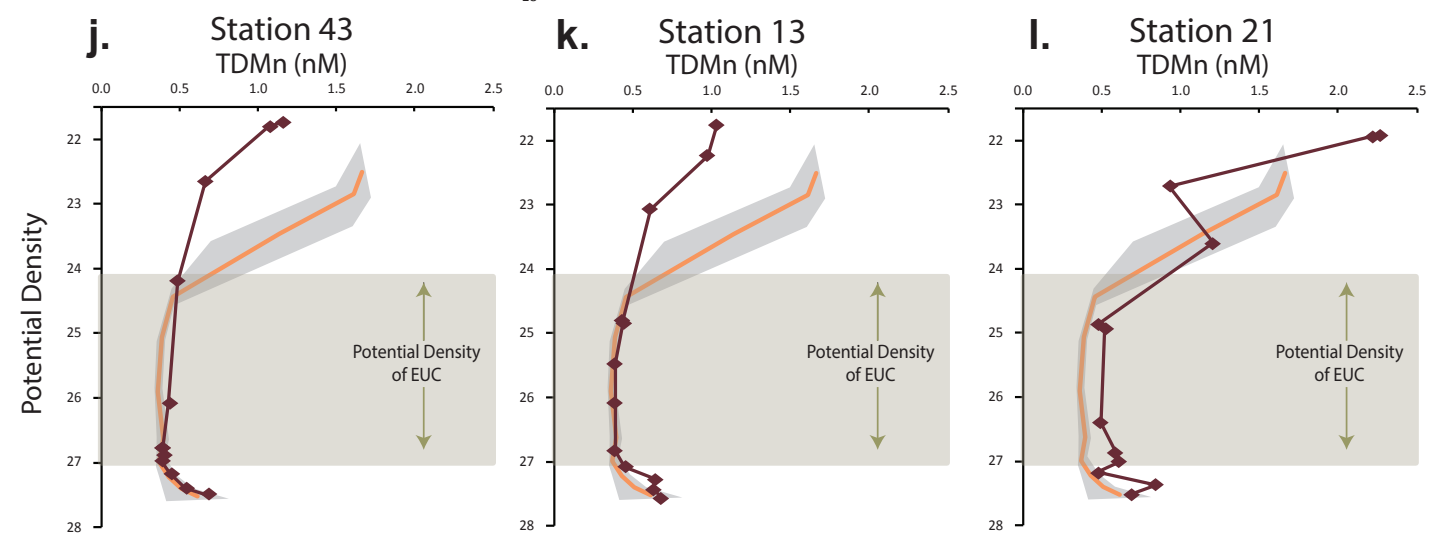

Straits

\section{Outside Solomon Sea}

Fig. 5. Total Dissolvable Mn (TDMn) profiles versus potential density from the PANDORA cruise. Red diamonds show measured TDMn concentrations. Orange line represents average inflow TDMn profile, while grey shading represents the range of inflow concentrations. Green box represents the density interval over which budget of the thermocline waters is calculated. (a-c) waters that are located south of the Solomon Sea; $(\mathbf{d}-\mathbf{f})$ profiles found along the NGCU; $(\mathbf{g}-\mathbf{i})$ profiles that are at the exit straits of the Solomon Sea; $(\mathbf{j}-\mathbf{l})$ located outside the Solomon Sea. 


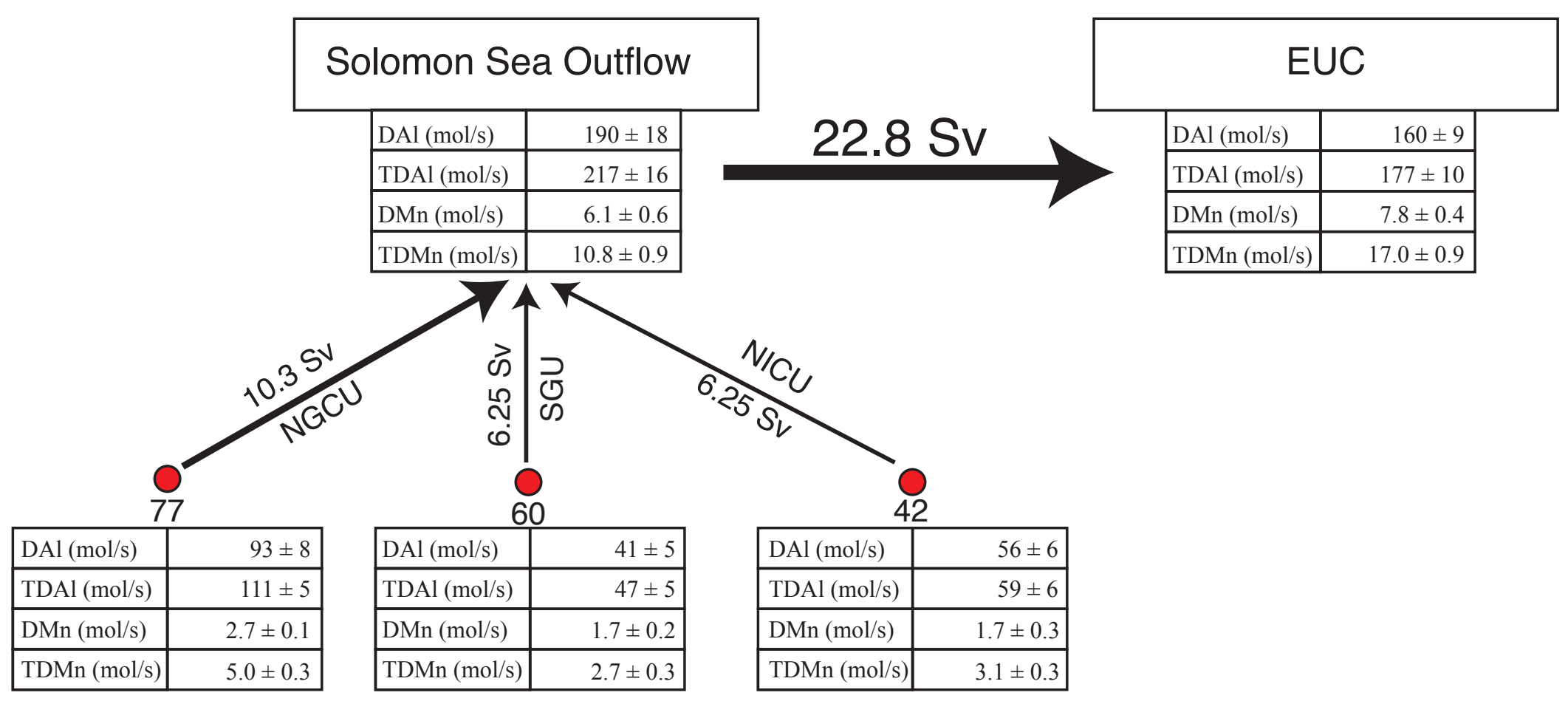

\section{Solomon Sea Average Concentration}

\begin{tabular}{|l|r|}
\hline $\mathrm{DAl}(\mathrm{nM})$ & $7.2 \pm 1.2$ \\
\hline $\mathrm{TDAl}(\mathrm{nM})$ & $9.6 \pm 1.6$ \\
\hline $\mathrm{DMn}(\mathrm{nM})$ & $0.28 \pm 0.03$ \\
\hline $\mathrm{TDMn}(\mathrm{nM})$ & $0.48 \pm 0.04$ \\
\hline
\end{tabular}

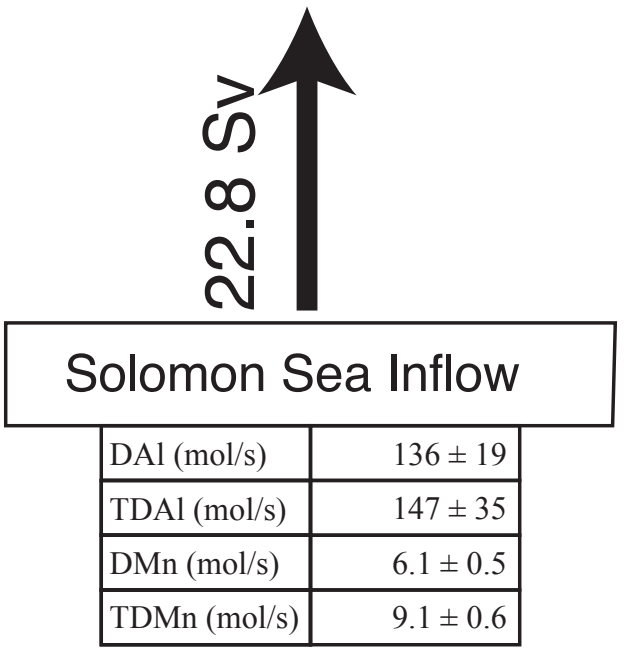

Fig. 6. Budget for 24-26.9 $\sigma_{\theta}$, showing the flux of DAl, TDAl, DMn, TDMn at the inflow, the outflow via currents (NGCU, NICU, and SGU), and the flux out of the EUC at $156^{\circ} \mathrm{E}$, as well as the average concentration of the Solomon Sea, calculated from stations most representive of the Solomon Sea. Red dots represent stations used to calculate concentrations at each exit strait over the potential density range of the EUC. 
a. Station 4

Al (nM)

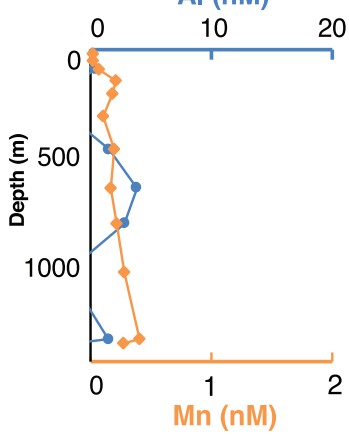

d. Station 34

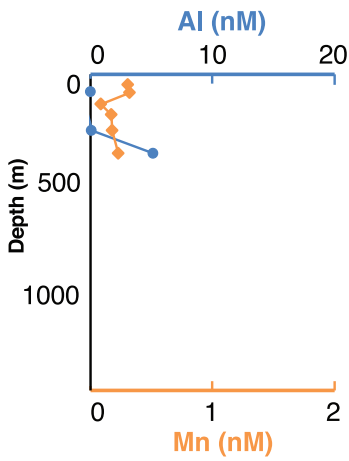

g. Station 77

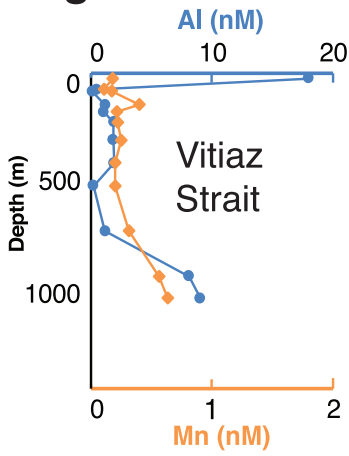

j. Station 43

Al (nM)

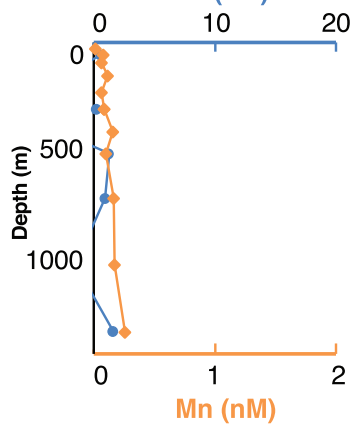

b. Station 10

$\mathrm{Al}(\mathrm{nM})$

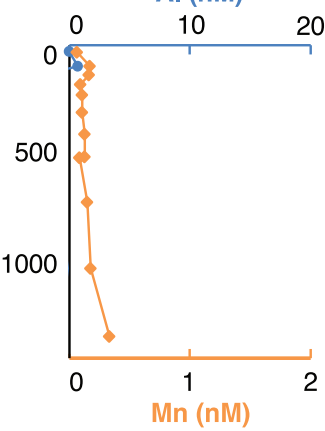

e. Station 39

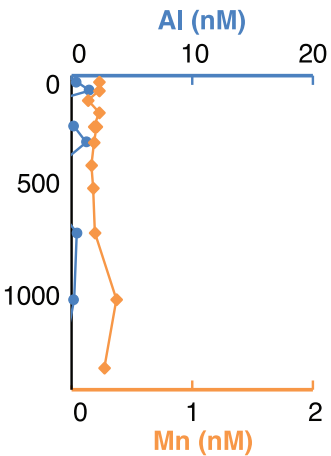

h. Station 60

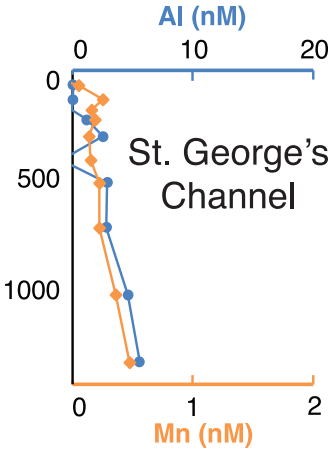

k. Station 13

Al (nM)

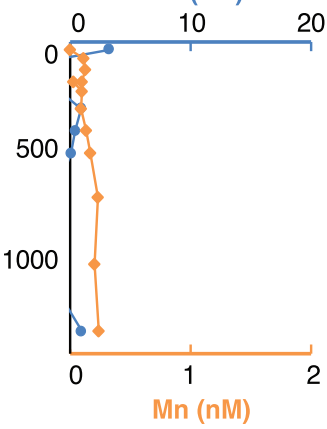

C. Station 82

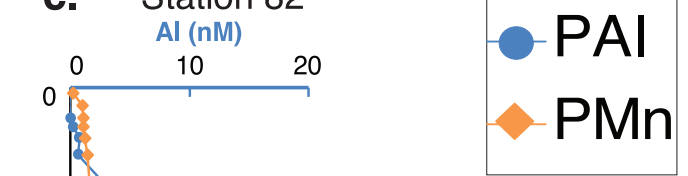

Inflow

1000

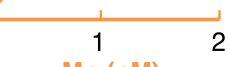

f. Station 71

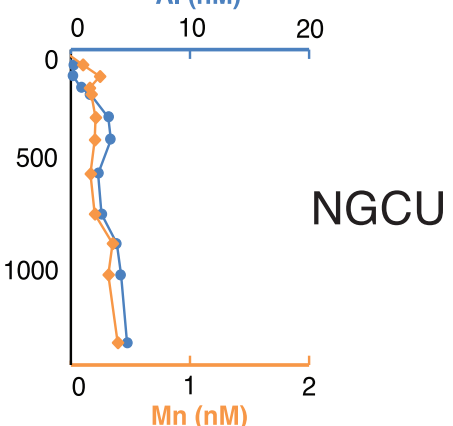

i. Station 42

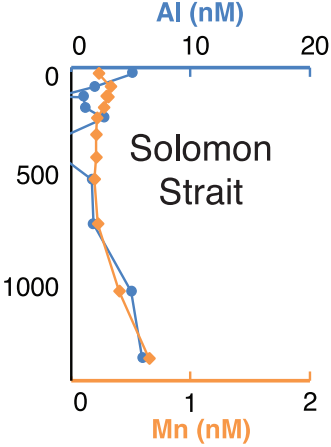

I. Station 21

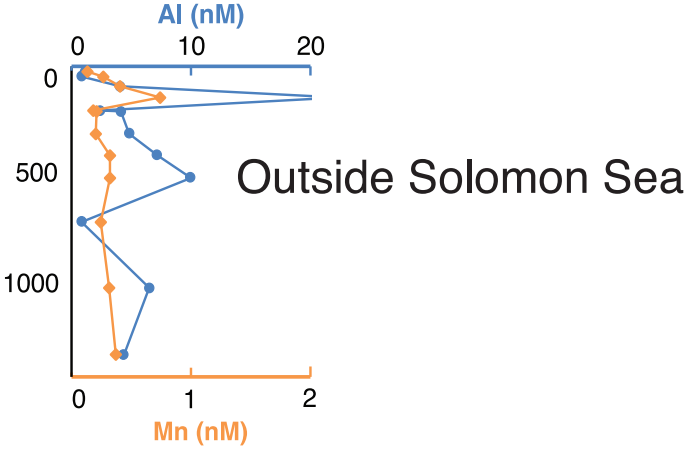

Supplemental Fig. 1. Implied labile particle concentrations of aluminum (PAl) and manganese (PMn). Where values are not reported, the dissolved (D) concentration exceeded the total dissolvable (TD) concentration, but within the standard deviation of the measurement. $\mathrm{P}=\mathrm{TD}-\mathrm{D}$. 

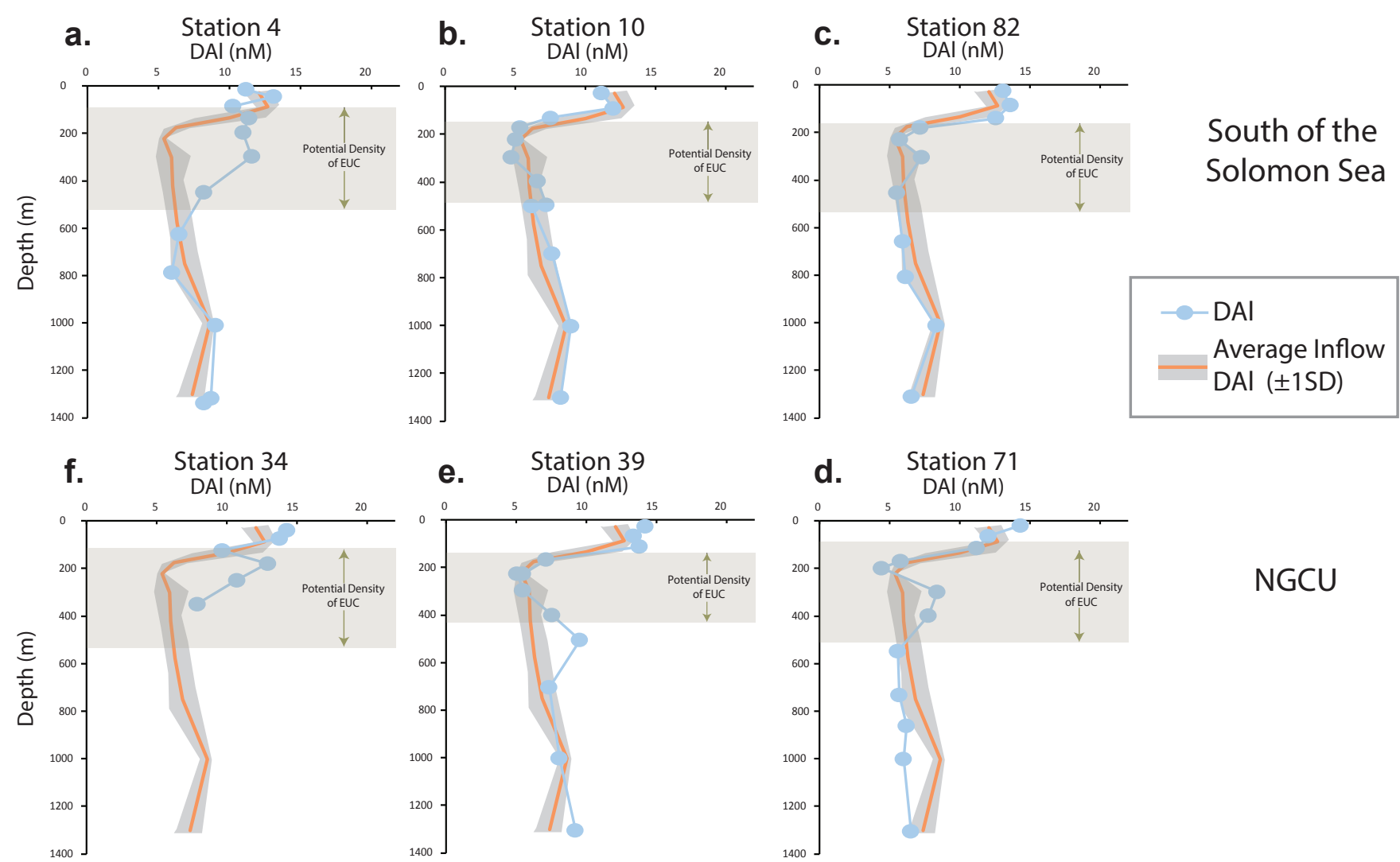

NGCU
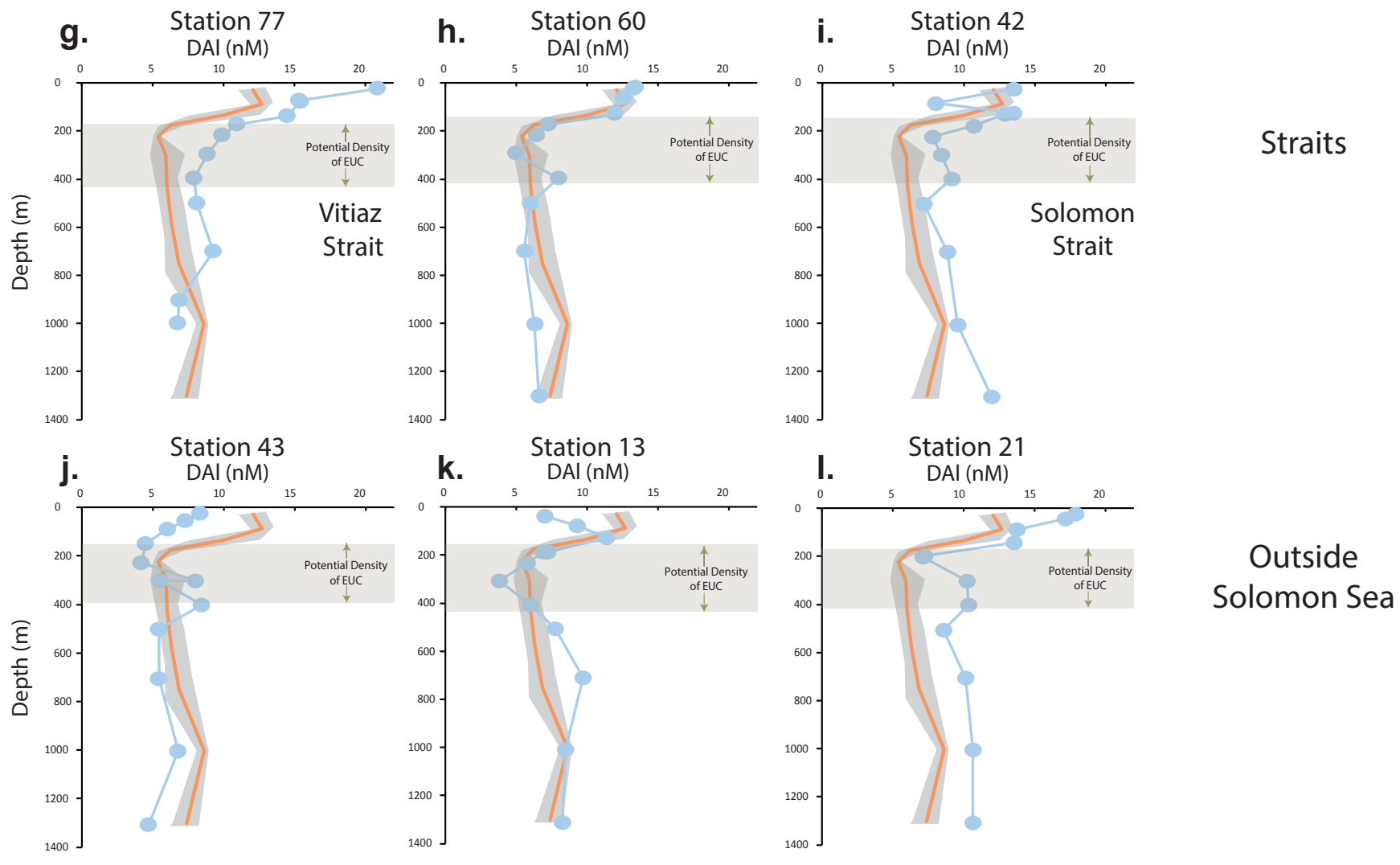

Supplemental Fig. 2. Dissolved Al (DAl) profiles versus depth from the PANDORA cruise. Light blue circles show measured DAl concentrations. Orange line represents average inflow DAl profile, while grey shading represents the range of inflow concentrations. Green box represents the density interval over which budget of the thermocline waters is calculated. $(\mathbf{a}-\mathbf{c})$ waters that are located south of the Solomon Sea; $(\mathbf{d}-\mathbf{f})$ profiles found along the NGCU; $(\mathbf{g}-\mathbf{i})$ profiles that are at the exit straits of the Solomon Sea; $(\mathbf{j}-\mathbf{l})$ located outside the Solomon Sea. 


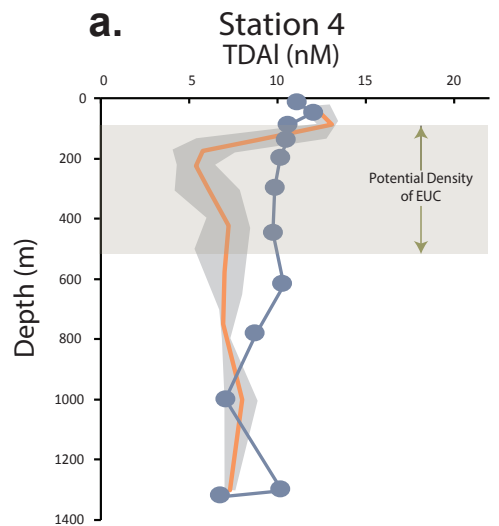

d. Station 34

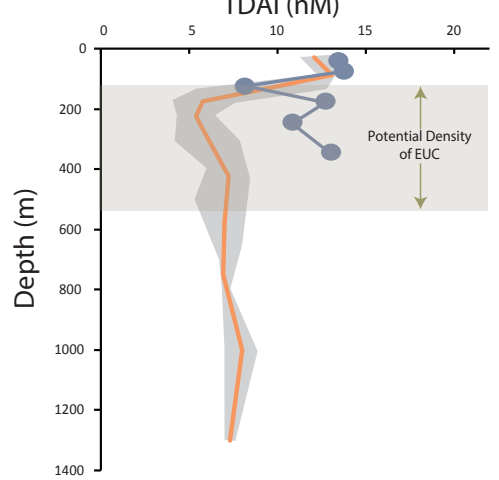

g. Station 77
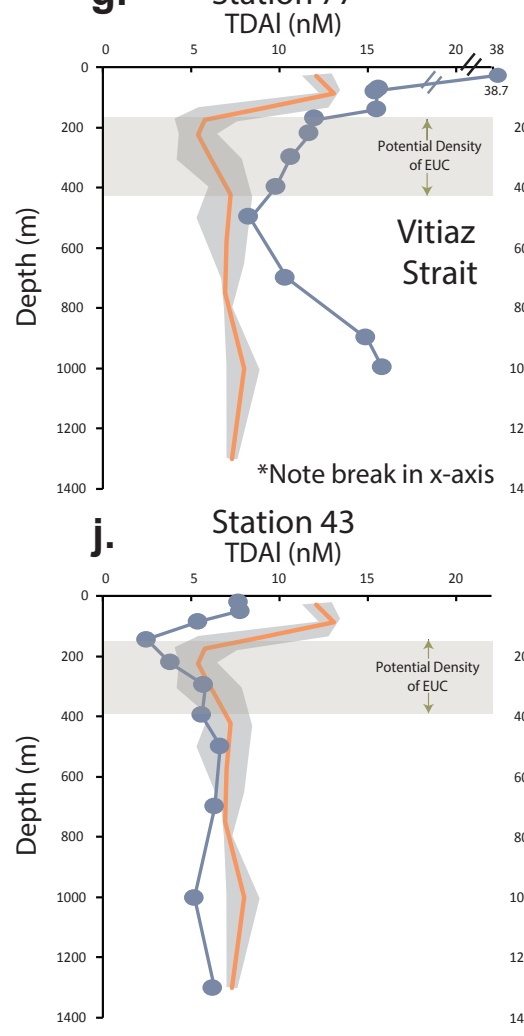

b. Station 10

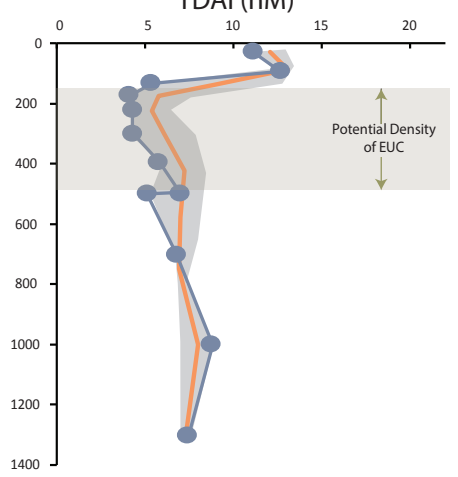

e. Station 39

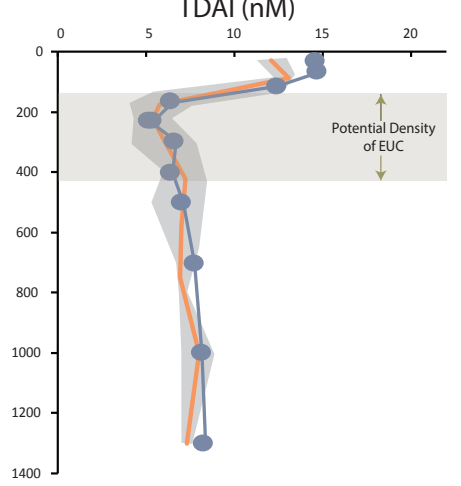

h. Station 60
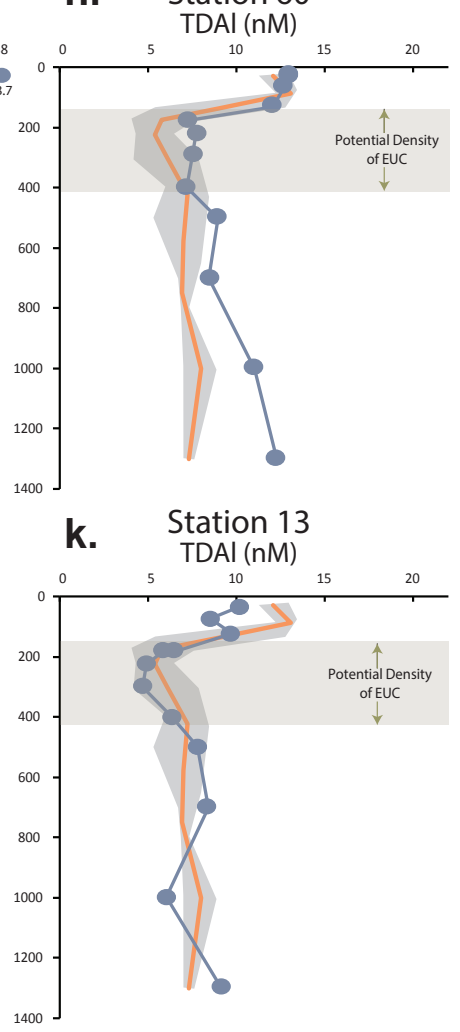

C. Station 82

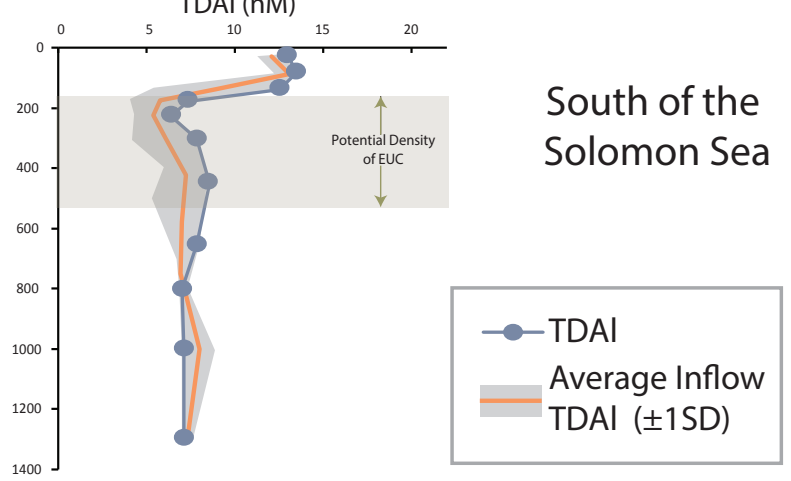

f. Station 71

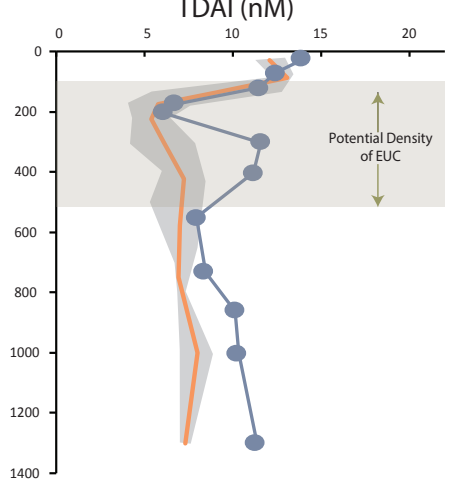

NGCU

i. Station 42
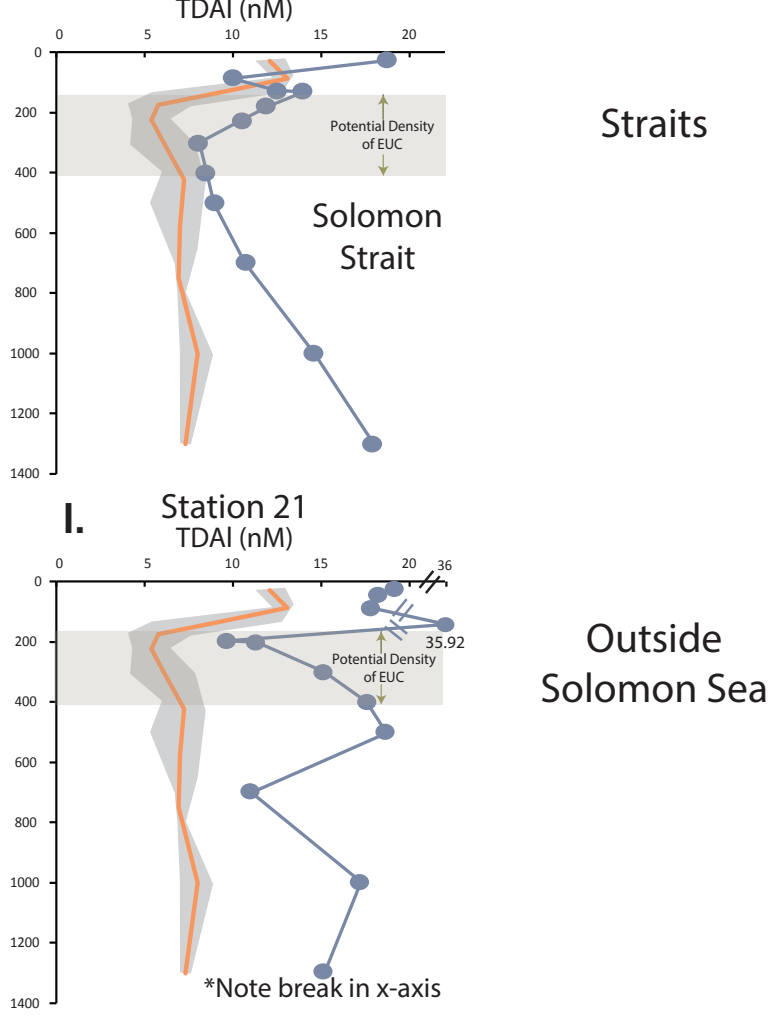

Supplemental Fig. 3. Total Dissolvable Al (TDAl) profiles versus depth from the PANDORA cruise. Blue circles show measured TDAl concentrations. Orange line represents average inflow TDAl profile, while grey shading represents the range of inflow concentrations. Green box represents the density interval over which budget of the thermocline waters is calculated. (a-c) waters that are located south of the Solomon Sea; $(\mathbf{d}-\mathbf{f})$ profiles found along the NGCU; $(\mathbf{g}-\mathbf{i})$ profiles that are at the exit straits of the Solomon Sea; (j-l) located outside the Solomon Sea. 


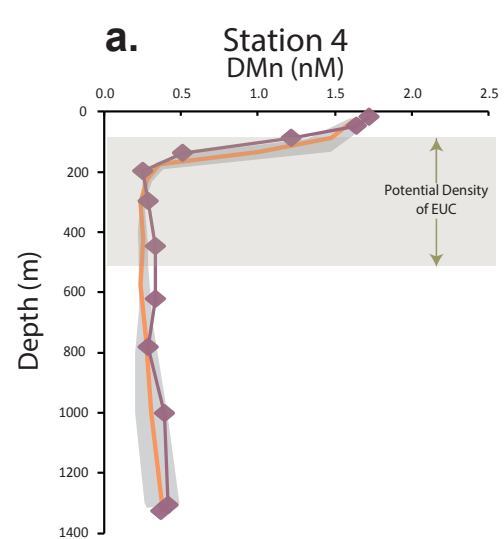

d. Station 34
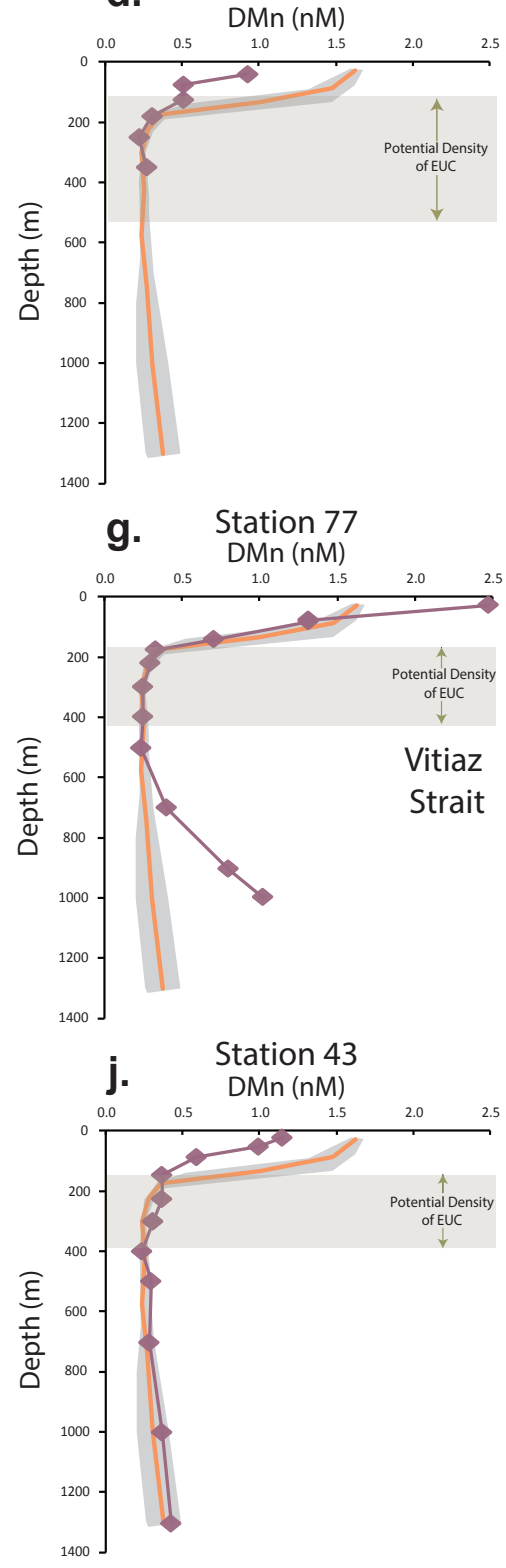

b. Station 10

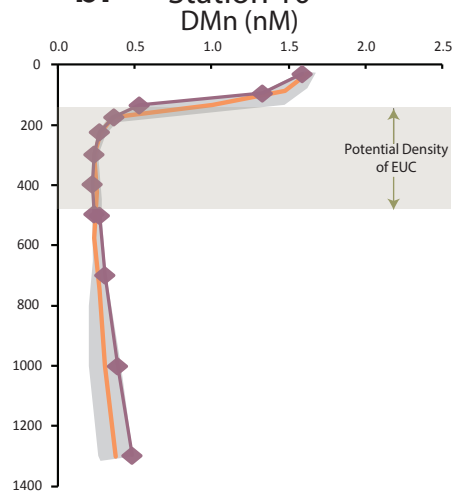

e. Station 39

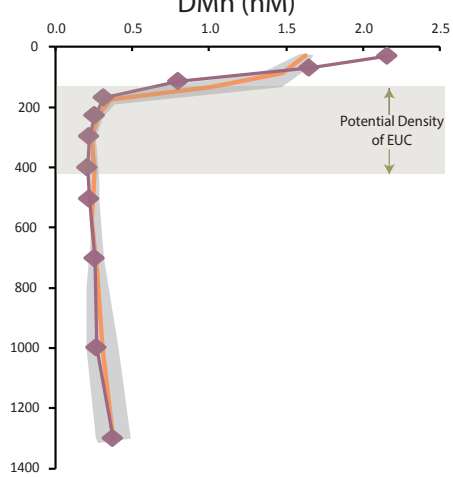

h. Station 60
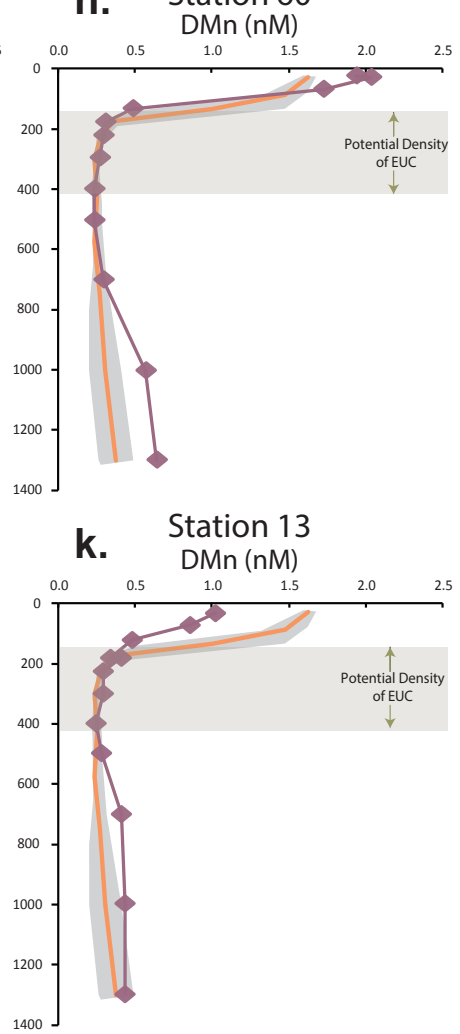

C. Station 82

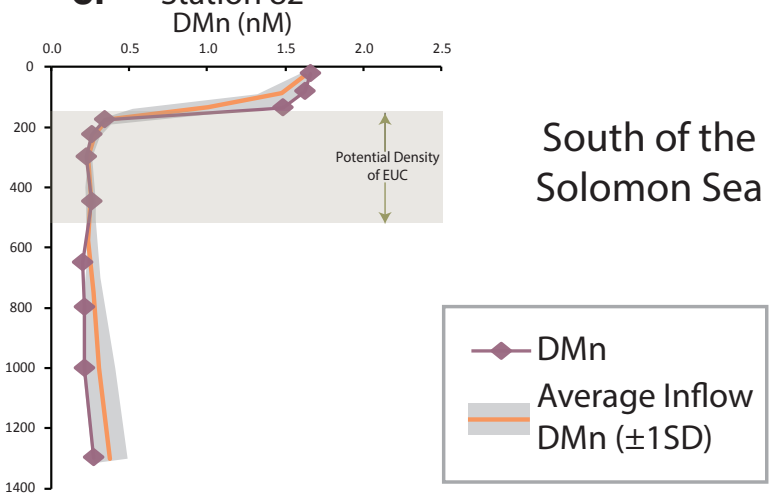

f. Station 71

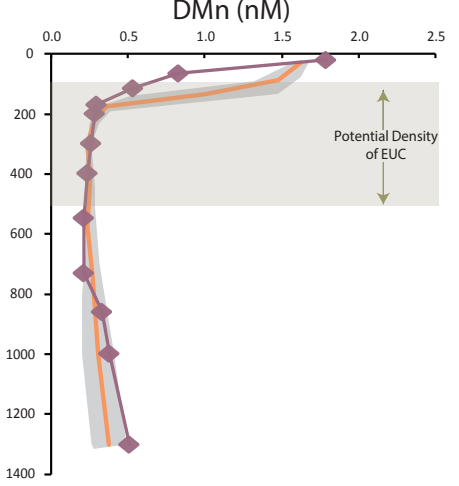

NGCU
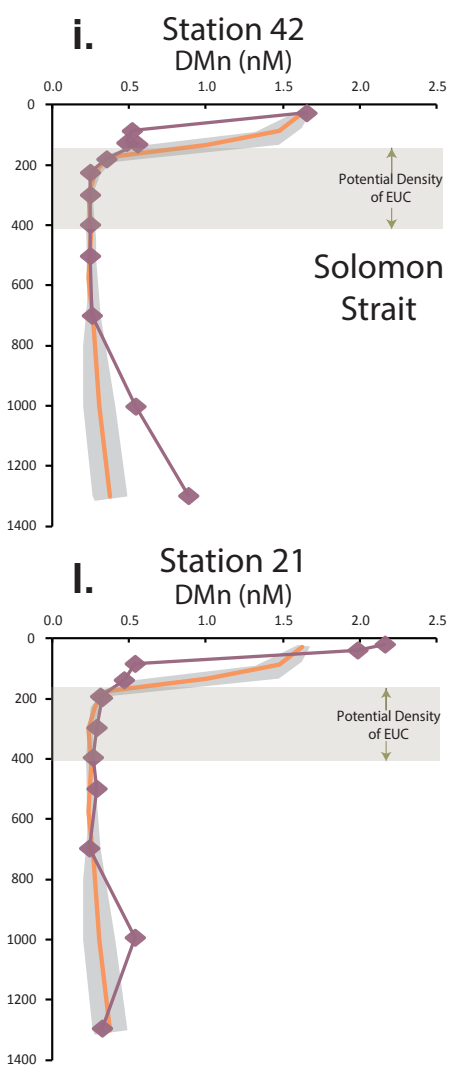

Straits

Outside

Solomon Sea

Supplemental Fig. 4. Dissolved Mn (DMn) profiles versus potential density from the PANDORA cruise. Pink diamonds show measured DMn concentrations. Orange line represents average inflow DMn profile, while grey shading represents the range of inflow concentrations. Green box represents the density interval over which budget of the thermocline waters is calculated. (a-c) waters that are located south of the Solomon Sea; $(\mathbf{d}-\mathbf{f})$ profiles found along the NGCU; $(\mathbf{g}-\mathbf{i})$ profiles that are at the exit straits of the Solomon Sea; $(\mathbf{j}-\mathbf{l})$ located outside the Solomon Sea. 


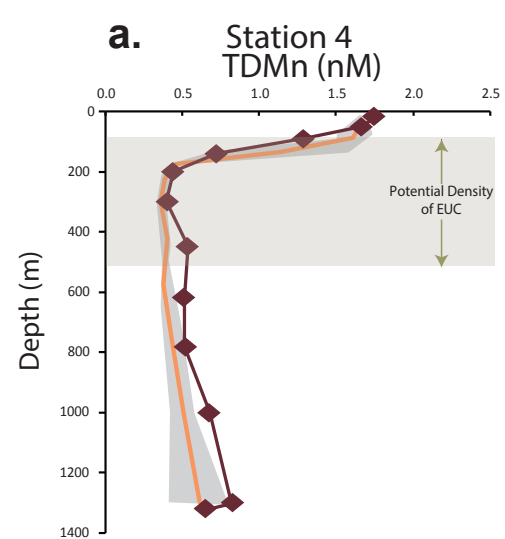

d. Station 34

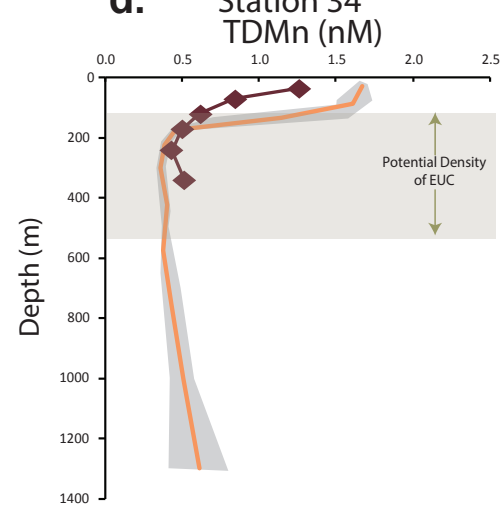

g. Station 77
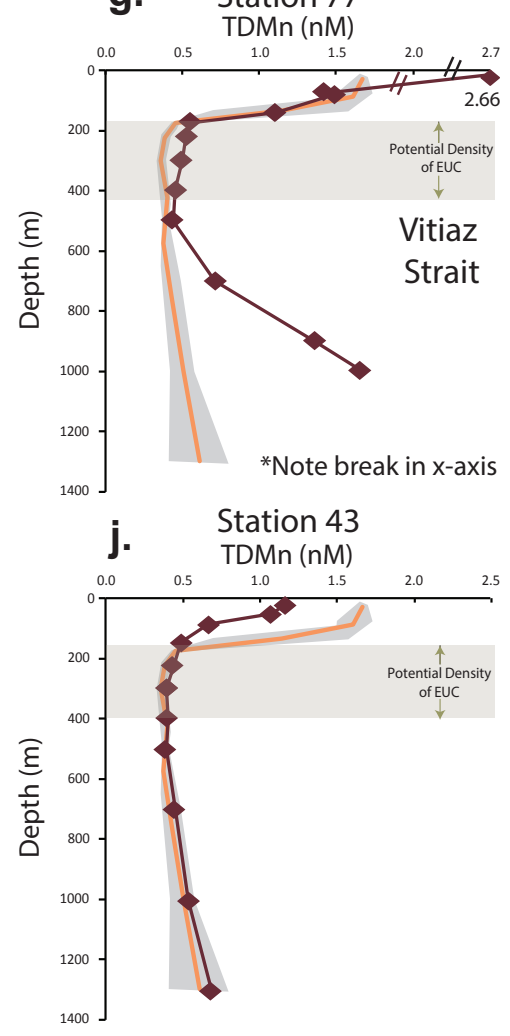

b. Station 10

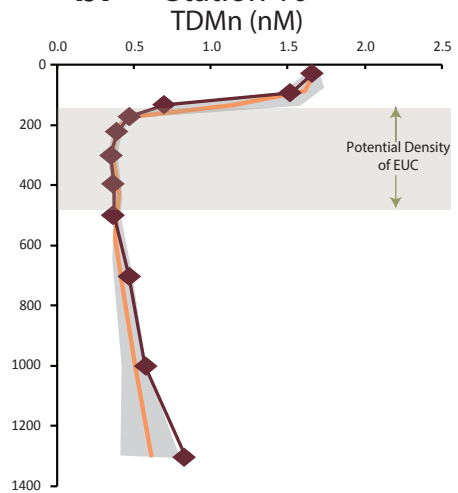

e. Station 39

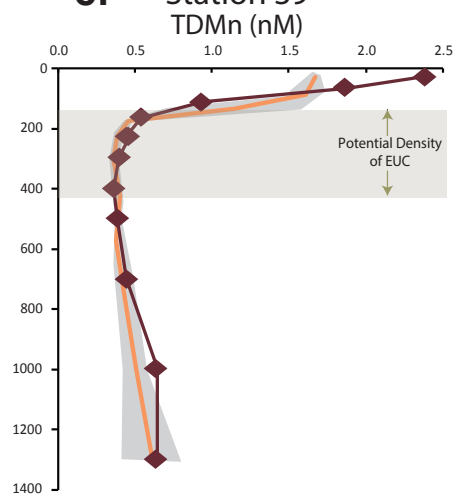

h. Station 60

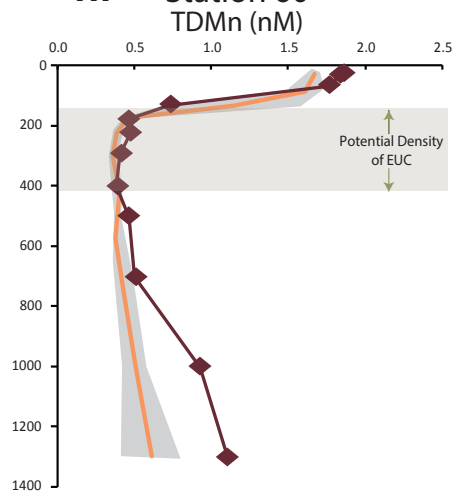

k. Station 13

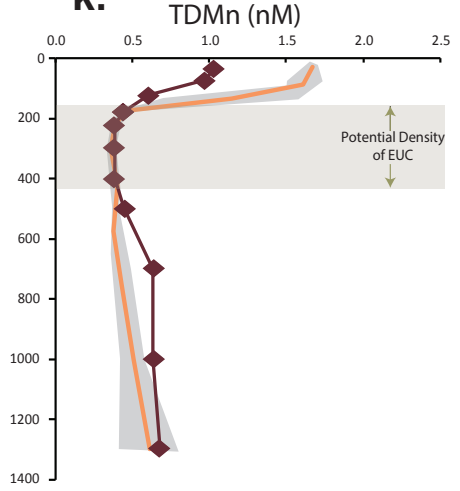

C. Station 82

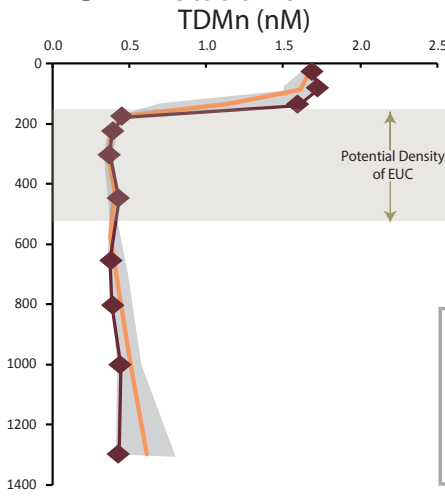

f. Station 71

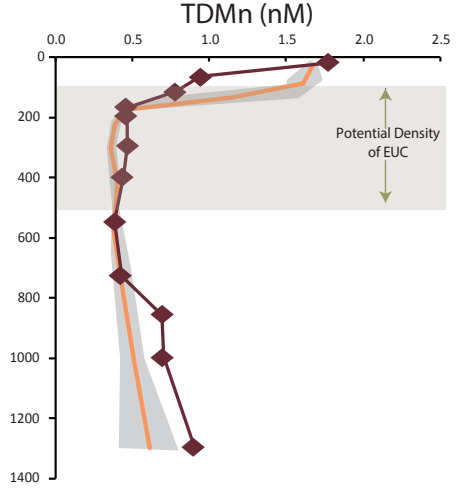

i. Station 42

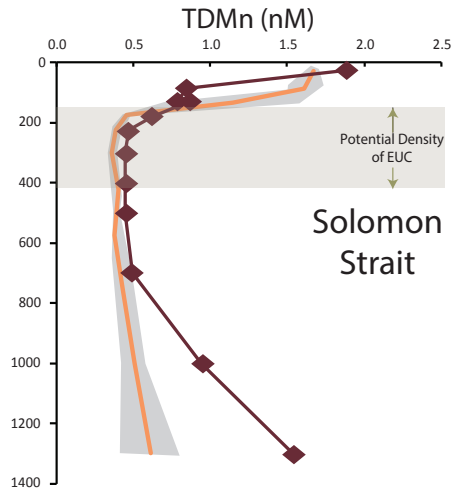

1400

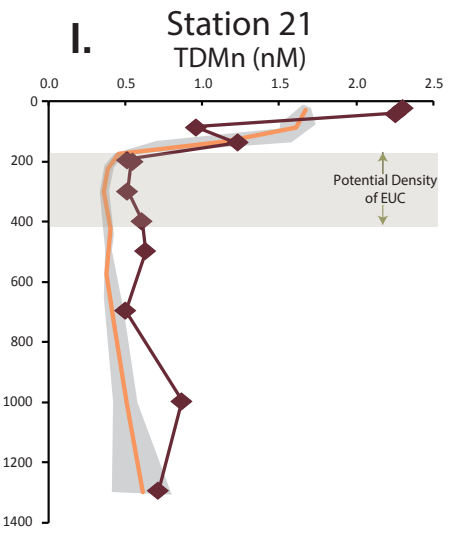

South of the Solomon Sea

$\multimap$ TDMn

Average Inflow

TDMn ( $\pm 1 S D)$

NGCU

\section{Outside \\ Solomon Sea}

Supplemental Fig. 5. Total Dissolvable Mn (TDMn) profiles versus depth from the PANDORA cruise. Red diamonds show measured TDMn concentrations. Orange line represents average inflow TDMn profile, while grey shading represents the range of inflow concentrations. Green box represents the density interval over which budget of the thermocline waters is calculated. $(\mathbf{a}-\mathbf{c})$ waters that are located south of the Solomon Sea; $(\mathbf{d}-\mathbf{f})$ profiles found along the NGCU; $(\mathbf{g}-\mathbf{i})$ profiles that are at the exit straits of the Solomon Sea; $(\mathbf{j}-\mathbf{l})$ located outside the Solomon Sea. 
Table S1: Potential density thresholds and corresponding depths used to calculate average concentrations over each depth range.

\begin{tabular}{rrrrr}
\hline Station & Surface $(\mathbf{m})$ & $\mathbf{2 4} \sigma_{\theta}(\mathrm{m})$ & $\mathbf{2 6 . 9} \sigma_{\theta}(\mathrm{m})$ & Deep $\left(\mathbf{2 7 . 5} \sigma_{\theta}\right)(\mathrm{m})$ \\
\hline 4 & 18 & 87 & 525 & 1321 \\
10 & 31 & 150 & 490 & 1303 \\
13 & 34 & 152 & 430 & 1299 \\
21 & 26 & 170 & 415 & 1302 \\
34 & 47 & 130 & $*$ & \\
39 & 26 & 137 & 430 & 1299 \\
42 & 25 & 150 & 420 & 1301 \\
43 & 25 & 152 & 405 & 1302 \\
60 & 23 & 145 & 420 & 1300 \\
71 & 23 & 105 & 515 & 1300 \\
77 & 25 & 173 & 435 & 999 \\
82 & 24 & 158 & 530 & 1298
\end{tabular}

*Profile collected only to $353 \mathrm{~m}\left(26.4 \sigma_{\theta}\right)$

Table S2: PANDORA Al and Mn dataset. Error reported is 1 standard deviation of the measurement

\begin{tabular}{|c|c|c|c|c|c|c|c|c|c|c|c|}
\hline & 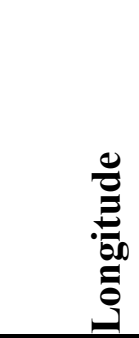 & $\frac{Z}{0}$ & 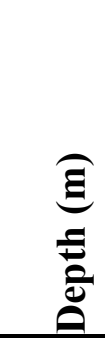 & 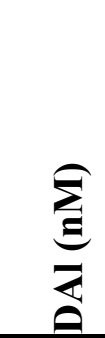 & 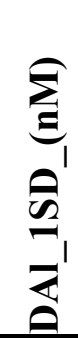 & 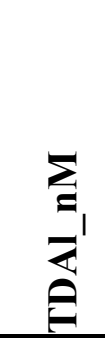 & 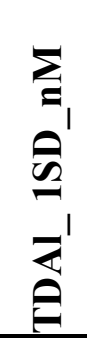 & 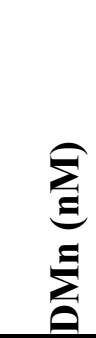 & 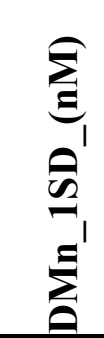 & 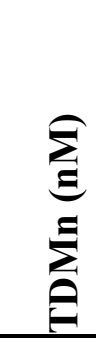 & $\sum$ \\
\hline-17.00 & 163.00 & 4 & 18 & 11.2 & 0.4 & 11.2 & 0.4 & 1.72 & 0.07 & 1.74 & 0.07 \\
\hline$-1^{\prime}$ & 3.00 & 4 & 50 & 13.1 & 0.4 & 12.1 & 0.4 & 63 & 0.07 & .66 & .07 \\
\hline-17.00 & 300 & 4 & 88 & 10.3 & 0.4 & 10.7 & 0.4 & 1.21 & 0.05 & 1.28 & 0.05 \\
\hline-17.00 & 163.00 & 4 & 139 & 11.5 & 0.4 & 10.6 & 0.4 & 0.51 & 0.02 & 0.72 & 0.03 \\
\hline-17.00 & 3.00 & 4 & 19 & 11.0 & 0.4 & 10.2 & 0.4 & 0.26 & 0.00 & 0.44 & 0.02 \\
\hline-17.00 & 1 & 4 & 298 & 11.6 & 0.4 & 9.9 & 0.4 & 0.29 & 0.00 & 0.40 & 0.02 \\
\hline-17.00 & 1 & 4 & 448 & 8.2 & 0.4 & 9.8 & 0.4 & 0.33 & 0.00 & 0.53 & 0.02 \\
\hline-17.00 & 163.00 & 4 & 619 & 6.5 & 0.4 & 10.3 & 0.4 & 0.34 & 0.00 & 0.51 & 0.02 \\
\hline-17.00 & 163.00 & 4 & 780 & 6.0 & 0.4 & 8.8 & 0.4 & 0.29 & 0.00 & 0.51 & 0.02 \\
\hline-17.00 & 163.00 & 4 & 1000 & 9.0 & 0.4 & 7.1 & 0.4 & 0.39 & 0.02 & 0.67 & 0.03 \\
\hline-17.00 & 163.00 & 4 & 1300 & 8.7 & 0.4 & 10.3 & 0.4 & 0.42 & 0.02 & 0.82 & 0.03 \\
\hline-17.00 & 163.00 & 4 & 1321 & 8.2 & 0.4 & 6.9 & 0.4 & 0.37 & 0.00 & 0.65 & 0.03 \\
\hline-12.00 & 163.00 & 10 & 31 & 11.1 & 0.4 & 11.1 & 0.4 & 1.59 & 0.06 & 1.65 & 0.07 \\
\hline
\end{tabular}




\begin{tabular}{|c|c|c|c|c|c|c|c|c|c|c|c|}
\hline 12.00 & .00 & 10 & 95 & 9 & 0. & .7 & 4 & 1.33 & 05 & 1 & .0 \\
\hline-12.00 & 3.00 & 10 & 135 & 7.6 & 0.4 & 5.4 & 0.4 & 0.53 & 0.02 & 0.70 & \\
\hline 2.00 & 63.00 & 10 & 175 & 5.4 & 0.4 & 4.2 & 0.4 & 0.37 & 0.02 & 0.47 & \\
\hline 2.00 & 63.00 & 10 & 224 & 5.1 & 0.4 & 4.3 & 0.4 & 0.28 & 0.00 & 0.39 & \\
\hline 2.00 & 3.00 & 10 & 301 & 4.7 & 0.4 & 4.3 & 0.4 & 0.24 & 0.00 & 0.35 & \\
\hline 12.00 & 3.00 & 10 & 399 & 6.6 & 0.4 & 5.9 & 0.4 & 0.24 & 0.00 & .37 & \\
\hline 2.00 & 3.00 & 10 & 500 & 7.2 & 0.4 & 7.0 & 0.4 & 0.24 & 0.00 & 0.37 & \\
\hline 2.00 & 63.00 & 10 & 501 & 6.2 & 0.4 & 5.1 & 0.4 & 0.28 & 0.00 & 0.37 & \\
\hline 2.00 & 63.00 & 10 & 700 & 7.6 & 0.4 & 6.8 & 0.4 & 0.32 & 0.00 & 0.47 & \\
\hline 12.00 & 3.00 & 10 & 1002 & 8.9 & 0.4 & 8.8 & 0.4 & 0.39 & 0.00 & 57 & \\
\hline 12.00 & 3.00 & 10 & 1303 & 8.3 & 0.4 & 7.5 & 0.4 & 0.49 & 0.02 & 0.83 & \\
\hline-9.00 & 33.00 & 13 & 34 & 6.9 & 0.5 & 10.2 & 0.5 & 1.02 & 0.04 & 1.02 & \\
\hline-9.00 & 63.00 & 13 & 74 & 9.3 & 0.5 & 8.6 & 0.5 & 0.85 & 0.03 & 0.96 & \\
\hline-9.00 & 3.00 & 13 & 125 & 11.3 & 0.5 & 9.7 & 0.5 & 0.47 & 0.02 & 0.60 & \\
\hline-9.00 & 3.00 & 13 & 179 & 7.1 & 0.5 & 6.5 & 0.5 & 0.33 & 0.05 & 43 & \\
\hline-9.00 & 3.00 & 13 & 181 & 6.9 & 0.5 & 5.9 & 0.5 & 0.40 & 0.05 & 0.44 & \\
\hline-9.00 & 63.00 & 13 & 225 & 5.8 & 0.5 & 4.9 & 0.5 & 0.28 & 0.05 & 0.38 & \\
\hline-9.00 & 63.00 & 13 & 298 & 3.8 & 0.5 & 4.7 & 0.5 & 0.29 & 0.05 & 0.38 & \\
\hline-9.00 & 3.00 & 1 & 400 & 6.0 & 0.5 & 6.4 & 0.5 & 0.25 & 0.05 & 0.38 & \\
\hline-9.00 & 3.00 & 13 & 501 & 7.7 & 0.5 & 7.8 & 0.5 & 0.28 & 0.05 & .44 & \\
\hline-9.00 & 3.00 & 12 & 700 & 9.6 & 0.5 & 8.4 & 0.5 & 0.40 & 0.05 & 0.63 & \\
\hline-9.00 & 3.00 & 13 & 1000 & 8.5 & 0.5 & 6.1 & 0.5 & 0.42 & 0.02 & 0.63 & \\
\hline-9.00 & 3.00 & 13 & 1299 & 8.2 & 0.5 & 9.2 & 0.5 & 0.43 & 0.02 & 0.67 & \\
\hline-10.01 & 0.36 & 21 & 26 & 17.9 & 0.4 & 9.1 & 0.4 & 2.15 & 0.09 & 2.28 & \\
\hline 10.01 & 0.36 & 21 & 45 & 17.2 & 0.4 & 18.1 & 0.4 & 1.97 & 0.08 & 2.24 & \\
\hline 10.01 & 0.36 & 21 & 89 & 13.8 & 0.4 & 17.8 & 0.4 & 0.54 & 0.02 & 0.95 & \\
\hline 10.01 & 0.36 & 21 & 140 & 13.6 & 0.4 & 35.9 & 0.4 & 0.48 & 0.02 & 1.22 & \\
\hline 10.01 & 0.36 & 21 & 198 & 7.3 & 0.4 & 9.6 & 0.5 & 0.32 & 0.05 & 0.50 & \\
\hline 10.01 & 0.36 & 21 & 202 & 7.2 & 0.4 & 11.3 & 0.4 & 0.33 & 0.05 & 0.54 & \\
\hline-10.01 & 0.36 & 21 & 303 & 10.3 & 0.4 & 15.1 & 0.5 & 0.30 & 0.02 & 0.51 & \\
\hline 10.01 & 50.36 & 21 & 401 & 10.3 & 0.4 & 17.5 & 0.4 & 0.28 & 0.05 & 0.60 & \\
\hline 10.01 & 60.36 & 21 & 504 & 8.6 & 0.4 & 18.6 & 0.6 & 0.30 & 0.02 & 0.62 & \\
\hline-10.01 & 0.36 & 21 & 700 & 10.1 & 0.4 & 10.9 & 0.5 & 0.25 & 0.05 & 0.49 & \\
\hline-10.01 & 160.36 & 21 & 1002 & 10.7 & 0.4 & 17.1 & 0.5 & 0.55 & 0.02 & 0.86 & \\
\hline 10.01 & 0.36 & 21 & 1302 & 10.7 & 0.4 & 15.1 & 0.5 & 0.34 & 0.02 & 0.71 & \\
\hline 11.45 & 4.67 & 34 & 47 & 14.3 & 0.3 & 13.4 & 0.3 & 0.93 & 0.18 & 1.24 & \\
\hline 11.45 & 154.67 & 34 & 79 & 13.7 & 0.3 & 13.8 & 0.3 & 0.51 & 0.02 & 0.83 & \\
\hline-11.45 & 154.67 & 34 & 129 & 9.6 & 0.3 & 8.2 & 0.3 & 0.51 & 0.02 & 0.60 & \\
\hline 11.45 & 154.67 & 34 & 181 & 12.9 & 0.3 & 12.7 & 0.3 & 0.31 & 0.02 & 0.48 & \\
\hline 11.45 & 154.67 & 34 & 249 & 10.7 & 0.3 & 10.8 & 0.3 & 0.24 & 0.02 & 0.42 & \\
\hline
\end{tabular}




\begin{tabular}{|c|c|c|c|c|c|c|c|c|c|c|c|}
\hline 11.45 & 154.67 & 34 & 353 & 7.8 & 0.3 & 13.0 & 0.3 & 0.28 & 0.02 & 0.50 & 0.02 \\
\hline-9.17 & 154.19 & 39 & 26 & 14.2 & 0.3 & 14.6 & 0.3 & 2.16 & 0.09 & 2.38 & \\
\hline-9.17 & 54.19 & 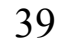 & 63 & 13.3 & 0.3 & 14.7 & .3 & 1.64 & 0.07 & .87 & \\
\hline-9.17 & 54.19 & 39 & 111 & 13.7 & 0.3 & 12.4 & 0.3 & 0.80 & 0.03 & 0.93 & \\
\hline-9.19 & 54.17 & 39 & 163 & 7.1 & 0.3 & 6.4 & 0.3 & 0.31 & 0.02 & 0.54 & \\
\hline-9.19 & 54.17 & 9 & 221 & 5.4 & 0.3 & 5.4 & 0.3 & 0.25 & 0.02 & 0.44 & \\
\hline-9.19 & 54.17 & 39 & 227 & 5.0 & 0.3 & 5.1 & 0.3 & 0.25 & 0.02 & 0.46 & \\
\hline-9.19 & 54.17 & 39 & 295 & 5.5 & 0.3 & 6.7 & 0.3 & 0.21 & 0.02 & 0.40 & \\
\hline-9.19 & 54.17 & 9 & 397 & 7.6 & 0.3 & 6.4 & 0.3 & 0.20 & 0.02 & 0.36 & \\
\hline-9.19 & 154.17 & 9 & 500 & 9.5 & 0.3 & 7.1 & 0.3 & 0.21 & 0.02 & 0.39 & \\
\hline-9.19 & 54.17 & 39 & 700 & 7.3 & 0.3 & 7.7 & 0.3 & 0.25 & 0.02 & 0.44 & \\
\hline-9.19 & 154.17 & 3 & 998 & 8.0 & 0.3 & 8.2 & 0.3 & 0.26 & 0.02 & 0.64 & \\
\hline-9.19 & 4. & 39 & 1299 & 9.2 & 0.3 & 8.3 & 0.3 & 0.37 & 0.02 & 0.64 & \\
\hline-5.14 & 53.30 & 42 & 25 & 13.5 & 0.4 & 18.7 & 0.4 & 1.64 & 0.07 & 1.88 & \\
\hline-5.14 & 3. & 42 & 83 & 8.0 & 0.4 & 9.9 & 0.4 & 0.51 & 0.02 & 0.84 & \\
\hline-5.14 & 153.30 & 4 & 129 & 13.5 & 0.3 & 12.4 & 0.4 & 0.48 & 0.02 & 0.78 & \\
\hline-5.14 & 153.3 & 42 & 130 & 12.9 & 0.4 & 13.9 & 0.4 & 0.5 & 0.02 & 0.86 & \\
\hline-5.15 & 1 & 42 & 181 & 10.6 & 0.4 & 11.9 & 0.4 & 0.35 & 0.02 & 0.62 & \\
\hline-5.15 & 9 & 42 & 227 & 7.7 & 0.4 & 10.5 & 0.4 & 0.24 & 0.02 & 0.46 & \\
\hline-5.15 & 153.29 & 42 & 297 & 8.4 & 0.4 & 8.0 & 0.4 & 0.24 & 0.02 & 0.45 & \\
\hline-5.12 & 153.3 & 4 & 401 & 9.1 & 0.3 & 8.4 & 0.4 & 0.24 & 0.02 & 0.45 & \\
\hline-5.12 & 3. & 42 & 501 & 7.1 & 0.3 & 8.9 & 0.4 & 0.25 & 0.02 & 0.45 & \\
\hline-5.12 & 153.33 & 42 & 700 & 8.8 & 0.3 & 10.7 & 0.4 & 0.26 & 0.02 & 0.49 & \\
\hline-5.12 & 15333 & 42 & 1000 & 9.5 & 0.3 & 14.6 & 0.4 & 0.54 & 0.02 & 0.94 & \\
\hline-5.12 & 153.33 & 4 & 1301 & 11.9 & 0.3 & 17.9 & 0.4 & 0.88 & 0.04 & 1.53 & \\
\hline-4.00 & 155.5 & 4 & 25 & 8.3 & 0.4 & 7.7 & 0.5 & 1.1 & 0.05 & 1.16 & \\
\hline-4.00 & 1 & 4 & 56 & 7.2 & 0.4 & 7.9 & 0.5 & 0.99 & 0.04 & 1.07 & \\
\hline-4.00 & 1 & 4. & 91 & 6.0 & 0.4 & 5.5 & 0.5 & 0.60 & 0.02 & 0.66 & \\
\hline-4.00 & $1-\sigma^{-r}$ & 4 & 160 & 4.5 & 0.5 & 2.5 & 0.3 & 0.37 & 0.01 & 0.49 & \\
\hline-4.00 & 155.59 & 4. & 224 & 4.2 & 0.4 & 3.9 & 0.5 & 0.37 & 0.08 & 0.44 & \\
\hline-4.00 & 155. & 43 & 300 & 8.0 & 0.4 & 5.8 & 0.5 & 0.31 & 0.08 & 0.39 & \\
\hline-4.00 & 155. & 4 & 300 & 5.6 & 0.4 & 5.8 & 0.5 & 0.30 & 0.08 & 0.39 & \\
\hline-4.00 & 155.59 & 4 & 401 & 8.4 & 0.5 & 5.6 & 0.3 & 0.24 & 0.01 & 0.40 & \\
\hline-4.00 & 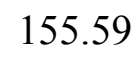 & 43 & 500 & 5.4 & 0.5 & 6.7 & 0.3 & 0.29 & 0.01 & 0.39 & \\
\hline-4.00 & 1 & 43 & 701 & 5.5 & 0.5 & 6.4 & 0.3 & 0.28 & 0.01 & 0.45 & \\
\hline-4.00 & 155. & 4 & 1002 & 6.7 & 0.5 & 5.3 & 0.3 & 0.37 & 0.01 & 0.54 & \\
\hline-4.00 & 155.59 & 43 & 1302 & 4.7 & 0.5 & 6.4 & 0.3 & 0.42 & 0.02 & 0.68 & \\
\hline-6.17 & 152.50 & 60 & 23 & 13.3 & 0.3 & 12.9 & 0.3 & 1.92 & 0.08 & 1.85 & \\
\hline-6.17 & 1 & 60 & 29 & 13.3 & 0.3 & 12.9 & 0.3 & 2.01 & 0.08 & 1.83 & \\
\hline-6.17 & 152.50 & 60 & 65 & 12.5 & 0.3 & 12.6 & 0.3 & 1.71 & 0.07 & 1.76 & \\
\hline
\end{tabular}




\begin{tabular}{|c|c|c|c|c|c|c|c|c|c|c|c|}
\hline-6.17 & 52.50 & 60 & 127 & 11.9 & 0.3 & 12.0 & 0.3 & 0.48 & 0.02 & 0.73 & 0.03 \\
\hline-6.17 & 52.50 & 60 & 176 & 7.2 & 0.3 & 7.2 & 0.3 & 0.30 & 0.01 & 0.46 & 0.02 \\
\hline-6.17 & 2.50 & 60 & 220 & 6.4 & 0.3 & 7.7 & 0.3 & 0.29 & 0.01 & 0.48 & 0.02 \\
\hline-6.17 & 2.50 & 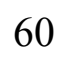 & 293 & 4.9 & 0.3 & 7.4 & 0.3 & .27 & .01 & .41 & .02 \\
\hline-6.17 & 2.50 & 60 & 401 & 8.0 & 0.3 & 7.1 & 0.3 & 0.23 & 0.01 & .38 & .02 \\
\hline-6.17 & 2.50 & 60 & 499 & 5.9 & 0.3 & 8.8 & 0.3 & 0.23 & .01 & .46 & 02 \\
\hline-6.17 & 2.50 & 60 & 699 & 5.5 & 0.3 & 8.4 & 0.3 & 0.28 & 0.01 & 0.50 & 0.02 \\
\hline-6.17 & 2.50 & 60 & 1000 & 6.3 & 0.3 & 10.9 & 0.3 & 0.56 & .02 & .92 & 0.04 \\
\hline-6.17 & 2.50 & 0 & 00 & 6.6 & 0.3 & 12.2 & 0.3 & 0.63 & 0.03 & .10 & .04 \\
\hline-8.34 & 1.29 & 71 & 23 & 14.3 & 0.6 & 13.9 & 0.6 & 1.79 & 0.07 & 1.77 & 0.0 \\
\hline-8.34 & 1.29 & 1 & 69 & 12.0 & 0.6 & 12.3 & 0.6 & 0.84 & 0.03 & 0.94 & . \\
\hline-8.34 & 1.29 & 1 & 118 & 11.2 & 0.6 & 11.4 & 0.6 & 0.54 & 0.02 & 0.78 & 0.03 \\
\hline-8.34 & 1.29 & & 168 & 5.8 & 0.6 & 6.7 & 0.6 & 0.30 & 0.01 & 0.46 & .02 \\
\hline-8.34 & 1.29 & 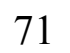 & 201 & 4.3 & 0.6 & 6.0 & 0.6 & 0.28 & )1 & .46 & .0 \\
\hline-8.33 & 1.29 & 1 & 299 & 8.3 & 0.6 & 11.5 & 0.6 & 0.26 & 0.01 & 46 & 0.02 \\
\hline-8.33 & 1.29 & 71 & 400 & 7.7 & 0.6 & 11.1 & 0.6 & 0.24 & 0.01 & 0.44 & 0.02 \\
\hline-8.33 & 1.29 & & 551 & 5.5 & 0.6 & 7.9 & 0.6 & 0.21 & 0. & 0.38 & 0.02 \\
\hline-8.33 & 1.29 & & 730 & 5.7 & 0.6 & 8.3 & 0.6 & 0.22 & 1 & .42 & 0.02 \\
\hline-8.33 & 1.29 & 1 & 60 & 6.2 & 0.6 & 10.0 & 0.6 & .34 & 0.01 & .69 & 0.0 \\
\hline-8.33 & 1.29 & 1 & 1000 & 6.0 & 0.6 & 10.2 & 0.6 & 0.38 & 0.01 & 0.70 & 0.0 \\
\hline-8.33 & 1.29 & 71 & 1300 & 6.5 & 0.6 & 11.2 & 0.6 & 0.51 & 0. & 0.90 & 0.04 \\
\hline-5.95 & 7.67 & 77 & 25 & 20.7 & 0.4 & 38.7 & 0.4 & 2.48 & 0 . & 2.66 & 0.1 \\
\hline-5.95 & 7.67 & 77 & 75 & 15.3 & 0.4 & 15.7 & 0.4 & 1.31 & 0.05 & 1.42 & 0 \\
\hline-5.95 & 7.67 & 77 & 81 & 15.4 & 0.4 & 15.5 & 0.4 & 1.32 & 0.05 & 1.49 & 0.0 \\
\hline-5.95 & 7.66 & 7 & 142 & 14.4 & 0.4 & 15.6 & 0.4 & 0.70 & 0.03 & 1.10 & 0.0 \\
\hline-5.95 & 7.66 & 77 & 174 & 11.0 & 0.4 & 12.0 & 0.4 & 0.33 & 0.01 & 0.54 & 0.02 \\
\hline-5.95 & 7.66 & 7 & 220 & 9.9 & 0.4 & 11.8 & 0.4 & 0.30 & 0.01 & 0.52 & 0.0 \\
\hline-5.95 & 7.66 & 77 & 299 & 8.9 & 0.4 & 10.7 & 0.4 & 0.24 & 0.01 & .49 & 0.0 \\
\hline-5.95 & 7.66 & 77 & 39 & 8.0 & 0.4 & 9.9 & 0.4 & 0.25 & 0.01 & .45 & 0.0 \\
\hline-5.95 & 7.66 & 77 & 501 & 8.2 & 0.4 & 8.4 & 0.4 & 0.23 & & 0.43 & 0.0 \\
\hline-5.95 & 7.66 & 7 & 702 & 9.3 & 0.4 & 10.4 & 0.4 & 0.40 & 0.01 & 0.71 & 0.0 \\
\hline-5.95 & 7.66 & 77 & 902 & 6.9 & 0.4 & 15.0 & 0.4 & 0.80 & 0.03 & 1.36 & 0.0 \\
\hline-5.95 & 7.66 & 77 & 999 & 6.8 & 0.4 & 15.8 & 0.4 & 1.02 & 0.04 & 1.65 & 0.0 \\
\hline 4.00 & 6.01 & 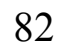 & 24 & 13.0 & 0.4 & 13.0 & 0.4 & 1.66 & 0.07 & 1.68 & 0.0 \\
\hline 4.00 & 6.01 & 82 & 80 & 13.5 & 0.4 & 13.4 & 0.4 & 1.63 & 0.07 & 1.72 & $0.0^{\circ}$ \\
\hline 4.00 & 6.01 & 82 & 135 & 12.5 & 0.4 & 12.5 & 0.4 & 1.48 & 0.06 & 1.59 & 0.0 \\
\hline 4.00 & 6.01 & 82 & 174 & 7.1 & 0.4 & 7.3 & 0.4 & 0.34 & 0.01 & 0.45 & 0.0 \\
\hline 4.00 & 6.01 & 82 & 224 & 5.6 & 0.4 & 6.4 & 0.4 & 0.27 & 0.01 & 0.39 & 0.0 \\
\hline .00 & 6.01 & 82 & 300 & 7.2 & 0.4 & 7.8 & 0.4 & 0.23 & 0.01 & 0.37 & 0.0 \\
\hline 4.00 & 156.01 & 82 & 447 & 5.4 & 0.4 & 8.5 & 0.4 & 0.27 & 0.01 & 0.43 & 0 \\
\hline
\end{tabular}




$\begin{array}{rrrrrrrrrrrr}-14.00 & 156.01 & 82 & 651 & 5.9 & 0.4 & 7.9 & 0.4 & 0.21 & 0.01 & 0.38 & 0.02 \\ -14.00 & 156.01 & 82 & 799 & 6.1 & 0.4 & 7.0 & 0.4 & 0.22 & 0.01 & 0.39 & 0.02 \\ -14.00 & 156.01 & 82 & 1001 & 8.3 & 0.4 & 7.1 & 0.4 & 0.22 & 0.01 & 0.44 & 0.02 \\ -14.00 & 156.01 & 82 & 1298 & 6.5 & 0.4 & 7.1 & 0.4 & 0.28 & 0.01 & 0.43 & 0.02\end{array}$

